\title{
Structural Biology of Calcium Phosphate Nanoclusters Sequestered by Phosphoproteins
}

\author{
Samuel Lenton ${ }^{1,2}\left(\mathbb{D}\right.$, Qian Wang ${ }^{3,4}(\mathbb{D})$, Tommy Nylander ${ }^{2,4}\left(\mathbb{D}\right.$, Susana Teixeira ${ }^{5,6}(\mathbb{D}$ \\ and Carl Holt $7, *$ (D) \\ 1 Theoretical Chemistry, Lund University, POB 124, SE-221 00 Lund, Sweden; samuel.lenton@teokem.lu.se \\ 2 Lund Institute of Advanced Neutron and X-ray Science (LINXS), Scheelevägen 19, 22370 Lund, Sweden; \\ Tommy.Nylander@fkem1.lu.se \\ 3 School of Chemistry and Chemical Engineering, Harbin Institute of Technology, 92 Xidazhi Street, \\ Nangang District, Harbin 150001, China; wangqian_jane@yeah.net \\ 4 Physical Chemistry, Lund University, P.O. Box 124, SE-221 00 Lund, Sweden \\ 5 Department of Chemical and Biomolecular Engineering, University of Delaware, 150 Academy Street, \\ Newark, DE 19716, USA; susanat@udel.edu \\ 6 The NIST Centre for Neutron Research, National Institute of Standards and Technology, 100 Bureau Drive, \\ Gaithersburg, MD 20899, USA \\ 7 Institute of Molecular, Cell and Systems Biology, University of Glasgow, Glasgow G12 8QQ, Scotland, UK \\ * Correspondence: carl.holt@glasgow.ac.uk
}

Received: 4 August 2020; Accepted: 21 August 2020; Published: 27 August 2020

\begin{abstract}
Biofluids that contain stable calcium phosphate nanoclusters sequestered by phosphopeptides make it possible for soft and hard tissues to co-exist in the same organism with relative ease. The stability diagram of a solution of nanocluster complexes shows how the minimum concentration of phosphopeptide needed for stability increases with $\mathrm{pH}$. In the stable region, amorphous calcium phosphate cannot precipitate. Nevertheless, if the solution is brought into contact with hydroxyapatite, the crystalline phase will grow at the expense of the nanocluster complexes. The physico-chemical principles governing the formation, composition, size, structure, and stability of the complexes are described. Examples are given of complexes formed by casein, osteopontin, and recombinant phosphopeptides. Application of these principles and properties to blood serum, milk, urine, and resting saliva is described to show that under physiological conditions they are in the stable region of their stability diagram and so cannot cause soft tissue calcification. Stimulated saliva, however, is in the metastable region, consistent with its role in tooth remineralization. Destabilization of biofluids, with consequential ill-effects, can occur when there is a failure of homeostasis, such as an increase in $\mathrm{pH}$ without a balancing increase in the concentration of sequestering phosphopeptides.
\end{abstract}

Keywords: calcium phosphate; biocalcification; phosphoprotein; serum; milk; saliva; urine

\section{Introduction}

Understanding the mechanisms of biocalcification and the chemistry of the resulting mineral phases of hard tissues has been the subject of several excellent recent reviews [1-11]. In these reviews, extensive coverage is given to the effects of proteins, particularly phosphoproteins on the control of biomineralization but overwhelmingly, studies have been made on the effects observed at low molar ratios of the phosphoprotein to calcium phosphate. In this review, we concentrate on the functions of complexes formed between intrinsically disordered phosphoproteins or phosphopeptides (IDPs) and calcium phosphate $(\mathrm{CaP})$ at higher molar ratios where the complexes formed are thermodynamically stable, or at least stable for a long time (Figure 1). 


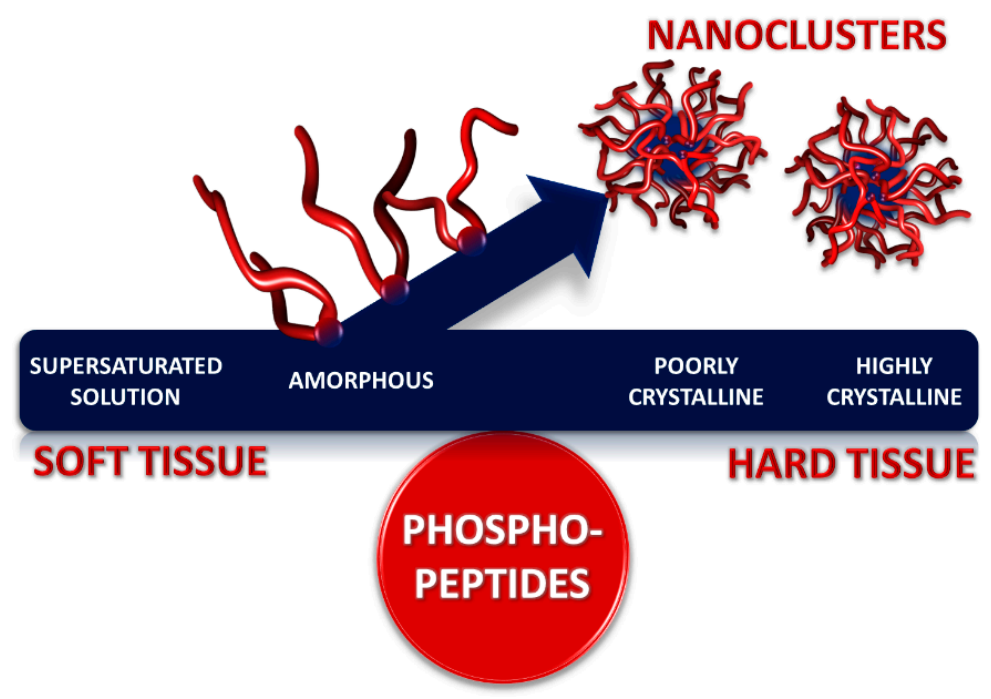

Figure 1. Maintaining a balance between soft and hard tissues: role of sequestered forms of amorphous calcium phosphate nanoclusters in the control of biocalcification. With excess of certain phosphoproteins or phosphopeptides (Table 1), stable solutions containing calcium and $P_{i}$ can remain in contact with soft tissues without causing the tissue to become calcified. The concentration of the nanocluster complexes can be arbitrarily high, as in milk. A similar solution, in contact with a hard tissue, such as bone or tooth, can act as a reservoir of ions for mineralization of the tissue.

Hydroxyapatite (HA), or apatite, is a basic CaP mineral present in hard tissues such as bone, cementum, dentine, and enamel. Apatite was named by geologists from the Greek word apate meaning deceive because of the variable crystal habit and composition of apatite rocks. Soft tissues and most biofluids, by contrast, contain little or no mineral in their normal, physiological state. Soft tissues can become mineralized and hard tissues can become demineralized as a result of degenerative, dysfunctional, or diseased conditions. However, under physiological conditions, soft tissues remain soft and hard tissues remain hard, even though they are permeated by the same extracellular fluid. The challenge posed by the co-existence of soft and mineralized tissues in the same organism can be phrased in chemical terms. For the hard tissue to stay mineralized the permeating biofluid must be at least saturated with respect to the hard tissue mineral and yet, for the soft tissues and biofluids to remain unmineralized, the permeating biofluid must be stable. Studies on solutions containing sequestered amorphous CaP complexes, including milk and other biofluids, showed that they were undersaturated with respect to the first-formed amorphous phase but supersaturated with respect to more crystalline forms of $\mathrm{CaP}[12,13]$. Thus, the solutions and the nanocluster complexes within them are stable. If the solutions are brought into contact with a crystalline form of $\mathrm{CaP}$, the more stable crystalline phase will tend to grow at the expense of the nanocluster complexes.

A solution to the problem of the stability of biofluids and the co-existence of soft and mineralized tissues must have been found more than about 500 million years ago when the first calcium carbonate or phosphate mineralized tissues appear in the fossil record. These include the cone-shaped denticles or teeth of extinct agnathan chordates resembling eels, called conodonts. By about 50 million years later, homologues of the modern hard tissue types were established. For example, the bone-like head plates of placoderms may have allowed sense organs, mounted on this stable platform to build up a three-dimensional picture of their environment. Concomitantly, a paralogous group of phosphoproteins evolved called SCPPs (secreted calcium- or CaP-binding phosphoproteins) [14-16]. Members of this group of proteins are seemingly involved in every aspect of biomineralization. One of the earliest members of the group of SCPPs was osteopontin (OPN) which has a very wide occurrence in the tissues and biofluids of chordate species [17]. 
Table 1. Selected known or potential CaP-SLiMs formed by the action of the Golgi kinase FAM20C on secreted phosphoproteins ${ }^{1}$.

\begin{tabular}{|c|c|c|c|c|c|c|c|}
\hline Protein & Species & UniProt & CaP-SLiM & Protein & Species & UniProt & CaP-SLiM \\
\hline \multicolumn{4}{|c|}{ SIBLING SCPPs } & \multicolumn{4}{|c|}{ Non-SIBLING SCPPS } \\
\hline MEPE & Human & Q9NQ76 & 493-DDSSESSDSGSSSESDGD- 510 & CSN1S1 & Guinea & P04656 & $19-$ SSSSSSSEER-28 \\
\hline DSPP & Human & $\overline{\mathrm{Q9NZW4}}$ & 661-DSSSSSDSSNSSDSSDS- 677 & & pig & & 54-IISESTEERE-63 \\
\hline IBSP & Human & $\underline{P} 21815$ & 55-GDDSSEEEEE- 64 & & & & $65-$ SSISSSEEV- 73 \\
\hline \multirow[t]{3}{*}{ OPN } & Cow & P31096 & 6-TSSGSSEEKQ-15 & CSN1S2 & Pig & P39036 & 5-EHVSSSEESI-14 \\
\hline & & & 42-QNSVSSEETD-51 & & & & 54-ASSSSSEESVE-63 \\
\hline & & & 99-SDESHHSDES-108 & & & & 130-ELSTSEEPVS-139 \\
\hline \multirow[t]{3}{*}{ DMP1 } & Mouse & $\underline{\mathrm{O} 55188}$ & 8-NTESESSEER-17 & CSN2 & Human & $\underline{\mathrm{P} 05814}$ & 5-ESLSSSEESI-14 \\
\hline & & & 28 -PTNSESSEES -37 & Statherin & Human & $\overline{\mathrm{P} 02808}$ & 1-MIGADSSEE-10 \\
\hline & & & 161-DSAQDSESEE-170 & ENAM & Human & Q9NRM1 & $36-$ SSRSEE-41 \\
\hline \multicolumn{4}{|c|}{ Non-SCPPs } & AMBN & Human & Q9NP70 & $26-$ SLSLE -30 \\
\hline FETUA & Human & $\underline{\mathrm{P} 02765}$ & 307-SLGSPSGEVS-316 & & & & $246-\operatorname{SSEE}-249$ \\
\hline SPP24 & Human & $\overline{\mathrm{Q} 13103}$ & 108 -SWSSSTSESYSSEE-117 & AMTN & Human & Q6UX39 & $100-\operatorname{SSEE}-103$ \\
\hline MGP & Human & $\underline{\mathrm{P} 08493}$ & 2-ESHESMESYE -11 & SCPPPQ1 & Anolis & E0YCE6 & $4-R R S A S S S E E R R R-15$ \\
\hline PRB4 & Human & P10163 & 2-SSSEDVSQEE-11 & ODAM & Human & $\overline{\mathrm{A} 1 \mathrm{E} 959}$ & $25-$ SASNSNE-31 \\
\hline RBP & Chicken & $\overline{\mathrm{P} 02752}$ & 192-ESSSMSSSEE-201 & FDCSP & Human & $\overline{\mathrm{Q} 8 \mathrm{NFU} 4}$ & 11-KRSISDSDELA-21 \\
\hline
\end{tabular}

${ }^{1}$ Sequence numbers are for the mature peptide chain without the signal sequence. Known phosphorylation sites and sites predicted for the canonical recognition sequences of FAM20C are in boldface red. 
Caseins are also SCPPs. It has been known for many years that the CaP nanoclusters of casein micelles allow stable milk to be formed containing much higher calcium and phosphate concentrations than the solubility of inorganic CaPs at milk pH. Because of the ready availability of milk, the high concentrations of the caseins responsible for its stability and the study of artificial nanocluster complexes made with pure phosphopeptides, we have been able to gain a detailed understanding of the reasons for its stability. These insights have led to a hypothesis, supported by indirect experimental evidence that essentially the same mechanism but with different phosphoproteins, stabilizes other, supersaturated, biofluids. Ideas about biofluid stability are important not only for understanding the control of physiological calcification, but also for the development of effective treatments for the diseases of pathological calcification. We review the literature on the composition, structure and stability of equilibrium $\mathrm{CaP}$ nanocluster complexes with phosphoproteins with emphasis on the last 26 years since the first artificial complexes made with a pure phosphopeptide were described [18].

In this review, we will use stability to mean exclusively stability with respect to the precipitation of CaP. A metastable solution is one that shows no obvious sign of precipitation for some time but is not thermodynamically stable. The term $\mathrm{CaP}$ nanocluster complex applies to the core $\mathrm{CaP}$ nanocluster and its shell of sequestering phosphopeptides and can be abbreviated to nanocluster complex. CaP nanocluster is synonymous with the older term from the dairy literature of colloidal calcium phosphate but neither $\mathrm{CaP}$ nanoclusters nor colloidal calcium phosphate are known as stable independent particles. Protein and peptide are used interchangeably, and residue numbers apply to the mature peptide after cleavage of the signal sequence. The term competent phosphopeptide means one capable, in principle, of forming an equilibrium nanocluster complex in a thermodynamically stable solution if it is present at a high enough concentration. Structural requirements of a competent phosphopeptide are known only incompletely so they are defined by examples such as the ones in this review. Molar and molal concentrations are in units of moles per liter of solution and moles per $1000 \mathrm{~g}$ of water, respectively. Where a numerical value is quoted with a confidence interval, it is the mean and estimated standard deviation. We will refer to a solution of nanocluster complexes while recognizing that it could equally well be called a dispersion.

\section{Role of IDPs in the Control of Biocalcification}

The need for organisms to form ordered, functional, mineralized tissue while simultaneously preventing unwanted calcification of soft tissue, requires strict control of the biocalcification process. In vivo biocalcification is a hierarchical process influenced by many factors including proteins, salts, lipids, and sugars, but the main emphasis in this review is on the effects of proteins on the formation of calcium phosphate phases from various biofluids. Phase separation can be divided into three main stages: nucleation, usually as an amorphous substance, growth and maturation of composition and structure to give a more-or-less crystalline morphology [19-21]. Each stage of the biocalcification process is influenced by a range of non-collagenous proteins, the vast majority of which are acidic IDPs $[9,11,19,22]$. IDPs are characterized by the lack of a well-defined solution structure over much of their sequence. Instead, they rapidly sample an ensemble of interchangeable, dynamic, conformations. Because of their dynamic nature, IDPs tend to interact with ligands and other proteins through short linear functional motifs, or SLiMs [23]. Typically, SLiMs comprise 3-10 consecutive residues that act together to form weak and reversible interactions with their targets. A single IDP may contain several SLiMs of the same or different types and these confer on the IDP many of its key properties. Not rarely, the affinity of a SLiM for its target can be modulated by secondary modifications such as phosphorylation, sometimes by several orders of magnitude. In this review, the main focus will be on SCPPs [15] which are usually phosphorylated, and all are known or predicted IDPs [11,22,24,25].

\subsection{Secreted Calcium- or Calcium Phosphate-Binding Proteins}

The paralogous group of SCPPs are thought to have evolved by gene duplication and in humans are mostly found on chromosome 4 apart from amelogenin, located on the non-autosomal parts of 
the sex chromosomes $[15,16]$. They share a similar intron/exon gene structure and several functional motifs despite considerable sequence divergence at the level of the mature protein [26]. For example, the highly acidic SIBLING subgroup (small integrin-binding ligand N-linked glycoprotein) [27] all contain the integrin receptor-binding motif RGD whereas the non-SIBLINGs contain Pro- and Gln-rich (P,Q-rich) sub-sequences. The P,Q-rich sequences are weakly interacting flexible linkers punctuated by functional motifs such as short sequences of hydrophobic and order-promoting residues (HO-SLiMs). Other motifs include the CaP-SLiMs and short cationic or anionic sequences that promote attractive, electrostatic, protein-protein interactions [28]. Through a range of different types of interactions mediated by their SLIMs, the non-SIBLING SCPPs have a tendency to associate to form homotypic or heterotypic oligomers or larger assemblies such as gels or amyloid fibrils and ribbons [28-34].

Genes in the SIBLING group include the bone and tooth associated DMP1 (dentin matrix protein 1), DSPP (dentin sialophosphoprotein), IBSP (integrin-binding bone sialophosphoprotein) encoding BSP (bone sialophosphoprotein), MEPE (matrix extracellular phosphoglycoprotein) and the more widely expressed SPP1 (secreted phosphoprotein 1) which encodes OPN. The non-SIBLING genes encode, among others, the casein family of milk proteins, the salivary proteins statherin and three proline-rich proteins, and the tooth proteins enamelin and amelogenin.

\subsection{Calcium Phosphate-Binding Short Linear Motifs (CaP-SLiMs)}

The CaP-SLiMs are short sequences phosphorylated at several, sometimes adjacent, sites. They commonly also contain a variable number of Asp or Glu residues and (usually) seryl residues in protein kinase recognition sequences. The Golgi kinase consensus recognition sequences include $\mathrm{S}-\mathrm{X}-\mathrm{E} / \mathrm{pS}$ where $\mathrm{X}$ is any residue and $\mathrm{pS}$ is phosphoserine with the result that sequences of consecutive phosphorylated residues can be created from, for example, S-S-S-E-E. A sequence of three consecutive phosphoseryl residues creates a high-affinity binding site for $\mathrm{Ca}^{2+}$ and $\mathrm{H}^{+}$[35-39] and a higher affinity of binding to $\mathrm{CaP}$ than the same number of phosphorylated residues in a more extended CaP-SLiM $[38,40]$. Biocalcification processes can be controlled precisely by varying the sequences of CaP-SLiMs, their degree of phosphorylation and the concentration and composition of the non-collagenous phosphoproteins in the extracellular milieu [1,41-43].

Within the SIBLING subgroup of SCPPs, the CaP-SLiMs have been called ASARM (acidic serine and aspartate-rich motif) sequences but in general, glutamate usually predominates over aspartate. Similar sequences in caseins have been called phosphate centers. The MEPE ASARM peptide is at the C-terminus and can be cleaved from the protein by the action of cathepsin B [44]. The human sequence, shown in Table 1, contains 9 seryl residues and when the peptide is co-expressed in epithelial cells with the Golgi kinase FAM20C, up to 9 seryl residues can be phosphorylated [45]. The phosphorylated peptide is an inhibitor of in vivo and in vitro mineralization $[44,46,47]$. In a survey of ASARM-like sequences among SIBLINGS [48], 20 were identified in DSPP, four in DMP1, one in BSP, and three in OPN. However, the phosphophoryn region in the C-terminal half of DSPP contains many more ASARM-like tandem repeats. A few examples of CaP-SLiM sequences are shown in Table 1. Among the non-SIBLING SCPPs, conserved CaP-SLIMs are common in five of the six known casein gene products but are rare or absent in $\mathrm{k}$-caseins (Table 1). Statherin contains a CaP-SLiM near its N-terminus in which two consecutive residues are normally phosphorylated [49]. Other candidates are identified for enamelin (ENAM), ameloblastin (AMBN), amelotin (AMTN) and odontogenic ameloblastin-associated protein (ODAM). Also included in Table 1 are some sequences from non-SCPP proteins. These include Fetuin A (FETUA), secreted phosphoprotein 24 (SPP24) and matrix Gla-protein (MGP) which have been associated with calcified bodies from blood serum, and the basic salivary proline-rich protein (PRB4).

CaP-SLiMs are therefore prevalent in many of the proteins involved in the control of biocalcification. They occur in all the phosphoproteins and phosphopeptides known to sequester CaP nanoclusters and may be essential. Their precise function is discussed further in Sections 3 and 4. In particular, in Section 4.3 experimental evidence is given to show that increasing the number and proximity of phosphorylated residues in a CaP-SLiM increases its affinity for CaP. Longer sequences of consecutive 
phosphorylated residues may contain additional, high-affinity, binding sites for cations, and have an even higher affinity for $\mathrm{CaP}$. The bone acidic glycoprotein- 75 has a remarkable ability to bind many phosphate ions with high affinity, suggesting that it has specific binding sites for the anion [50]. Similar anion binding sites may be important also in the binding of CaP. The CaP-SLiMs in Table 1 do not appear to contain or flank any of the recognized motifs associated with binding phosphate anions such as anion nests or P-loops containing a basic residue (GXXXXGK(S,T)) [51-53]. The involvement of basic residues in the folding and binding of the N-terminal region of statherin to HA has been reported [54-56]. However, much more work is needed to investigate the potential co-binding to calcium and $\mathrm{P}_{\mathrm{i}}$ ions in the CaP by basic and acidic residues in or around the CaP-SLiM sequences.

\subsection{Conformational Flexibility and Adaptability}

The observed preponderance of IDPs in biocalcification is due to several key physical properties that provide functional advantages compared to globular proteins. One of the first proposals for a physiological role for IDPs was in the control of biocalcification [57,58]. It was suggested that conformational flexibility allowed the protein to bind to and modulate the further growth of $\mathrm{CaP}$ nuclei at a more rapid rate than would be possible for a more rigid protein. Since then there have been many other proposals for biological functions for IDPs, including diverse roles in biocalcification. For example, flexible IDPs can adapt their conformation to achieve a higher density of CaP-SLiMs than could be achieved by a more rigid globular protein of the same size (Figure 2). Thus, individual phosphopeptides with a single CaP-SLiM may pack together tightly. A protein with several CaP-SLiMs may form loops and trains on the surface of CaP. Alternatively an IDP such as phosphophoryn with very many tandem CaP-SLiMs may adopt a sessile conformation so that many of its CaP-SLiMs bind to the surface $[59,60]$. The behavior of phosphophoryn may be compared to that of a synthetic polyelectrolyte adsorbed onto a surface of opposite charge where the conformation adopted depends on an interplay between the adsorbed polymers and between the polymers and the surface [61]. The N-terminal OPN 1-149 has a flexible, adaptable, conformation containing three CaP-SLiMs (see Table 1), each of which binds to the CaP nanocluster core [24,62]. These interactions would be sterically forbidden/less favorable if the CaP-SLiMs were part of a rigid or globular protein. Another example of the modulation of CaP precipitation is provided by the acidic proline-rich proteins (PRPs) of saliva. Their two sites of phosphorylation are not close together in the sequence, so they occupy a larger surface area of hydroxyapatite per protein molecule than the other main salivary inhibitor, statherin [63]. The CaP-SLiM of statherin, as with many of the other examples in Table 1 is formed from phosphorylation sites close together in the sequence $[63,64]$. In Section 3.5 we show that the surface area per CaP-SLiM is an important parameter determining the equilibrium size and free energy of formation of nanocluster complexes with phosphoproteins. In Section 4, several examples are given of nanocluster complexes where a high density of CaP-SLiMs is achieved at the core surface either by close packing of short peptides containing a single CaP-SLiM or through the flexible and adaptable conformation of a longer sequestering phosphopeptide containing several CaP-SLiMs.

The collapse of IDPs into a more compact conformation is disfavored by the prevalence of charged and neutral hydrophilic residues in these proteins [65]. The net charge of extracellular acidic IDPs may be further increased in vivo by phosphorylation during secretion via the Golgi route, mainly by the kinase Fam20C [66-68]. The natural abundance of charged amino acids combined with the increased prevalence of phosphorylated residues, facilitates the interaction between IDPs and mineral surfaces $[4,11,69]$. The dentin matrix phosphoprotein 1 (DMP1) provides an example of the importance of phosphorylation for the interaction of an IDP with mineral surfaces. The extent of phosphorylation of the protein determines whether it has an inhibitory or promoting effect on the growth of HA [70]. Indeed, the apparently contradictory effects, of either promoting or inhibiting HA growth, depending on the presence of phosphorylated residues, has been observed in several other IDPs involved in the process of biocalcification, including the salivary IDP statherin [71], the tooth maturation protein amelotin [72], bone phosphophoryn [73], bone sialoprotein [74] and OPN [75,76]. 
Although it is generally considered an inhibitor of mineralization it was shown that OPN could promote the intrafibrillar mineralization of collagen [41].

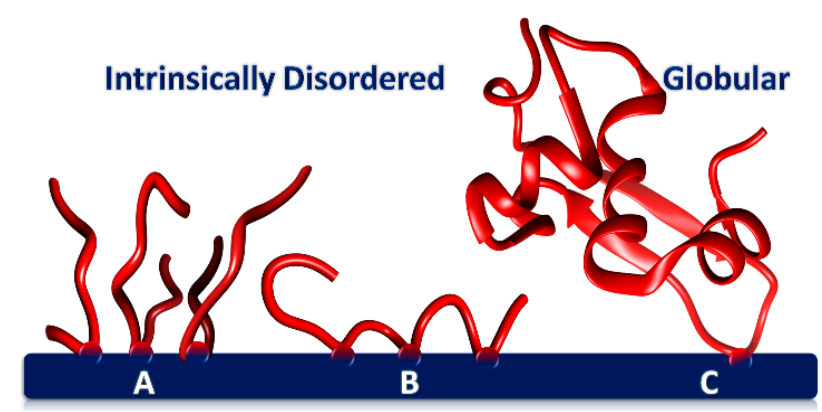

Figure 2. Phosphoproteins adsorbed onto a CaP surface through one or more CaP-SLiMs. (A) Tightly packed layer of flexible, short acidic peptides with a single CaP-SLiM (B) IDP with three CaP-SLiMs (e.g., OPN 1-149) forming two loops and two trains. A protein such as phosphophoryn has many $\mathrm{CaP}-\mathrm{SLiMs}$ and as a result adopts a more sessile conformation on the surface. (C) Globular protein adsorbed through a single CaP-SLiM but with a large footprint.

The interaction between the charged residues of IDPs and mineralized surfaces can, in some instances, induce or stabilize specific secondary structures. For example, the $\mathrm{N}$-terminal region of statherin adopts an $\alpha$-helical conformation upon absorption to mineral surfaces [54,55]. It has been suggested that this folding upon binding prevents further growth of HA by shielding the surface of the mineral phase from further addition of CaP [54]. Folding-upon-binding events of IDPs may induce secondary structure elements that recruit other proteins involved in the biocalcification process to the mineral surface.

Another key advantage of IDPs in the regulation of biocalcification is their rapid sampling of a large conformational space, which results in an acceleration of protein-ligand interactions $[57,58,77]$. In the sequestration of $\mathrm{CaP}$ nanoclusters, this flexibility provides a mechanism through which the protein can rapidly react with nucleating clusters of amorphous calcium phosphate (ACP), to prevent or slow the irreversible formation of more crystalline phases $[57,58]$. Slower sequestration resulting from a low affinity of binding, a low concentration of sequestrant or a more rigid conformation may result in the irreversible formation of crystalline, or poorly crystalline, CaP.

In summary, all proteins that sequester ACP have been found to have two key properties. First, they contain at least one CaP-SLiM and second, they lack a well-defined conformation. The lack of a well-defined globular conformation may be beneficial, if not a prerequisite, for stable CaP nanocluster complexes.

\section{Basic Science of Amorphous Calcium Phosphate Sequestration by Phosphoproteins}

The control of $\mathrm{CaP}$ (or calcium carbonate [4]) biocalcification by acidic IDPs is critically dependent on the formation of amorphous precursor complexes where the free energy of binding of the protein is at least comparable to the free energy of forming molecular clusters, nuclei, or nanoclusters of the mineral.

\subsection{Ostwald Rule of Stages and Non-Classical Nucleation of Calcium Phosphate}

At physiological $\mathrm{pH}, \mathrm{CaP}$ does not precipitate directly from solution as the most thermodynamically stable phase, HA. Instead, according to the Oswald rule of stages [78-81], precipitation passes through several unstable or metastable stages from the most soluble to the least, as shown in Figure 3. However, Ostwald's rule is not a universal law and local minima separated by an activation free energy may exist to prevent the achievement of the lowest free energy state within a reasonable time. Some of these enduring, but in principle transient states, involving amorphous precursors of crystalline substances, are exploited in biology [7,82]. 

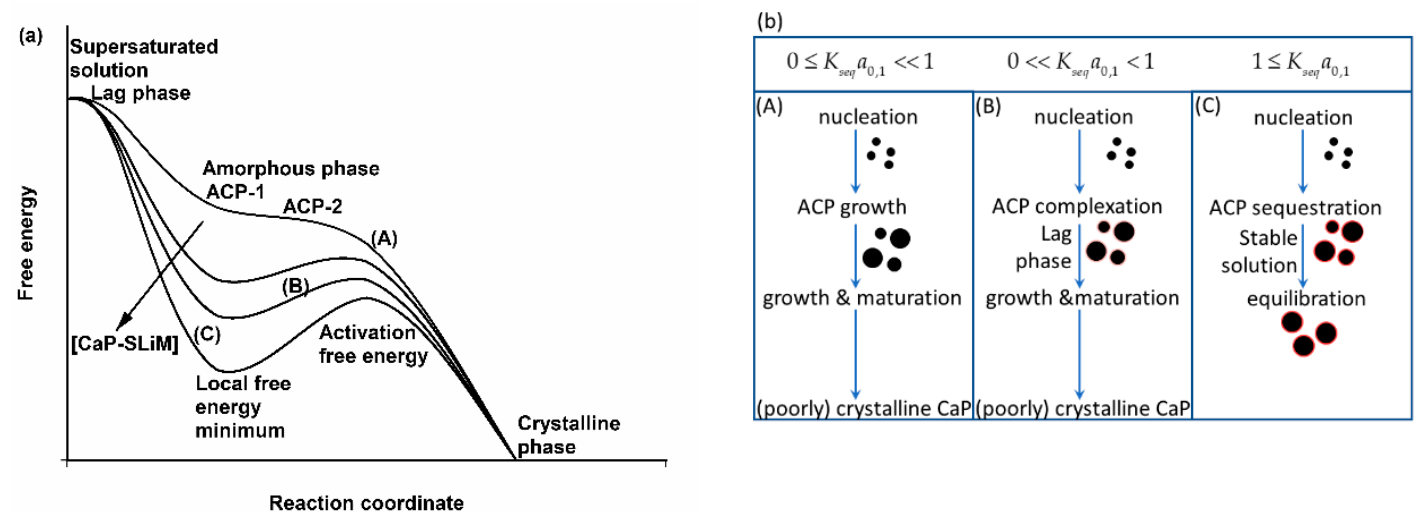

Figure 3. Effect of phosphopeptides on the free energy changes during the precipitation and maturation of $\mathrm{CaP}$ from a supersaturated solution. (a) In the absence of the phosphopeptide (curve A), nuclei of amorphous $\mathrm{CaP}$ form during the lag phase and grow into a precipitate of $\mathrm{ACP}-1$ which matures into ACP-2, and further matures to form a poorly crystalline or crystalline phase. Adding a phosphopeptide at any point in the reaction up to the stage where the ACP begins to mature into a crystalline form generates a local free energy minimum (curves $B$ and $C$ ) and an activation free energy barrier to slow or stop further maturation. The position of the minimum, the composition of the sequestered ACP and the size of the nanocluster particles depend on the affinity of the phosphopeptide for the CaP $\left(K_{s e q}\right)$, its concentration in the continuous phase at equilibrium $\left(a_{0,1}\right)$ and other factors. (b) The phosphopeptide can act as an inhibitor and as a nucleator of CaP precipitation, either increasing or decreasing the time spent in the lag phase, depending on which effect predominates. For a given phosphopeptide the course of the reaction can be expressed in terms of the value of the product $K_{\text {seq }} a_{0,1}$. (A) Homogeneous nucleation in the presence of a non-binding phosphopeptide or heterogeneous nucleation at a very high molar ratio of CaP to phosphopeptide. Effectively, $K_{\text {seq }} a_{0,1}<<1$ (curve (A) in (a)) and the ACP matures to form a (poorly) crystalline CaP. (B) An intermediate situation $\left(0<K_{s e q} a_{0,1}<1\right)$ (curve (B) in (a)) in which competent sequestering phosphopeptides are present and form kinetically stabilized complexes with $\mathrm{CaP}$ to decrease (in this example) or increase the time spent in the lag phase, but the activation free energy barrier is not large enough to prevent further growth and maturation of the ACP. (C) For $K_{\text {seq }} a_{0,1} \geq 1$ (curve (C) in (a)), the activation free energy is large enough for stable nanocluster complexes to form in a local free energy minimum and reach an equilibrium size and composition. Their formation may occur reversibly, starting from either a supersaturated solution or by adding the phosphopeptide to a pre-formed phase of ACP. (b) reproduced with permission from Holt et al. [24] (C)2009FEBS.

It has been recognized for many years that an initial and highly unstable amorphous phase, ACP-1 is succeeded by a more stable and less soluble amorphous phase, ACP-2 [83,84]. Both phases have the same $\mathrm{Ca} / \mathrm{P}_{\mathrm{i}}$ ratio of 1.35 which is significantly lower than that of a basic tricalcium phosphate $\left(\mathrm{Ca} / \mathrm{P}_{\mathrm{i}}=1.5\right)$ but above that of an acidic dicalcium phosphate $\left(\mathrm{Ca} / \mathrm{P}_{\mathrm{i}}=1.0\right)$. The empirical chemical formula $\mathrm{Ca}\left(\mathrm{PO}_{4}\right)_{0.52}\left(\mathrm{HPO}_{4}\right)_{0.22}$ is consistent with an $\mathrm{ACP}$ of $\mathrm{Ca} / \mathrm{P}_{\mathrm{i}}=1.35$ [83]. In similar studies [84-87], the $\mathrm{Ca} / \mathrm{P}_{\mathrm{i}}$ ratio of $\mathrm{ACP}$ has been reported to be as high as 1.5 [88] and as low as 1.18 [87], demonstrating that a range of more-or-less acidic ACP phases are possible with distinct short-range structures [89-91]. The variable co-ordination geometry of calcium ions in calcium salts and variable stoichiometry of CaPs are well recognized [92]. For example in the crystalline dicalcium phosphates three structures have been reported of anhydrous, monohydrate and, dihydrate salts [93].

Maturation of ACPs often proceeds by a mechanism called solution-mediated solid-to-solid transformation $[2,94,95]$ in which a less soluble phase gradually dissolves, its ions pass into solution where a less soluble phase nucleates and grows. The transformation rate depends on many factors, including the addition of seed crystals and the solution concentration of effective inhibitors such as ions of magnesium, citrate, phosphonates, or phosphate esters such as phosphoproteins [1,2]. Usually, $\mathrm{ACP}$ matures first at neutral or alkaline $\mathrm{pH}$ into poorly crystalline, impure, and non-stoichiometric 
phases, the more stoichiometric octacalcium phosphate and the most stable, least soluble crystalline phase, HA [96]. The mineralized tissues of bone, cementum, and dentine all contain poorly crystalline CaPs with carbonate substitutions for the other anions. Even so, the surface of bone is not a highly insoluble apatite-type phase but a highly hydrated layer, rich in hydrogen phosphate ions [97]. This surface layer is in dynamic exchange with the extracellular matrix where biomolecule-ion-mineral interactions take place. Tooth enamel comprises highly crystalline prisms of almost pure HA in contact with re-mineralizing saliva [98].

\subsection{Effect of Phosphopeptides}

Phosphoproteins and phosphopeptides can affect every aspect of the precipitation process by acting as either heterogeneous nucleators of an amorphous or crystalline $\mathrm{CaP}$ or as partial inhibitors to produce a metastable solution of colloidal complexes with CaP or to form a thermodynamically stable solution of sequestered $\mathrm{CaP}$ nanoclusters $[1,11]$. The outcome depends on the concentration of the phosphoprotein, the concentration of $\mathrm{CaP}$ precipitating from the supersaturated solution and the affinity of the phosphopeptide for the $\mathrm{CaP}$ under the conditions of $\mathrm{pH}$ and other ion concentrations in the solution. Clearly, inhibition or nucleation properties are not intrinsic to a given protein and it should not be considered surprising that it can act in various ways, depending on its concentration, other solution conditions and its degree and pattern of phosphorylation. The absence of phosphorylated residues may allow the default process of ACP maturation by Ostwald ripening to proceed more quickly than with a phosphorylated form. On the other hand, phosphorylated sequences may nucleate $\mathrm{CaP}$ and if the molar ratio of $\mathrm{CaP}$ to nucleating agent is high, then the initial ACP may mature into a crystalline phase. If the molar ratio is lower, the nucleating agent may also inhibit maturation and the solution may remain in a lag phase, sometimes with little change in appearance or turbidity for a prolonged period.

These various possibilities are summarized schematically in Figure 3.

\subsubsection{Nucleation Versus Inhibition}

The interfacial free energy is important in the heterogeneous nucleation of one substance by another and chemical similarity is important in nucleating amorphous substances. The heterogeneous nucleation of $\mathrm{CaP}$ on surfaces rich in phosphate ester groups is common and can be used to create specific shapes of the mineral phase, oriented growth of crystals [99] and more complex hierarchical structures. Examples include hollow shells grown on phospholipid vesicles [100] and templated growth on DNA molecules [101]. Examples of nucleation of CaP by phosphoproteins are given in Section 2.3. It is sometimes considered paradoxical that a protein can be a nucleator of $\mathrm{CaP}$ in one circumstance and an inhibitor in another (see Section 2.3 and Figure 3). However, facilitated nucleation at a low molar ratio of phosphoprotein to $\mathrm{CaP}$ or complete sequestration at a higher ratio could be essentially similar processes producing either a mineral phase by nucleation or metastable complexes or stable complexes as the ratio increases.

\subsubsection{Kinetic Stability of Complexes in Metastable Solutions}

This topic is the subject of very many publications and to do it justice requires a review of its own. Reference is made to some of the cited literature in the comprehensive reviews mentioned at the beginning of this article, particularly [1,2,8-11]. We briefly mention here only a few of the most salient points.

In general, kinetic stability giving rise to a lag phase during precipitation can arise from the electrostatic, entropic, or enthalpic interactions of adsorbed polymers. In colloid science entropic or enthalpic repulsion between dispersed phases is often called steric stabilization and is a highly effective means of preventing the agglomeration of otherwise unstable colloidal particle [102]. In the science of IDPs, a similar effect giving rise to repulsion between hydrophilic proteins is described as due to entropic chains [103]. More specifically, the extent of stabilization, as measured by time 
spent in the lag phase, is influenced by the degree of coverage and conformation of the adsorbed protein, the dynamics of adsorption, and the strength of binding determined by acidic sequences such Asp- or Glu- or pSer-rich SLiMs. In addition, the time spent in the lag phase can be determined by maturation of the ACP and hence is affected by selective adsorption of the protein to specific growth sites or developing crystal planes and the consequential effect on the rate of conversion of the initial ACP into more crystalline phases [49,71,104-109]. In this review, we stress that it is not the absolute concentration of protein that determines the stability of the lag phase but the affinity and concentration of binding proteins in relation to the concentration of $\mathrm{CaP}$ formed by the supersaturated solution (Figure $3 \mathrm{a}, \mathrm{b}$ ). In a metastable solution in the lag phase, the CaP in the form of kinetically stabilized complexes is said to be in a state of arrested precipitation.

\subsubsection{Thermodynamically Stable Complexes}

When the first $\mathrm{CaP}$ nanocluster complexes were prepared in the laboratory at milk-like concentrations of salts and CaP-SLiMs, it was presumed that the CaP in the core of the complex was in a state of arrested precipitation $[18,110,111]$. Experimental evidence accumulated, however, to show that the solutions were thermodynamically stable. For example, any initial turbidity in the solutions disappeared on storage of the solutions for several days rather than growing into a precipitate. Moreover, the solutions were remarkable stable. They could be stored at room temperature for years without apparent change, they could be frozen and thawed, steam sterilized and dried and reconstituted. Most convincingly, it was found that the nanocluster complexes could be formed by a "forward" reaction from a supersaturated solution containing a large enough concentration of competent phosphopeptides and by a "back" reaction by adding the competent phosphopeptide to a pre-formed, fresh, precipitate of ACP [112]. The "back" reaction is slower than the "forward" reaction and thereby less practicable. If the ACP matures before adding the phosphopeptide or if phosphopeptide is used to attempt to disperse a poorly crystalline $\mathrm{CaP}$, the dispersion reaction does not occur. The conclusion from these experiments is that the sequestered nanocluster solution can be thought of as existing in a local free energy minimum with an activation free energy sufficiently high to prevent it from phase separating into a saturated solution at equilibrium with a more stable crystalline phase of CaP. The position and depth of the minimum are clearly important in determining the stability of the equilibrium complexes or the lag time of a metastable solution, and the partition of salts between the complexes and continuous phase.

We envisage (Figure 3) that CaP complexes with phosphoproteins can undergo a reversible transition between kinetically or thermodynamically stabilized states, depending on the concentration of sequestering phosphopeptide, its degree and pattern of phosphorylation, and other conditions in the solution, such as $\mathrm{pH}$. To reiterate, the condition required to form a thermodynamically stable complex with a competent phosphopeptide, requires an excess of the phosphopeptide to be in the continuous phase after the complexes have formed. This condition is explained further and made quantitative in Section 3.5 and summarized in Figure 3. It is important to emphasize that the mechanism of stabilizing biofluids by forming the equilibrium $\mathrm{CaP}$ nanocluster complexes is applicable at $\mu \mathrm{M}$ or lower concentrations of phosphoproteins, as found in blood serum, the extracellular matrix, or other biofluids as well as the $\mathrm{mM}$ concentrations in milk. Moreover, any of the phosphorylated proteins listed in Table 1 are capable, at least in principle, of forming the equilibrium complexes provided they have a high enough affinity for $\mathrm{CaP}$ at their physiological concentration.

\subsubsection{Destabilization of Thermodynamically Stable Solutions}

Destabilization of a supersaturated biofluid containing complexed forms of ACP can occur if is brought into contact with a more stable crystalline phase of $\mathrm{CaP}$ or if there is not enough of the stabilizing protein or polymer to sequester the CaP formed by the biofluid. Section 3.7 shows how thermodynamically stable or unstable regions can be defined, depending on $\mathrm{pH}$. 
In both the thermodynamically stable and unstable regions, the continuous phase is supersaturated with respect to HA, but nucleation is suppressed by an excess of the sequestering phosphopeptide. In Section 3.5 expressions are given showing how the size of the equilibrium $\mathrm{CaP}$ nanocluster complexes depends on the affinity and concentration of the sequestering phosphopeptides. In Section 4 a calculation is given to show that as the concentration of free sequestering phosphopeptide decreases towards zero, the size of the complexes increases towards infinity. In other words, precipitation of $\mathrm{CaP}$ occurs. In Section 5.6, these ideas are used to explain how, in biomimetic mineralization experiments using stable or metastable CaP complexes, intrafibrillar mineralization of collagen fibers can occur while extrafibrillar mineralization is suppressed.

When a poised solution in the lag phase, or a thermodynamically stable solution of the equilibrium nanocluster complexes, is brought into contact with a thermodynamically more stable crystalline phase, the ACP in both types of mineral-protein complexes will tend to undergo the same solution-mediated solid-to-solid transformation that ACP undergoes in the presence of crystalline $\mathrm{CaP}$ [113]. This theoretically predicted transfer of ions from CaP nanoclusters to hydroxyapatite has been demonstrated experimentally using native casein micelles [113].

\subsection{Ion Activity Product in the Continuous Phase of Solutions Containing Calcium Phosphate Nanocluster Complexes}

It is possible to apply equilibrium thermodynamics to a metastable supersaturated solution in a prolonged lag phase $[83,84]$ in order to define an effective solubility product, applicable to any supersaturated solution provided it is well away from the spinodal boundary where no lag phase can exist [114]. We justify the approach because the time needed for ions to reach equilibrium with the continuous phase is likely to be short compared to the time spent in the lag phase and we restrict our application to nearly stable solutions with lag times of days or longer. Likewise, we can use equilibrium thermodynamics to define the solubility product of $\mathrm{CaP}$ nanocluster complexes formed by competent sequestering phosphopeptides. The solubility products are analogous to those formed by a bulk phase of $\mathrm{CaP}$ in equilibrium with a saturated solution. The $\mathrm{CaP}$ nanoclusters are not a bulk phase but typically contain several hundred $\mathrm{CaP}$ molecules, considerably larger than pre-nucleation clusters formed in the earliest stages of precipitation in a non-classical nucleation mechanism [115-117]. Thus, the form and magnitude of the solubility constant can depend on the nature of the sequestering phosphopeptide. Urine has been described as an equilibrium single-phase fluid and as a supersaturated system poised on the brink of phase separation [118-120] but in both descriptions, an effective solubility constant describes the partition of salts between the continuous phase and either a bulk phase or complexed forms of $\mathrm{CaP}$.

Using a generic empirical chemical formula for a phase, containing both $\mathrm{HPO}_{4}^{2-}$ and $\mathrm{PO}_{4}^{3-}$ [82], the equilibrium can be written as.

$$
\mathrm{Ca}^{2+}+y \mathrm{HPO}_{4}^{2-}+\frac{2(1-y)}{3} \mathrm{PO}_{4}^{3-} \leftrightarrow\left[\mathrm{Ca}\left(\mathrm{HPO}_{4}\right)_{y}\left(\mathrm{PO}_{4}\right)_{\frac{2(1-y)}{3}}\right]_{\text {solid }}
$$

The corresponding ion activity product is $\left\{\mathrm{Ca}^{2+}\right\}>\left\{\mathrm{HPO}_{4}^{2-}>\right\}^{y}>\left\{\mathrm{PO}_{4}^{3-}>\right\}^{2(1-y) / 3}$. If the solid is stable or metastable for long enough to reach equilibrium with the continuous phase, the ion activity product can be treated as an invariant thermodynamic property of the system with the same value, irrespective of the activities of the individual ions. Conversely, if the composition of the solid phase is unknown, the determination of the invariant ion activity product gives the value $y$, the effective solubility of the $\mathrm{CaP}\left(K_{S}\right)$ and its $\mathrm{Ca} / \mathrm{P}_{\mathrm{i}}$ ratio, $3 /(2+y)$. For example, a basic tricalcium phosphate has $y$ $=0$, the ACP-1 and ACP-2 phases of Christoffersen et al. [83] have $y=0.22$ and an acidic dicalcium phosphate has $y=1.0$.

The ion activity products of $\mathrm{CaP}$ salts of samples of bovine milk and the human biofluids blood serum and stimulated saliva have been calculated [13] and are shown in Figure 4 [13,121-124]. Results 
were expressed as a saturation index, SI, by dividing the ion activity product by the corresponding thermodynamic solubility product and are plotted as $\log (\mathrm{SI})$ versus sample $\mathrm{pH}$ (Figure 4). Thus, undersaturated, saturated, and supersaturated biofluids have $\log (\mathrm{SI})$ values that are negative, zero, or positive, respectively, and a set of $\log (\mathrm{SI})$ values that are consistently close to zero and show no dependence on $\mathrm{pH}$ allows the empirical chemical formula of the CaP substance to be deduced.
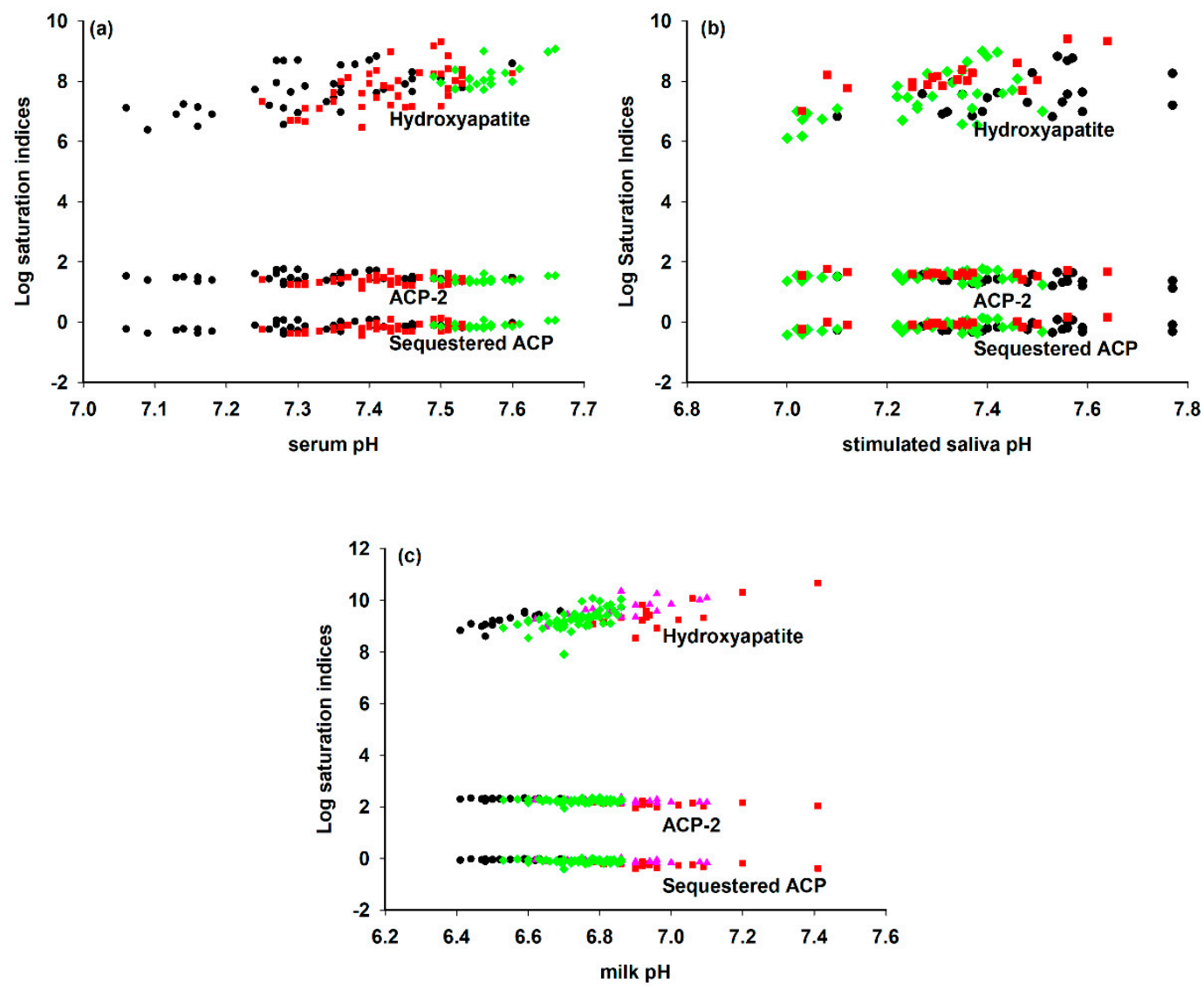

Figure 4. Ion activity products in milk, blood serum and stimulated saliva calculated for three different chemical formulae and divided by the invariant thermodynamic solubility constant for the formula to give the saturation index [13]. The invariant ion activity product of CaP nanoclusters prepared with casein phosphopeptides was used for the milk samples and for the other biofluids an invariant ionic activity product of CaP nanoclusters complexed with the N-terminal OPN 1-149 phosphopeptide was used [24]. (a) Human blood ultrafiltrates from subjects who were healthy (green diamond), had hypercalcemia (red square) or renal disease (black circle). Original data from $[125,126]$. (b) Stimulated parotid (black circle), whole (green diamond) and submaxillary (red square) saliva ultrafiltrates. Original data of [122]. (c) Bovine milk ultrafiltrates from cows in early (green diamond), middle (black circle) or late (pink triangle) lactation or with mastitis (red square). Original data from [127], modified by [128]. Reprinted with permission from Holt et al. [13] (C2013The Authors. Published by Elsevier Inc. All rights reserved.

Although there is considerable variation in the composition of each set of samples, the three biofluids all exhibit an invariant ion activity product, consistent with an equilibrium distribution of calcium and phosphate ions between the continuous phase and sequestered $\mathrm{CaP}$ nanoclusters. Indeed, for milk the evidence of such an equilibrium is abundant and compelling through the existence of $\mathrm{CaP}$ nanoclusters in casein micelles as determined by chemical analysis and a range of structural methods [39,127,129-135]. 


\subsection{Calculation of the Partition of Salts in a Biofluid Containing CaP Nanocluster Complexes}

The CaP nanocluster complex $A_{k, m}$ of concentration $a_{k, m}$ comprises $k$ molecules of CaP and $m$ bound phosphopeptides. Concentrations are expressed as mole fractions, i.e., the number of moles of a component divided by the sum of the number of moles of all components in the solution. Standard states are therefore for the pure substances. The total mole fraction of the peptide is $a^{\text {total }}$ and the mole fractions of bound and free peptides are $a^{\text {bound }}$ and $a^{\text {free }}$, respectively, so

$$
\begin{array}{r}
a^{\text {total }}=a^{\text {bound }}+a^{\text {free }}=\sum_{\substack{m=1 \\
\text { Nanoclusters Serum }}}^{\infty} m a_{k, m}+a_{0,1} \\
\text { Nanolust }
\end{array}
$$

where $a_{0,1}$ is the mole fraction of free phosphopeptide. Likewise, $a_{1,0}$ is the mole fraction of single $\mathrm{CaP}$ molecules in the solution. An equation corresponding to Equation (2) can be written for the total concentration of $\mathrm{CaP}$ molecules, $a_{\mathrm{CaP}}^{\text {total }}$

$$
a_{\mathrm{CaP}}^{\text {total }}=a_{\mathrm{CaP}}^{\text {bound }}+a_{\mathrm{CaP}}^{\text {free }}=\sum_{\substack{m=1 \\ \text { Nanoclusters Serum }}}^{\infty} \sum_{k=1}^{\infty} k a_{k, m}+a_{1,0}
$$

where $a_{\mathrm{CaP}}^{\text {bound }}$ and $a_{\mathrm{CaP}}^{\text {free }}$ are concentrations of CaP molecules in the CaP nanoclusters and continuous phase, respectively.

Partition is typically achieved by means of ultrafiltration through a membrane with a molar mass cut-off of 10,000 Da to separate the nanocluster complexes and free sequestering peptide from the serum or continuous phase. A thermodynamic model of the biofluid is used to calculate the equilibria among the principal small ions in the continuous phase such as $\mathrm{Ca}^{2+}, \mathrm{HPO}_{4}^{2-}$ and $\mathrm{CaHPO}_{4}$ but it needs to be recognized that biofluids are usually more complex than the model because of a plethora of minor ions and other constituents. The model also assumes that all components in the continuous phase are in the form of simple ions and ion complexes and that the concentrations of pre-nucleation clusters are small compared to other free ions and ion pairs in the model (for references see [13]). A tractable theory of the additional calculation of the partition of salts between sequestered and free forms in a physiological fluid containing phosphopeptides can be formulated on the assumption that there is a further equilibrium reaction in which phosphopeptides bind strongly to ACP to form a distribution of complexes.

An estimate of the composition of the CaP nanocluster complex is obtained by subtracting the ultrafiltrate from the total concentrations. If there is a significant concentration of excess free sequestering peptide then it is also necessary to know its concentration and ion binding properties. Limited experimental evidence over a restricted range of a few compositional variables shows that the sequestered nanocluster complexes have a nearly constant composition and size, and that the serum exhibits an invariant ion activity product [24,112].

Application of the model to simple nanocluster complexes made with single short acidic peptides, and to milk and some other biofluids has been described $[13,24,112,128]$. An improved calculation procedure called Model 2 has allowed a more detailed description of the partition of the individual caseins [39].

\subsection{Thermodynamic Description of the Formation of CaP Nanoclusters Sequestered by Short Acidic Phosphopeptides}

In this Section an expression is derived for the size distribution of the nanocluster complexes formed with short acidic phosphopeptides. The complexes have no tendency to associate with themselves and form larger structures such as the casein micelles of milk. Thus, they comprise a core of the CaP nanocluster surrounded by a sequestering shell of bound peptides. A simple balance of the 
free energy of forming the core against the free energy of sequestration gives the following expression for the equilibrium radius of the core.

$$
r_{\text {core }}=\frac{2 V_{A C P} \Delta G_{\text {shell }}^{*} / A}{-\Delta G_{\text {CaP }}^{*}}
$$

where $\Delta G_{\text {shell }}^{*} / A$ is the standard free energy of forming the shell of sequestering phosphopeptides per unit area of core surface, $\Delta G_{\mathrm{CaP}}^{*}$ is the standard free energy of forming the core of $\mathrm{CaP}$ and $V_{\mathrm{CaP}}$ is the molar volume of the CaP [24]. Equation (4) is very similar to the expression for the size of a critical droplet in the capillary theory of nucleation originally formulated by Volmer [136] but with the important difference that $\Delta G_{\text {shell }}^{*}$ is negative and $\Delta G_{C a P}^{*}$ is positive. In qualitative terms, the formation of the complexes is driven by the negative free energy of sequestration to the extent that the formation of the core occurs from a solution formally undersaturated with respect to a bulk phase of the core CaP. The implications of this analysis for the stability of biofluids that contain the nanocluster complexes are profound. We have also used the equilibrium thermodynamics of associated solutions [137] to derive expressions for the free energy of forming the CaP nanocluster in an ideal solution [24]. A distribution law was derived for the core size of single nanocluster particles stabilized by either short casein phosphopeptides or the larger N-terminal half of OPN. The treatment assumed that the complex was formed by association of "monomers" of a single peptide with a proportion of the CaP already bound to them. Here we summarize a modified treatment [138] that starts from separate molecules of CaP and sequestering peptides to bring out the effect of the peptide concentration explicitly.

The free energy of formation of the complex is formally divided into two processes. This is a formal exercise to derive the overall free energy change and is not a description of the sequence of events or mechanism of forming the complexes. The first process is formation of the core by successive additions of single molecules of $\mathrm{CaP}, A_{1,0}$

$$
A_{1,0}+A_{k-1,0} \rightleftarrows A_{k, 0}
$$

The standard free energy change for the formation of the $k$-mer from $k$ monomers is

$$
\Delta G_{k}^{*}=\mu_{k, 0}^{*}-k \mu_{1,0}^{*}=k \Delta G_{C a P}^{*}
$$

where $\Delta G_{C a P}^{*}$ is the free energy of forming a pure phase of the nanocluster core $\mathrm{CaP}, \mu_{0,1}^{*}$ and $\mu_{k, 0}^{*}$ are the standard chemical potentials of the monomer and $k$-mer, respectively. This phase, in contact with solvent, forms a saturated solution containing a mole fraction $a_{1,0, \text { sat }}$ of CaP molecules so that $\Delta G_{C a P}^{*}=R T \ln a_{1,0, s a t}$.

In the second formal process, $m$ molecules of free peptide sequester the $\mathrm{CaP} k$-mer within a shell of $m$ peptides

$$
A_{k, 0}+m A_{0,1} \rightleftarrows A_{k, m}
$$

If $V_{C a P}$ is the volume of a CaP molecule then the number of sequestering peptide molecules, $m$ is given by

$$
m=s_{C a P} k^{2 / 3}
$$

where

$$
s_{C a P}=\left(36 \pi V_{C a P}^{2} / A_{C a P}^{3}\right)^{1 / 3} \theta_{s e q} k^{2 / 3}
$$

$\theta_{s e q}$ is the fraction of total binding sites occupied by the peptides. The standard free energy change of this reaction is

$$
\Delta G_{\text {shell }}^{*}=\mu_{k, m}^{*}-m \mu_{0,1}^{*}-\mu_{k, 0}^{*}
$$


The standard free energy of forming the shell is formally equivalent to the standard free energy of sequestration by $m$ molecules of the phosphoprotein

$$
\Delta G_{\text {shell }}^{*}=m \Delta G_{\text {seq }}^{*}
$$

For equal and independent binding sites on the surface of the $\mathrm{CaP}$,

$$
\theta_{\text {seq }}=K_{\text {seq }} a_{0,1} /\left(1+K_{\text {seq }} a_{0,1}\right)
$$

where $\Delta G_{s e q}^{*}=-R T \ln K_{s e q}$. The free energy of forming the complex becomes

$$
\Delta G_{k, m}=s_{C a P} k^{2 / 3} \Delta G_{s e q}^{*}+R T \ln \left(\frac{a_{1,0, s a t}^{k} a_{k, m}}{a_{1,0}^{k} a_{0,1}^{s_{C a P} k^{2 / 3}}}\right)
$$

Hence, at equilibrium, the distribution of chemical species becomes

$$
a_{k, m}=a_{0,1}^{s_{C a P} k^{2 / 3}} S^{k} \exp \left(-\frac{s_{C a P} k^{2 / 3} \Delta G_{s e q}^{*}}{R T}\right)
$$

where the saturation ratio is defined as $S=a_{1,0} / a_{1,0}$ sat so that a thermodynamically stable solution has $S \leq 1$. The normalized number fraction distribution of complexes, $N(k)$, can be generated from Equation (14) by multiplication of the function by a constant $C^{\prime}$, such that $1=C^{\prime} \sum_{k=1}^{\infty} a_{k, m}$. The normalized distribution has a peak at

$$
k^{\prime}=\left[\frac{-2 s_{C a P} \ln \left(K_{s e q} a_{0,1}\right)}{3 \ln S}\right]^{3}
$$

In a solution containing a competent phosphopeptide and certain concentrations of calcium and phosphate ions, the CaP nanoclusters form spontaneously $(k>1)$ if $S<1$, and $K_{\text {seq }} a_{0,1}>1$. In other words, a biofluid containing nanocluster complexes is at equilibrium below the saturation level for the bulk phase of $\mathrm{CaP}$; the solution cannot precipitate pure $\mathrm{CaP}$ if this condition is met. The minimum concentration of free sequestering peptide in a stable biofluid, $a_{0,1, \min }$, is specified by $a_{0,1, \mathrm{~min}}=K_{\mathrm{seq}}^{-1}$. Thus, a higher affinity of the peptide for the core $\mathrm{CaP}$, means a lower minimum concentration of free peptide. There is no maximum concentration of free peptide as this is determined by the concentration of $\mathrm{CaP}$ that might form in the biofluid. Indeed, an arbitrarily large number of nanocluster complexes may be present in the biofluid without it becoming unstable. This property is exploited in forming milk and may apply to extracellular fluid near the mineralization front of hard tissues. For a given biofluid composition the total peptide concentration required for stability varies with $\mathrm{pH}$ as shown in a biofluid stability diagram (as described in Section 3.7).

\subsection{Evaluation of the Number Fraction Distribution}

The position and shape of $N(k)$ depends on the saturation, $S$ and the product $K_{\text {seq }} a_{0,1}$. Numerical evaluation of the normalized distribution function shows that at a given value of $k^{\prime}$, the distribution becomes narrower and $S$ decreases as $K_{\text {seq }} a_{0,1}$ increases. At a given constant value for $k^{\prime}$, the breadth of the distribution decreases as $K_{\text {seq }} a_{0,1}$ increases, as shown in Figure 5. 


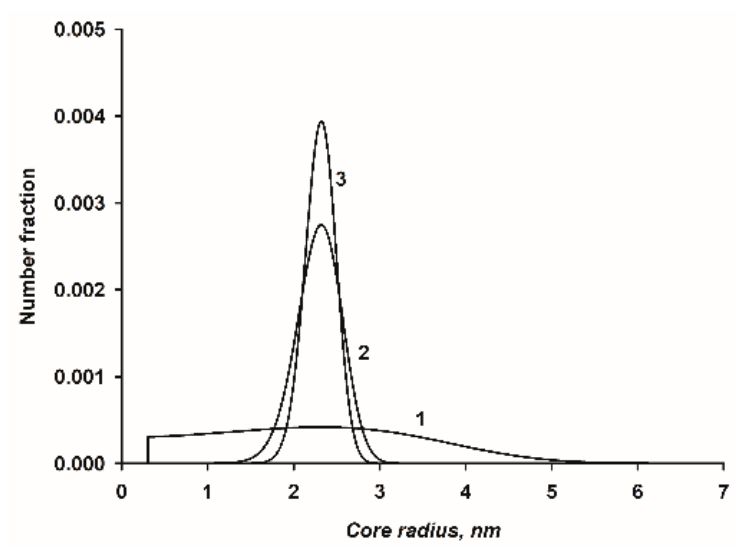

Figure 5. Three example size distribution curves of nanocluster complexes where the radius of the peak of the distribution was held constant and the product $K_{\text {seq }} a_{0,1}$ was either 1.05, 3.65 or 10.0 in curves 1,2 , and 3, respectively. Parameters that were kept constant were, $A_{C a P}=1.7 \mathrm{~nm}^{2}, V_{C a P}=0.12 \mathrm{~nm}^{3}$, empirical chemical formula of the CaP: $\mathrm{Ca}\left(\mathrm{HPO}_{4}\right)_{0.4}\left(\mathrm{PO}_{4}\right)_{0.4}$. The lower bound of the distributions, as clearly shown in curve 1 is the radius of the core formed from a single molecule of CaP $(k=1)$. Curve 2 is a narrow distribution that describes the size distribution of $\mathrm{CaP}$ nanoclusters sequestered by $\beta$-casein $1-25$, as discussed in Section 4.1.

\subsection{Stability of Biofluids and the Facile Co-Existence of Soft and Mineralized Tissues}

Certain biofluids such as saliva have a role in the remineralization of a hard tissue, in this case the tooth, but ectopic deposition of $\mathrm{CaP}$ on other surfaces such as gums must be limited or reversible. In principle, a solution containing nanocluster complexes can satisfy both requirements [139]. In contact with soft tissue, the biofluid is stable, even though it is supersaturated with respect to crystalline CaPs, because it is undersaturated with respect to the first-formed amorphous form of CaP. In contact with a hard tissue such as a tooth, however, a solution-mediated transfer of calcium and phosphate ions from the continuous phase of the biofluid to the tooth mineral is thermodynamically favorable and was observed experimentally when casein stabilized CaP nanoclusters were equilibrated with HA [113].

Although a biofluid may be stable under conditions of homeostasis, a destabilizing fluctuation in its composition may render the biofluid unstable and prone to form ectopic CaP deposits. A measure of how resistant a biofluid is to destabilizing fluctuations is provided by the biofluid stability diagram.

The minimum concentration of CaP-SLiMs needed to sequester the quantity of $\mathrm{CaP}$ formed at equilibrium in response to a change of composition can be calculated from the condition $K_{\text {seq }} a_{0,1} \geq 1$ if $K_{s e q}$ is known, otherwise an approximation is to find the stoichiometric concentration of sequestering peptide required to react with the $\mathrm{CaP}$ nanoclusters assuming they have a constant size and composition. This latter criterion has been used as a function of $\mathrm{pH}$ to calculate the stability diagram for a variety of biofluids $[13,39]$. An example of the stability diagram for an average bovine milk is shown in Figure 6 .

The stability diagram defines areas of stability and instability. Below a certain $\mathrm{pH}$, called the critical $\mathrm{pH}, \mathrm{pH}_{\mathrm{c}}$, no phosphopeptides are needed to make the biofluid stable. If the physiological $\mathrm{pH}$ is above the critical $\mathrm{pH}$, it will be liable to nucleate CaP. Nevertheless, if it contains a high enough concentration of a sequestering phosphopeptide it can be perfectly stable, even at the physiological $\mathrm{pH}$, but at equilibrium it will then contain nanoclusters of sequestered CaP. For the example calculation shown in Figure 6, the physiological $\mathrm{pH}$ is about 6.7 where the minimum concentration of CaP-SLiMs needed for stability is about $900 \mu \mathrm{M}$. About $80-90 \%$ of the CaP-SLiMs on caseins are required to sequester $\mathrm{CaP}$ and the remainder are available to buffer the effect of an increase in $\mathrm{pH}$. Bovine milk is well buffered to cope with the loss of $\mathrm{CO}_{2}$ and hence small increase of $\mathrm{pH}$ when it is exposed to air but human milk is not and an increase of $0.2 \mathrm{pH}$ units or more can occur [140]. 


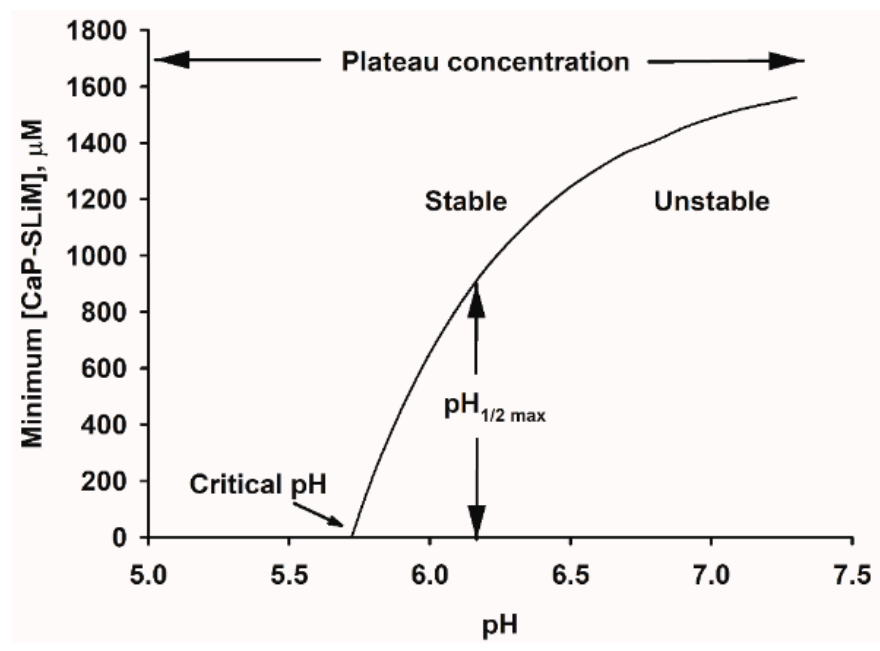

Figure 6. Stability diagram for a typical bovine milk. Above a critical $\mathrm{pH}$ the solution becomes supersaturated with respect to $\mathrm{CaP}$ and a certain minimum concentration of sequestering peptide or protein is required to maintain its stability. At or above this minimum concentration the milk is stable and below it is metastable or unstable and phase separation/precipitation of CaP can occur. At about $\mathrm{pH} 8$, the curve separating the stable and unstable regions reaches a plateau concentration. The shape of the curve is further characterized by the $\mathrm{pH}$ where half the plateau concentration of sequestering protein is required for stability. Reprinted with permission from Holt et al. [13] (C2013The Authors. Published by Elsevier Inc. All rights reserved.

As $\mathrm{pH}$ increases, the minimum concentration of CaP-SLiMs, $C_{\min }$, increases in a curvilinear manner up to a plateau value, $C_{\max }$, typically above $\mathrm{pH}$ 8. Close to the boundary line, on the higher $\mathrm{pH}$ side, is an ill-defined area of metastability where precipitation may be delayed for some time in a lag phase. Farther to the right of the thermodynamic stability curve (i.e., at higher $\mathrm{pH}$ ), beyond the region identified as metastable, lies the spinodal boundary. This marks the practical limit of metastability for a single-phase system. Experiments to determine the position of the spinodal in a milk-like casein-CaP system have not been reported, but the approximate position of the spinodal in an artificial blood system using an osteopontin phosphopeptide mixture as the sequestrant has been described [13]. It is apparently paradoxical that the saturation index of blood serum should be so similar to that of a solution of OPN nanocluster complexes whereas circulating levels of OPN are seemingly low compared to the major blood phosphoprotein, fetuin A [17,141].

A simple analytical expression to describe the stability diagrams is desirable. The stability diagram of milk and some other biofluids [13] is similar in shape to a binding isotherm and can be fitted nicely by a type of Hill equation [142] using a non-linear least squares method. The equation can be written as

$$
C_{\max } / C_{\min }=1+\exp \left[n \ln \left(\frac{\mathrm{pH}_{1 / 2}-\mathrm{pH}_{c}}{\mathrm{pH}-\mathrm{pH}_{c}}\right)\right]
$$

Where the dependent variable on the ordinate is $C_{\min }$ and the independent variable on the abscissa is $\mathrm{pH}$. The fitted parameter $\mathrm{pH}_{1 / 2}$ is the $\mathrm{pH}$ value at which $C_{\min } / C_{\max }=1 / 2$ and $n$ is a fitted shape parameter. In the original Hill equation $n$ described the co-operativity of binding oxygen molecules to molecules of hemoglobin but it has no direct physical meaning here.

The stability diagram of a reference bulk milk is shown in Figure 6 and fitted curves for milk samples from 18 individual cows have been reported [39]. Considerable variation was found in the stability diagrams of the individual milk samples. Half were stable to any change of $\mathrm{pH}$ and 16 were stable at or above the natural $\mathrm{pH}$ but two were slightly metastable at their natural $\mathrm{pH}$. Three of these examples are shown in Figure 7. All three individual milk samples have a similar total concentration of CaP-SLiMs, a little over $1.6 \mathrm{mM}$ but the corresponding stability curves are very different because of 
differences in salt composition. Thus, sample PM04 is stable to $\mathrm{pH}$ variation, sample JL09 is stable up to $\mathrm{pH} 7.4$ but JL01 is unstable even at its physiological $\mathrm{pH}$.

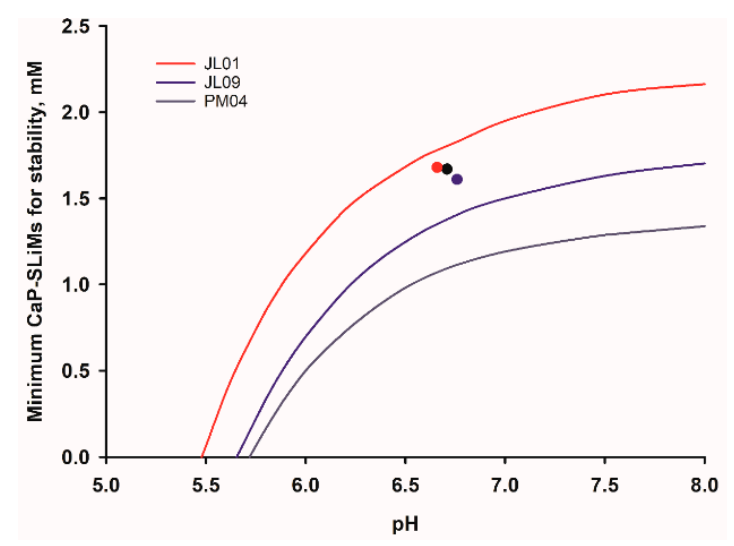

Figure 7. Stability diagrams for three milk samples from individual cows showing similar total concentrations of casein and CaP-SLiMs but very different stability curves because of differences in salt composition [39].

Stability diagrams can be constructed for any biofluid for which there is enough compositional information. Some further examples for blood serum, saliva, milk, and urine are discussed in Section 5.

\section{Properties of Some Calcium Phosphate Nanocluster Complexes}

Historically, the scientific study of nanocluster complexes began with the characterization of the native substructures of the casein micelles in milk, known then as colloidal $[143,144]$ or micellar [145] CaP, which established that the CaP occurred as amorphous particles with a size of several $\mathrm{nm}[91,146,147]$. Attempts to isolate the CaP from its casein matrix always co-extracted tightly bound peptides corresponding to the most highly phosphorylated casein sequences [148]. Further understanding of the nature of the nanocluster complexes came from model studies using single pure casein, OPN, and recombinant phosphopeptides. Major achievements of the work on the artificial nanocluster complexes were the successful calculation from basic principles of the partition of salts between casein micelles and the continuous phase $[39,128]$ and precise prediction of the scale of the substructure of casein micelles from the core molecular mass [149]. In the early work on artificial nanocluster complexes $[18,110,111]$, it was believed that the complexes were metastable, i.e., in an arrested state of precipitation, and so a special technique was developed to make the preparation of artificial nanocluster complexes as reproducible as possible. The peptide and salts were mixed at a low $\mathrm{pH}$ where the solution was undersaturated and the $\mathrm{pH}$ was raised homogeneously and in a controlled manner by hydrolyzing urea with the enzyme urease to release the strong base ammonia. Subsequently it was shown [112] that the complexes were equilibrium structures and that even an initial precipitate, if formed during mixing, would dissolve if sufficient time was allowed for the system to equilibrate.

Several commercial applications have been found for casein phosphopeptides prepared on a large scale by chromatography or precipitation methods [150]. CaP nanoclusters sequestered by a mixture of bovine casein phosphopeptides have been used in dental products to promote the remineralization of demineralized tooth lesions [151].

\subsection{Size and Structure of Calcium Phosphate Nanoclusters Sequestered by $\beta$-Casein 1-25}

The first artificial CaP nanocluster complex to be prepared used the $\mathrm{N}$-terminal tryptic phosphopeptide, $\beta$-casein 1-25 [18,110]. It remains the only one for which a precise molar mass has been determined [111]. Using a combination of small-angle neutron scattering with contrast matching and approach-to-equilibrium analytical ultracentrifugation, the weight average core and shell masses and root mean square Z-average core radius were $6 \cdot 10^{4} \mathrm{Da}, 1.37 \cdot 10^{5} \mathrm{Da}$ and $2.4 \mathrm{~nm}$, 
respectively [111]. These properties are consistent with a narrow normalized distribution of core-shell particles (Equation (14)) with a peak at $k^{\prime}=436, K_{\text {seq }} a_{0,1}=3.65, S=0.94$ and $\theta_{\text {seq }}=0.785$, as shown in Figure 8 using the parameters of Table 2. The example distribution has a narrow dispersion, as measured by the ratio $\bar{k}^{2} /(\bar{k})^{2}-1=0.0988$ where the bar over the $k$ or $k^{2}$ indicates a number average. The core surface area per peptide was $1.7 \mathrm{~nm}^{2}$, which is comparable to the area per statherin peptide in a monolayer adsorbed onto HA [55]. The relatively small area per peptide indicates that only a fraction of the peptide is in contact with the core surface, as in example A of Figure 2. The contact sequence is most likely the acidic CaP-SLiM (Table 1) 14-EpSLpSpSpSEE-21 in the middle, least mobile, region of the peptide $[110,152]$. The other parameters used in the calculation were the molecular volume of the $\mathrm{CaP}$ calculated from its empirical chemical formula, as determined from the form of an ion activity product in the nanocluster solution to be $\mathrm{Ca}\left(\mathrm{HPO}_{4}\right)_{0.4}\left(\mathrm{PO}_{4}\right)_{0.4}$. Other distribution functions that gave reasonable agreement with the average radius of the core were also narrow with $K_{\text {seq }} a_{0,1}>3.65, S<0.94$ and $\theta_{\text {seq }}>0.785$.
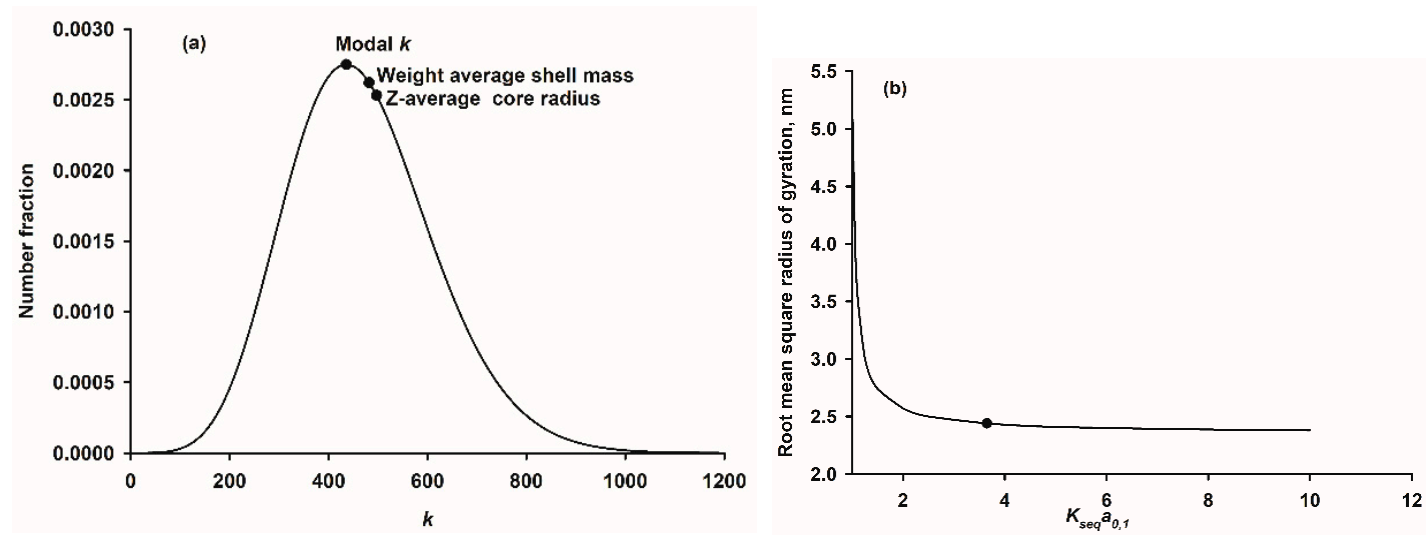

Figure 8. Comparison of calculated with experimental properties of the nanocluster complexes prepared with $\beta$-casein 1-25. (a) Theoretical size distribution matching that of $\mathrm{CaP}$ nanoclusters prepared with $\beta$-casein 1-25. The abscissa is the number of molecules of $\mathrm{CaP}$ in the core, $k$. The distribution is also shown as curve 2 in Figure 5 but with core radius as the abscissa. The example normalized distribution is consistent with the experimental average mass and radius of the core (Table 2). Marked on the distribution are the coordinates corresponding to the peak maximum and the core weight average molar mass and root mean square Z-average radius. (b) Dependence of the calculated root mean square radius of gyration of the core, determined by small-angle scattering, on the value of $K_{s e q} a_{0,1}$ in the range 1-10. The experimental value determined by small-angle neutron scattering at the protein matching contrast is shown as a data point [111]. The conclusion is that provided there is excess of the strongly binding phosphopeptide, the core radius is essentially constant.

It was observed experimentally that the initial size of the nanocluster complexes depended on the rate at which the $\mathrm{pH}$ was raised by the urea/urease reaction but after equilibration for $24-48 \mathrm{~h}$, the average size of nanocluster complexes was constant and relatively insensitive to the temperature, $\mathrm{pH}$ and concentrations of phosphopeptide, $\mathrm{Mg}$ and citrate in the solution from which they were formed [112]. The present calculations show that this is expected for the concentrations of salts and peptide used in experiments where there is an excess of strongly binding phosphopeptide which gives rise to a narrow, and almost invariant, particle size distribution (Figure 8).

The nanocluster complexes have been characterized by a variety of nuclear magnetic resonance methods [110,152]. Using an isotropic diffusion model for methyl resonances, the diffusion radius of the particles was in the range 1.6 to $1.9 \mathrm{~nm}$, depending on $\mathrm{pH}$ [152], significantly but not dramatically smaller than indicated by scattering measurements. In an earlier study [110] it was found that not all residues had the same mobility. A proportion of the $\mathrm{N}$ - and $\mathrm{C}$-terminal Arg residues were as mobile in the complexes as in the free peptide, but complexation greatly reduced the mobility of the 
phosphorylated residues. The size and structure of the complexes was also studied by small-angle X-ray scattering (SAXS) [112]. In the Guinier region, the radius of gyration was found to be constant at $2.55 \pm 0.08 \mathrm{~nm}$ between $\mathrm{pH} 6$ and 8 but the intensity of scattered X-rays increased with $\mathrm{pH}$ and reversed fully on acidification. Likewise, the radius of gyration was constant in the measured temperature range of 5 to $80^{\circ} \mathrm{C}$. The intensity of scattered X-rays increased with temperature but reversed fully on cooling. In a determination of the specific heat change on heating and cooling by differential scanning calorimetry, a reversible but smooth increase with temperature was noted without any indication of a sharp transition such as might be caused by a conformational change in the peptide shell or a phase change in the $\mathrm{CaP}$ core. These three demonstrations of the reversibility of $\mathrm{CaP}$ nanocluster formation are due to an increase in the number of the particles in the solution with increase of temperature or $\mathrm{pH}$ while the particles remain essentially constant in average size and, therefore, in average composition. The constant composition assumption is used in the calculation of salt partition in $\mathrm{CaP}$ nanocluster solutions, including milk $[39,112,128]$.

Table 2. Comparison of experimental average values of the core and shell weight average molar masses and the core root mean square radius [111] with calculated values from a theoretical distribution calculated from Equation (14).

\begin{tabular}{cccc}
\hline Parameter & Experiment & Parameter & Calculation \\
\hline Empirical volume $\mathrm{CaP}, \mathrm{nm}^{3}$ & 0.167 & & 0.12 \\
Surface area per peptide, $\mathrm{nm}^{2}$ & 1.62 & & 1.7 \\
$M_{w}($ CaP core $) 10^{-4} \mathrm{Da}$ & 6.0 & & 6.0 \\
$M_{w}$ (peptide shell $) 10^{-5} \mathrm{Da}$ & 1.37 & & 1.37 \\
$\left\langle r_{\text {core }}^{2}\right\rangle_{z}^{1 / 2}, \mathrm{~nm}$ & 2.44 & $K_{\text {seq }} a_{1,0}$ & 2.44 \\
Empirical formula CaP & $\mathrm{Ca}\left(\mathrm{HPO}_{4}\right)_{0.4}\left(\mathrm{PO}_{4}\right)_{0.4}$ & $S=a_{0,1} / a_{0,1, \text { sat }}$ & 3.65 \\
$\mathrm{pK}$ & 8.0 & $\theta_{\text {seq }}$ & 0.940 \\
& & $\mathrm{Modal}^{\prime}$ & 0.785 \\
& & $\bar{k}_{n} \pm \mathrm{SD}$ & 436 \\
& & $\bar{k}_{n}^{2} /\left(\bar{k}_{n}\right)^{2}-1$ & $468 \pm 147$ \\
\hline
\end{tabular}

In addition to these observations demonstrating the reversibility of the system, it was found that the $\mathrm{CaP}$ nanocluster complex solution could be stored at room temperature for months or years without visible change. They can even withstand steam sterilization or freezing and thawing due to the stabilizing effect of the phosphopeptide.

The reversibility of the properties of solutions containing nanocluster complexes is similar to the reversibility in the partition of milk salts with $\mathrm{pH}$ and temperature [153-155]. Indeed, when CaP nanocluster solutions are prepared with similar total concentrations of salts and CaP-SLiM-containing peptides to those in milk, the partition of salts in the two types of solution are strikingly similar when compared at the same temperature and $\mathrm{pH}[110,112,128]$.

\subsection{Structure and Dynamics of a Calcium Phosphate Nanocluster Sequestered by OPN 1-149}

OPN has a multitude of in vivo functions [17], including various roles in the complex process of biomineralization [156-160]. The precise function of OPN within the various processes related to biomineralization is heavily influenced by its state of phosphorylation. Phosphoforms of OPN have been shown to slow or inhibit the precipitation of $\mathrm{CaP}[24,76,105,161,162]$ but unphosphorylated OPN has a much weaker effect. The presence of OPN in most biological fluids combined with its intrinsically disordered conformation $[24,27,62,163,164]$, ability to influence the precipitation of CaP and the presence of multiple CaP-SLiMs, suggests a possible general, in vivo, role for OPN in stabilizing biofluids through the sequestration of CaP. 
Highly phosphorylated OPN peptides (OPNmix) are abundant in bovine milk [165]. The larger OPN fragments isolated from OPNmix by gel filtration chromatography consists mainly of $\mathrm{N}$-terminal peptides which vary in length from 145-156 residues, formed through proteolytic cleavage of the mature sequence [166]. Due to the small differences in length and difficulty in further separation, these peptides were grouped together and referred to as OPN 1-149 [24]. Three multiply phosphorylated CaP-SLiMs can be identified within the N-terminal region [24,167], two of which are shown in Table 1. Various experimental studies have reported on the ability of OPN 1-149 to sequester CaP resulting in the formation of metastable [168] or equilibrium nanocluster complexes [13,24,62,169], depending on solution conditions and the molar ratio of OPN to CaP.

The nanocluster complexes stabilized by OPN 1-149 are significantly larger, on average, than those formed by $\beta$-casein 1-25 (Figure 9). The outer shell radius and thickness are consistent with a single layer of OPN 1-149 but folded so that all three of the CaP-SLiMs bind to the core [24,62]. This is in contrast to the structure of the CaP nanoclusters stabilized by $\beta$-casein 1-25 or $\alpha_{\mathrm{S1}}$-casein 59-79 where the outer shell comprises a layer of protein interacting through a single CaP-SLiM [111,112]. However, the radius of gyration of the $\mathrm{CaP}$ nanocluster sequestered by the recombinant phosphopeptide CK2-S-6H (Section 4.3) is also consistent with a surface loop conformation [40]. The core radius of the CaP nanocluster formed by OPN 1-149 is about 4 times larger than that of the complex formed by $\beta$-casein 1-25. According to Equation (4), the size of the core is dependent on the ratio of the free energy of sequestration per unit of core area to the free energy of formation of the bulk core phase $[24,139]$. The CaP core of OPN 1-149 complexes is more basic than in casein nanocluster complexes $(y=0$ in Equation (1)), although with similar molar ratios of Ca and $P_{i}$ to CaP-SLiM. The conclusion was that the core of the OPN 1-149 complex was more highly hydrated or contained more void spaces than the $\mathrm{CaP}$ nanocluster complex formed with $\beta$-casein 1-25. Neutron diffraction of hydrated samples using contrast matching of protein showed that the core $\mathrm{CaP}$ was amorphous [170]. Previous determinations of the amorphous nature of the CaP core had all used freeze-dried samples which might have lost crystalline order through the removal of water $[91,145,146]$.

(a)

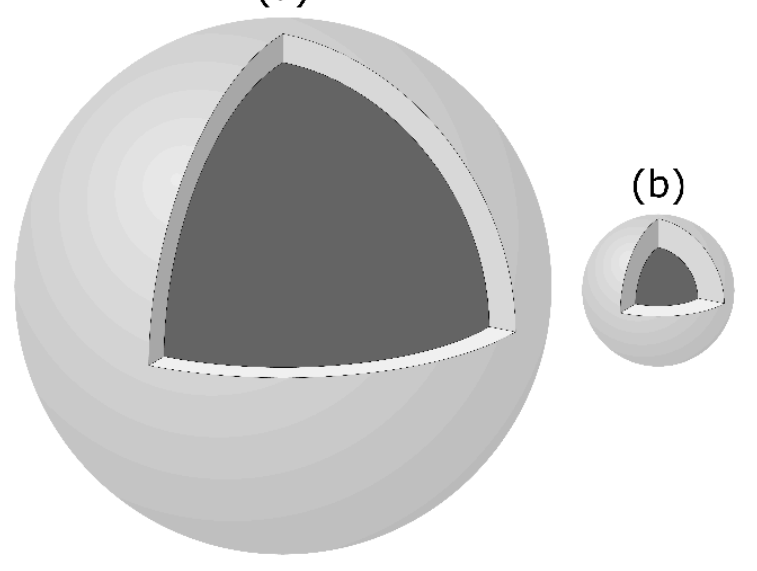

Figure 9. Comparison of the relative size and substructure of the nanocluster complexes formed by OPN 1-149 (a) and $\beta$-casein 1-25 (b). The illustration shows the core-shell substructure by removing a one eighth segment of the shell. Z-average core radii are 12.5 and $2.4 \mathrm{~nm}$ and shell thicknesses 1.5 and $1.6 \mathrm{~nm}$ for the OPN 1-149 and $\beta$-casein 1-25 complexes, respectively [24,111].

Neutron scattering has been used to quantify the dynamic properties of OPN 1-149 and its CaP nanocluster complex at nanosecond-Ångström resolution. Using elastic incoherent neutron scattering it was found that the molecular fluctuations of the free phosphopeptide were similar to those of other IDPs [62]. When complexed to the CaP nanoclusters, however, there was increased resilience of the diffusive motions. The molecular fluctuations became more like those of a typical globular protein. Studies of the effect of phosphorylation on the dynamic properties of a similar recombinant human 
OPN1-156 peptide were made by quasi-elastic neutron scattering experiments. These confirmed that the protein was highly dynamic compared to globular proteins. When a phosphorylated form of human OPN1-156 was studied [163] it was found that phosphorylation blocked some nanosecond side chain motions while increasing the flexibility of others on the faster timescale. The combined results from the dynamic measurements agree in showing that the free bovine and human sequences are highly flexible. It is suggested that the flexibility allows phosphoforms of OPN to rapidly react with growing nuclei of $\mathrm{CaP}$ and form a compact shell of protein around the $\mathrm{CaP}$ core. The sequestration of the CaP nanoclusters therefore reduced the flexibility of the protein significantly because of steric restriction and, possibly, because all three CaP-SLiMs in the sequence bind to the surface of the core.

The ability of OPN 1-149 to sequester ACP and stabilize CaP nanoclusters shows that CaP-SLiM-containing IDPs other than those belonging to the casein family of proteins can stabilize solutions of $\mathrm{CaP}$. The sequestration of $\mathrm{CaP}$ nanoclusters by phosphorylated IDPs may therefore be of general physiological importance. It also reveals something about the specific influence of the chain length and sequence on the properties of the formed nanocluster complexes.

\subsection{Structures of Calcium Phosphate Nanoclusters Sequestered by Other Phosphopeptides or Mixtures of Phosphopeptides}

Nanocluster complexes have been prepared from a range of other phosphoproteins to study the effects of sequence variation on their composition, size, and structure. These included a tryptic phosphopeptide, residues 59-79 from $\alpha_{\mathrm{S} 1}$-casein, [112,171], tryptic phosphopeptides 1-42 and 2-25 from $\beta$-casein [111], mixtures of phosphopeptides derived from either whole casein [112,172] or bovine milk OPN (OPNmix) $[13,62,150,163,170]$ and several different recombinant phosphopeptides. The latter were expressed as phosphoforms by a double plasmid transformation of E. coli. A high copy number plasmid expressed the desired peptide while a low copy number plasmid was used to co-express the catalytic subunit of casein kinase II (CK2) $[40,163]$. Sequences of some of these sequestering phosphopeptides are given in Table 3.

Table 3. Sequences of tryptic phosphopeptides from bovine $\beta$ - and $\alpha_{\mathrm{S} 1}$-caseins, two recombinant, tryptic phosphopeptides, based on $\beta$-casein (CK2-S and CK2-SS) and a soluble whole construct based on the $\mathrm{N}$-terminal region of $\beta$-casein with a C-terminal 6-His tag (CK2-S-6H) [40,112]. Phosphorylated residues are shown in boldface red.

\begin{tabular}{cc}
\hline Phosphopeptide & Sequence \\
\hline$\alpha_{\text {S1-casein B 59-79 4P }}$ & QMEAESISSSEEIVPNSVEQK \\
$\beta$-casein $\mathbf{A}^{2}$ 1-25 4P & RELEELNVPGEIVESLSSSEESITR \\
CK2-S 4P & MRELEELNVPGADDSSSDDDSDDDDRINKK \\
CK2-SS 4P & MRELEELNVPGADDSSSSDDDDDDDRINKK \\
CK2-S-6H 5P & MRELEELNVPGADDSSSDDDSDDDDRINKKIEDPNSSSVDKLAAALEHHHHH \\
\hline
\end{tabular}

Bovine $\alpha_{\mathrm{S} 1}$-casein $59-79$ is a highly acidic phosphopeptide, similar to $\beta$-casein $1-25$, with a single CaP-SLiM containing four phosphoseryl residues. The nanocluster complexes prepared using this peptide [112] are somewhat similar in size to those formed with $\beta$-casein 1-25. The Z-average radius of gyration determined by SAXS in the Guinier region was $2.23 \pm 0.05 \mathrm{~nm}$ and was essentially independent of $\mathrm{pH}$ in the range 6 to 8 . The composition of phosphopeptide mixtures derived from whole casein is complex and variable according to the commercial source and preparation and or purification methods. Nevertheless, they contain a proportion of less highly phosphorylated peptides. Hence, in the preparation of the nanocluster complexes a concentration of $10 \mathrm{mg} \mathrm{ml}^{-1}$ of the casein phosphopeptide mixture was used, rather than the standard $5 \mathrm{mg} \mathrm{ml}^{-1}$ employed with the pure phosphopeptides. The nanocluster complexes formed with the mixture of phosphopeptides were, on average, somewhat larger and the average radius of gyration determined by SAXS passed through a shallow minimum in the $\mathrm{pH}$ range 6 to 8 rather than being constant [112]. Nevertheless, an invariant ion 
activity product was found over this $\mathrm{pH}$ range for the empirical chemical formula $\mathrm{Ca}\left(\mathrm{HPO}_{4}\right)_{0.6}\left(\mathrm{PO}_{4}\right)_{0.27}$ with $\mathrm{pK}_{S}=7.8$, similar to the composition and solubility found in milk [12]. In contrast, an apparently similar study [172] reported that the complexes contained a basic CaP.

Protein engineering of recombinant peptides made possible a more systematic study of the structural requirements of CaP sequestration [40]. Most work was done with constructs comprising one or more tandem repeats encoding a sequence based on the bovine $\beta$-casein 1-25 peptide. The sequences were modified for (i) efficient overexpression in E. coli. (ii) phosphorylation by the $\alpha$-catalytic subunit of casein kinase II and (iii) rapid purification by means of a C-terminal 6-His-tag. Tandem repeats were separated by tryptic cleavage and further purified. A phosphorylated form of a human OPN-like peptide was also expressed [40] and studied [163] (see Section 4.2).

Because of its importance to $\mathrm{CaP}$ sequestration, particular attention was given to the characterization of recombinant peptide phosphoforms since it is the norm for kinases to only partially phosphorylate their substrates [173]. The designed kinase recognition sequences comprised a stretch of Asp residues on either side of the residues to be phosphorylated such as 13-D-D-S-S-S-D-D-D-S-D-D-D-D-26 in CK2-S (Table 3). Notwithstanding the efforts to obtain a completely phosphorylated CaP-binding SLiM, the expressed constructs invariably comprised a mixture of phosphoforms (Figure 10a) with, predominantly, four or five phosphorylated residues, three or four of which were in the above subsequence. Nevertheless, phosphorylation occurred only at consensus recognition sites for this kinase. When the expressed phosphoforms were chromatographed on a HA column (e.g., Figure 10b), the elution volume generally increased with the total number of phosphorylated residues. Some of the phosphoforms were bound to the column more strongly than others even if they had the same total number of phosphorylated residues. The evidence from all the phosphopeptides examined was consistent with the hypothesis that a high-affinity phosphoform contained a sequence where three phosphorylated residues were close together in the sequence, such as 15-pS-pS-pS-17 in CK2-S. On the other hand, lower affinity phosphoforms had only two of the three seryl residues in their main cluster converted to phosphoseryl residues (Figure 10c). The inference from these findings is that the minimum concentration at which a phosphopeptide is effective in CaP sequestration (i.e., $K_{\text {seq }}^{-1}$ ) is lower if the phosphopeptide contains three phosphorylated residues in a subsequence of 3 or 4 consecutive residues. It was similarly reported that in $\beta$-casein $1-25$, where there are three consecutive phosphorylated residues, and in similar peptides, there is a single high-affinity binding site for calcium $\left(\mathrm{Ca}^{2+}\right)$ or hydronium $\left(\mathrm{H}^{+}\right)$ions [37-39].

The ability of three CaP-SLiM-containing recombinant peptides to sequester CaP was determined by SAXS and further determinations of the radii of gyration were made on high-affinity fractions of two of the peptides from HA chromatography. The peptides CK2-S and CK2-SS were similar 28-residue tryptic peptides that formed stable nanocluster complexes with a radius of gyration of $8.85 \mathrm{~nm}$ within about 2 days and a high-affinity fraction of CK2-S formed an equilibrium complex of radius of gyration $9.89 \mathrm{~nm}$. The recombinant peptide CK2-S-6H is 53 residues long, including the CK2-S subsequence with a C-terminal extension plus a 6 His tag. It formed an equilibrium complex over $4-5$ days with a radius of gyration of $7.71 \mathrm{~nm}$. The high-affinity fraction of CK2-S-6H from HA chromatography formed a CaP nanocluster complex with a radius of gyration of $9.72 \mathrm{~nm}$ but equilibration was unusually slow (Figure 10d). The CK2-S and CK2-SS peptides are similar in length to the $\beta$-casein $1-25$ and $\alpha_{S 1}$-casein 59-79 peptides but the nanocluster complexes are more than three times larger pointing to a larger core radius as the cause. The high-affinity fraction of CK2-S forms an even larger complex, presumably due to a larger core radius. Nevertheless, the longer CK2-S-6H peptide forms a smaller complex than its subsequence, CK2-S, indicating that the shell peptide may loop back on itself in the shell like a multi-dentate ligand (Figure 2B,C). According to Equation (4) the core radius depends on the ratio of the free energy of sequestration of the shell peptide to the free energy of formation of the core $\mathrm{CaP}$ and on the area per CaP-SLiM. However, charge density in the shell, steric restraints on the density of packing of peptides in the shell and the hydration and chemical composition of the core may influence each of these terms. It is desirable that these preliminary observations are followed-up 
with more detailed and systematic studies of the effects of the structure of sequestering peptide on the substructure, shell and core masses of the nanocluster complexes and the partition of salts and peptide between the complexes and the continuous phase.

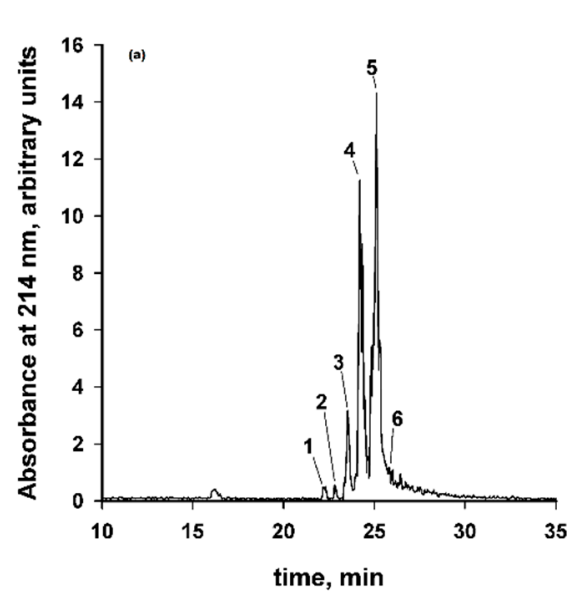

(c)

High affinity
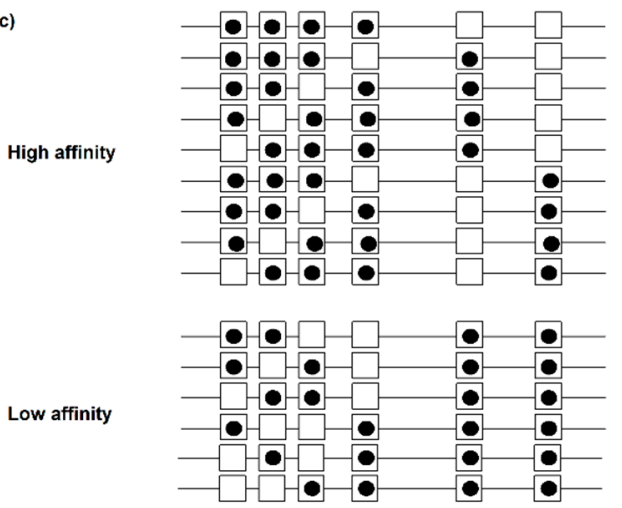
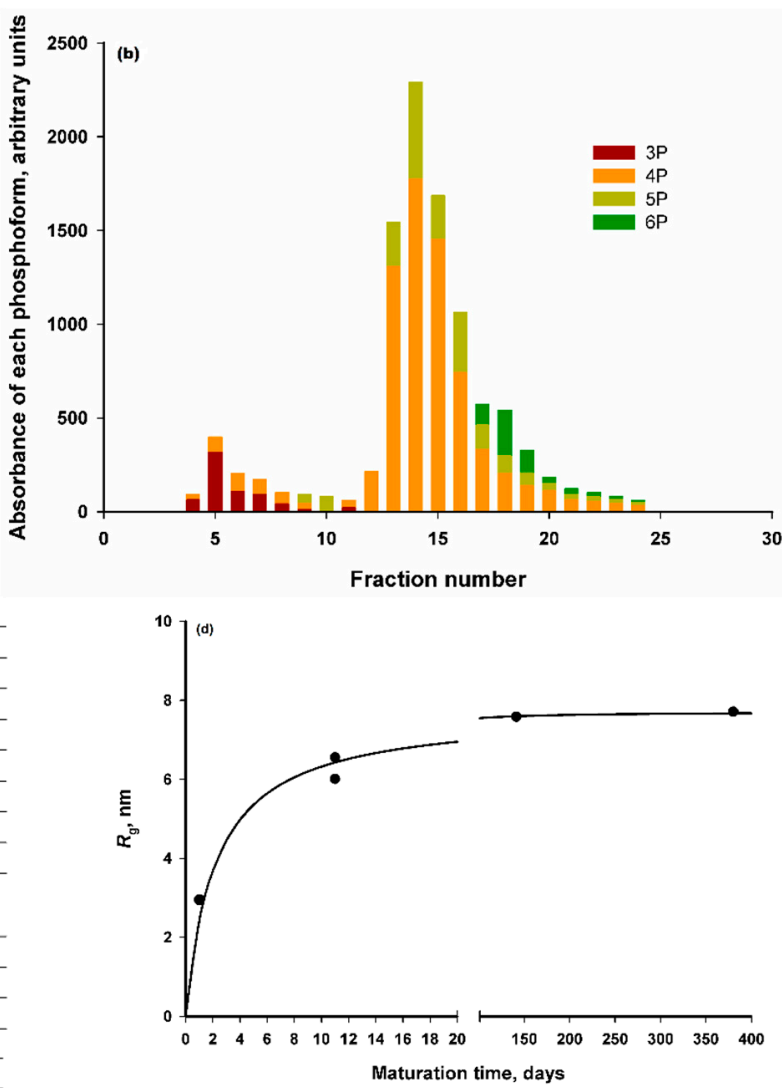

Figure 10. Phosphoforms of CK2-S-6H and nanocluster complexes formed by the high-affinity phosphoforms [40]. (a) RP-HPLC of the recombinant purified peptide with numbering corresponding to the total number of phosphorylated sites. Most phosphoforms have 4 or 5 phosphorylated residues. Five sites are in consensus kinase recognition sequences (Table 3) and a small proportion were in a 6-P form. (b) Ion exchange chromatography of CK2-S-6H on hydroxyapatite revealed groups of low and high-affinity phosphoforms, mostly separated by the number of phosphorylated residues but sensitive also to positional isomers. (c) Schematic rationalization for how the positional isomers of the 4-P phosphoform can occur as either low or high-affinity isomers. In the diagram, filled black circles are phosphorylated sites. The isomers with 3 or 4 phosphorylated residues close together form a high-affinity phosphoform. (d) Results from small-angle X-ray scattering measurements of the radius of gyration of nanocluster complexes made with the high-affinity fraction of CK2-S-6H showing the very slow change in the radius of gyration with time for this phosphopeptide.

\section{Application to Biofluids}

Nearly all physiological fluids are supersaturated with respect to HA and some other crystalline $\mathrm{CaP}$ phases. As a result, artificial biofluids that closely resemble their natural counterparts in salt composition and $\mathrm{pH}$ are unstable and will readily precipitate $\mathrm{CaP}$. They, and natural biofluids, therefore require stabilizing agents. Of all physiological fluids for which data are available, milk contains the highest concentration of CaP. The role of the casein SCPPs in stabilizing milk with respect to CaP precipitation is now well established. Other phosphoproteins are expressed in physiological fluids, hard and soft tissues, raising the possibility that phosphoproteins with CaP-SLiMs may perform a similar physiological role to casein in milk. The SCPP OPN is almost universally expressed in chordate tissues and biofluids [17] and as discussed in Sections 2 and 4.2, has all the key physical and chemical 
characteristics needed for the role. However, phosphoproteins such as fetuin A in blood and others in Table 1 must also be considered. In the extracellular matrix of mammalian bone, for example, OPN is the major non-collagenous phosphoprotein, though it is not as highly phosphorylated in bone as in bovine milk [1]. In saliva, the main inhibitor of CaP precipitation is the SCPP statherin, present at 3-27.3 $\mu \mathrm{M}$ with some additional effect from the acidic proline-rich salivary peptides $[63,174,175]$. Notwithstanding these general principles and suggestive experiments, the direct experimental observation of nanocluster complexes in any biofluid other than milk has not yet been reported.

The stability diagrams for salt solutions approximating the typical composition of three very different biofluids, urine, saliva, and blood serum have been calculated, on the assumption that OPN phosphopeptides are responsible for sequestration, and compared to experiment [13]. Table 4 gives the fitted parameters.

Table 4. Parameters of Equation (16) required to fit the stability curves of Figure 11.

\begin{tabular}{ccccc}
\hline Biofluid & $\boldsymbol{C}_{\mathbf{m a x}}, \mathbf{m M}$ & $\boldsymbol{n}$ & $\mathbf{p H}_{\mathbf{1} / \mathbf{2}}-\mathbf{p H}_{\mathbf{c}}$ & $\mathbf{p H}_{\mathbf{c}}$ \\
\hline Bovine milk & $1977 \pm 3.0$ & $1.190 \pm 0.003$ & $0.508 \pm 0.001$ & $5.716 \pm 0.004$ \\
Human milk & $743 \pm 1.6$ & $0.914 \pm 0.006$ & $1.458 \pm 0.583$ & $7.200 \pm 0.003$ \\
Human blood serum & $166 \pm 7.6$ & $0.949 \pm 0.024$ & $1.240 \pm 0.011$ & $7.760 \pm 0.002$ \\
Human stimulated saliva & $133 \pm 3.6$ & $1.036 \pm 0.003$ & $0.468 \pm 0.003$ & $6.880 \pm 0.002$ \\
Human urine & $398 \pm 5.8$ & $1.075 \pm 0.022$ & $0.531 \pm 0.015$ & $6.529 \pm 0.002$ \\
\hline
\end{tabular}
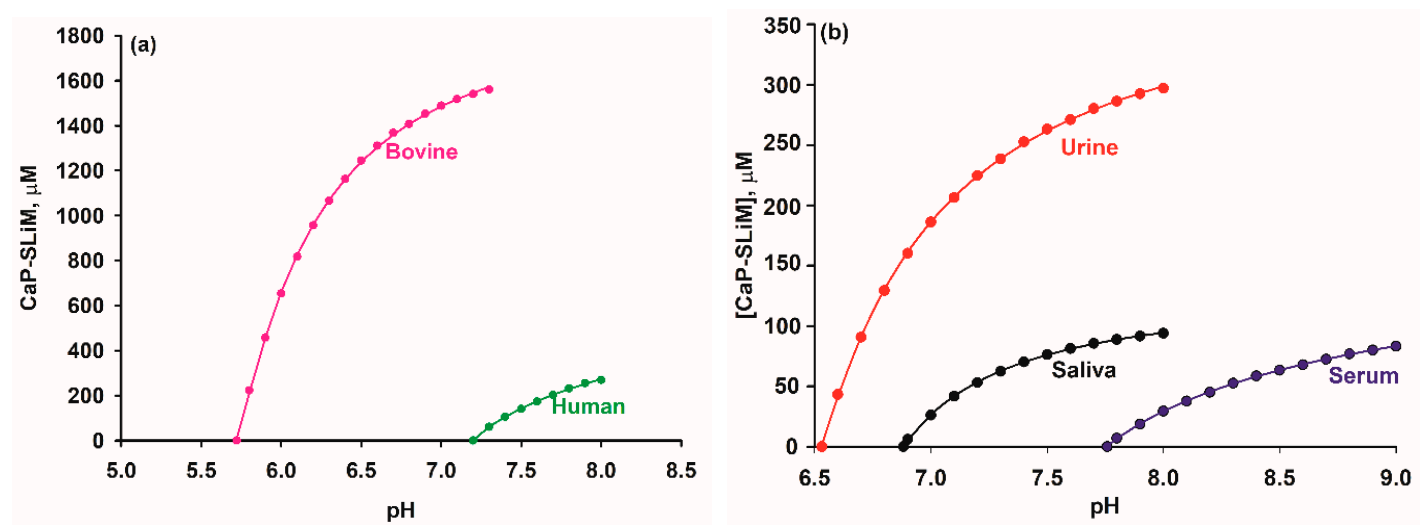

Figure 11. Stability diagrams for typical biofluids (a) bovine and human milk and (b) human urine, saliva, and blood serum. Reprinted with permission from Holt et al. [13] (C2013The Authors. Published by Elsevier Inc. All rights reserved.

Bovine milk is well buffered by proteins and phosphate ions and urine by phosphate ions, but human blood serum, milk, and saliva are, by comparison, poorly buffered. The homeostatic mechanisms that regulate blood $\mathrm{pH}$ do so through the exchange of $\mathrm{CO}_{2}$ with air through the chemical equilibria $\mathrm{CO}_{2}+\mathrm{H}_{2} \mathrm{O} \rightleftarrows \mathrm{H}_{2} \mathrm{CO}_{3} \rightleftarrows \mathrm{HCO}_{3}^{-}+\mathrm{H}^{+}$. In healthy individuals, blood $\mathrm{pH}$ is tightly monitored within a very narrow range (from about 7.3 to 7.5 ) by a group of nerve cells located in the medulla oblongata but regulatory control may be lost in certain conditions to produce more acidic or alkaline sera. According to the Davenport diagram for typical human blood [176] with a $\mathrm{pH}$ of 7.4 at equilibrium with a partial pressure of $\mathrm{CO}_{2}$ of $40 \mathrm{~mm} \mathrm{Hg}$, equilibration with air at a $\mathrm{CO}_{2}$ partial pressure of $17 \mathrm{~mm}$ $\mathrm{Hg}$ raises the $\mathrm{pH}$ to over 7.7 , close to the critical $\mathrm{pH}$ in the stability diagram where sequestering phosphopeptides are needed for stability. If the concentration of CaP-SLiMs is insufficient, calciprotein particles can form spontaneously [177]. Calciprotein particles have, indeed, been isolated from blood. These contain fetuin A as the major phosphoprotein component, MGP and SPP-24, among other acidic serum proteins [142,178-182] and, once formed, are cleared from the circulation by the liver [183].

The stability diagram calculations indicate that although the physiological $\mathrm{pH}$ of blood serum and human urine are slightly below the typical critical $\mathrm{pH}$ values of these biofluids, that of saliva ( 7.35) is 
above the critical $\mathrm{pH}$ and is predicted to contain some sequestered stable or metastable CaP particles. Human milk is on the borderline, with $\mathrm{pH}$ almost equal to $\mathrm{pH}_{\mathrm{c}}$. Hence when it equilibrates with air and loses $\mathrm{CO}_{2}$ [140], the rise in $\mathrm{pH}$ appears to be sufficient to form a small concentration of sequestered CaP nanoclusters in the casein micelles, as observed experimentally [184], though the concentration is much lower than in bovine milk. The physiological $\mathrm{pH}$ of urine is normally well below the critical $\mathrm{pH}$, at or around $\mathrm{pH} 6.0$ to minimize calcium oxalate stone formation at lower $\mathrm{pH}$ and $\mathrm{CaP}$ precipitation at higher $\mathrm{pH}$ [185]. The $\mathrm{pH}$ of urine is particularly sensitive to the effect of infection by bacteria secreting an extracellular urease to raise the $\mathrm{pH}$ to a high level where a variety of urinary stones may form, including CaP salts that can act as a nidus for nucleating other salts $[186,187]$. The calculations shown in Figure 11 and Table 4 demonstrate that for urine to be stable at alkaline $\mathrm{pH}$ would require high concentrations of sequestering peptides, comparable to those in human milk.

\subsection{Stability of Milk}

The composition of milk varies greatly among species, largely reflecting the nutritional needs of the neonate but also reflecting other physiological requirements, especially among the extremely altricial young of marsupials and monotremes [188-190]. However, the needs of the young must be balanced against those of the mother and it has been be argued that the protection of the mammary gland against ectopic or pathological calcification has been an important constraint on the composition of milk [191] because the gland goes through repeated cycles of development, lactation, and involution during the reproductive life of the female. In eutherians, the lactose concentration is inversely related to the concentrations of fat and protein, reflecting the caloric and growth rate requirements [192], particularly of aquatic mammals. The highest concentrations of fat and casein are, for example, found in seal milks where there is virtually no milk sugar and up to about $150 \mathrm{~g}$ casein per liter of water [193]. In primate milks, by contrast, the osmotic pressure is mainly provided by milk sugars and the casein concentration may be 50 times lower [194]. In milk, the main source of CaP-SLiMs are the calcium-sensitive caseins but all caseins contain adhesive sequences to promote mutual association. As a result, all milks contain colloidal particles called casein micelles instead of individual nanocluster complexes. These are formed by concentrating calcium and $P_{i}$ in Golgi vesicles of the mammary gland secretory cells, initially under crowded protein conditions. The casein micelle can be regarded as an assembly of nanocluster complexes with very similar properties to the simpler core-shell complexes $[131,138,169]$. For example, a bovine milk casein micelle with a radius of $100 \mathrm{~nm}$ contains about $800 \mathrm{CaP}$ nanoclusters and each is sequestered by about 30 calcium-sensitive caseins providing about 50 CaP-SLiMs [149]. The $\alpha_{S_{1}}$ and $\alpha_{S 2}$-caseins have more than one CaP-SLiM (Table 1) which means that these phosphoproteins can either form a loop on the surface of a single CaP nanocluster or they can form bridges linking two or more CaP nanoclusters into a larger casein micelle substructure. When casein micelles are treated with a high concentration of a chaotropic agent they do not fully dissociate suggesting that the caseins and $\mathrm{CaP}$ nanoclusters are crosslinked in the native micelle, though it is possible to argue that the crosslinked structures are formed after the addition of the dissociating agent $[195,196]$.

Figure 4 shows that cow's milk serum is highly supersaturated with respect to HA but there is no invariant ion activity product as a function of $\mathrm{pH}$ for this phase. There is a nearly invariant ion activity product for $\mathrm{ACP}-2$, the more stable phase of $\mathrm{ACP}$, but the serum is supersaturated with respect to ACP-2. Milk serum shows virtually the same invariant ion activity product as a solution of casein-CaP nanoclusters [112].

The similarity of size and composition between artificial nanocluster complexes and the casein micelle has provided the basis for calculating the partition of milk salts from first principles. When the ab initio calculations of the partition of milk salts are compared to experiment for individual cow milk samples with $\mathrm{pH}$ values in the physiological range, the agreement between theory and experiment is very satisfactory [128]. The extension of the theory to consider calcium salt addition has also been described [197]. The binding of the nanocluster complexes to surfaces in soft or hard tissues depends on the nature of both the sequestering peptide, the free calcium ion concentration and the surface to 
which they may bind [198]. For example, a neutron reflectometry study was made of the structure of interfacial layers on hydrophobic or hydrophilic surfaces formed by either co-adsorption or sequential adsorption of nanocluster complexes prepared with $\beta$-casein 1-25 and $\beta$-casein [199]. These studies revealed that the surface properties profoundly affected the rate of adsorption and the structure of the interfacial layer.

Milk is remarkably stable compared to other biofluids. It has evolved in the last $250 \mathrm{Myr}$ [190,200-205] from a more typical biofluid into a concentrated source of nutrients and other bioactive substances that are stored in the mammary gland for days, weeks, or months, depending on the species. Moreover, the mammary tissue goes though repeated cycles of development, lactation, and involution without forming amyloid or calcified bodies, though there are exceptions [206-209]. The stability of milk is exploited in dairy technology. It may be boiled, or ultra-heat-treated, dried to a powder and reconstituted, or pressure-treated at several hundred MPa and returned to atmospheric pressure without apparent ill effect. Many structured proteins would denature irreversibly if subjected to these treatments. Milk is highly supersaturated with respect to all basic forms of CaP, but mineral substances of any sort do not normally precipitate from milk under physiological conditions. However, they may do so during dairy processing operations [210]. Bovine milk contains highly amyloidogenic $k$ - and $\alpha_{S 2}$-caseins at very high concentrations where the formation of cytotoxic amyloid fibrils and plaque would be expected to occur. However, amyloid formation does not normally happen. The properties of casein lie at the heart of the scientific explanation of these remarkable properties. Caseins are IDPs and do not undergo temperature or pressure denaturation, although there is some evidence of a small temperature-dependent conformational transition in bovine $\beta$-casein [211]. They contain highly effective CaP-SLiMs that can reversibly sequester $\mathrm{CaP}$ to prevent it from precipitating and they can act as molecular chaperones to prevent amyloid fibril formation by themselves and other proteins, and can limit or prevent the aggregation of unfolding globular proteins, including the globular milk proteins $\beta$-lactoglobulin and $\alpha$-lactalbumin $[212,213]$. Caseins were once described as "random coil proteins with only a nutritional function" [214]. More recent research has shown them to be much more interesting.

\subsection{Stability of Blood Serum}

The stability diagram has been calculated for averaged blood serum [13] from healthy individuals $[125,126]$. The physiological $\mathrm{pH}$ is close to or a little lower than the critical $\mathrm{pH}$ and because of tight homeostasis of blood $\mathrm{pH}$ we might not expect it to contain sequestered CaP. The point is particularly important for human health because the cellular processes resulting in vascular calcification are common in the final stages of kidney disease, other degenerative conditions, and sometimes, fatal heart attacks [215-218]. We suggested [13] that a background level of sequestering phosphopeptide was desirable to cope with physiological fluctuations in composition and $\mathrm{pH}$ to ensure that precipitation of CaP arising from such fluctuations would be prevented or fully reversed when homeostasis was restored. The major source of CaP-SLiMs is also uncertain with the principal candidates being OPN polymorphs and fetuin A [8,141,219-221], with contributions from other phosphoproteins [178]. When the stability diagram of human serum is examined it can be seen (Figure 11) that the minimum concentration of sequestering peptide required for stability above $\mathrm{pH}_{\mathrm{c}}$ is low compared to urine or milk. This is mainly because it is a low phosphate biofluid in its physiological state. Nevertheless, much higher concentrations of stabilizing phosphopeptides are required in the pathological state of hyperphosphatemia, or physiological, post-prandial, hyperphosphatemia.

\subsection{Stability of Saliva}

Saliva is formed by mixing together different secretions from three major and many other minor glands [222]. It contains the major protein groups histatins, basic, acidic, and glycosylated PRPs and phosphoforms of statherin, together with hundreds of minor proteins, proteolytic fragments, derivatives and peptides [223-226]. From the composition and ion equilibria calculations it was recognized to 
be supersaturated with respect to crystalline CaPs $[122,227]$. Nevertheless, supersaturation does not lead directly to the formation of dental calculus [228,229]. It was proposed by Hay and Schlesinger that the solution remained poised and metastable because of the inhibiting effect of statherin on $\mathrm{CaP}$ precipitation [230]. Using an assay of the capacity of proteins to inhibit $\mathrm{CaP}$ precipitation, most saliva samples were found to have an inhibitory capacity fully explained by their statherin concentration, though in a minority of cases the inhibitory activity of the saliva was larger than expected [174].

A typical or average stability diagram of human saliva is difficult to calculate because the composition and $\mathrm{pH}$ is very variable. This biofluid is not very well buffered so equilibration with air causes the $\mathrm{pH}$ to rise following the loss of $\mathrm{CO}_{2}$. The results for stimulated saliva, however, are more reproducible and for this fluid the physiological $\mathrm{pH}$ is above the critical $\mathrm{pH}$ (Equation (16)), confirming earlier calculations. According to experiment and calculation, stimulated saliva contains sequestered $\mathrm{CaP}[13,122]$ although the nature and amount of the sequestering phosphoproteins or peptides is still not fully quantified. In Figure 12 the stability diagram for saliva [13] is superimposed on salt partition data obtained by ultrafiltration of stimulated whole and submaxillary saliva and stimulated and unstimulated parotid saliva [122,227]. The non-ultrafilterable calcium concentration of unstimulated saliva at $\mathrm{pH}<6.5$ was very small but stimulated saliva has the composition and $\mathrm{pH}$ expected to precipitate $\mathrm{CaP}$ and may do so if the concentration of sequestering phosphopeptides is not sufficiently high to form kinetic or thermodynamically stable CaP complexes. The compositional measurements in this work did not include proteins but in a separate study of stimulated parotid saliva from 68 individuals, the statherin concentration range was reported to be 3.0 to $27.3 \mu \mathrm{M}$ (mean $12.8 \pm 5.46 \mu \mathrm{M})$. However, according to the stability diagram, the concentration range of CaP-SLiMs needed to form thermodynamically stable stimulated saliva is larger or much larger, in the range 30-90 $\mu \mathrm{M}$, depending on $\mathrm{pH}$. These calculations confirm that stimulated saliva may, as we might expect for a fluid charged with tooth remineralization, be metastable, but further work is needed to determine in detail both the salt and protein composition of the same samples.

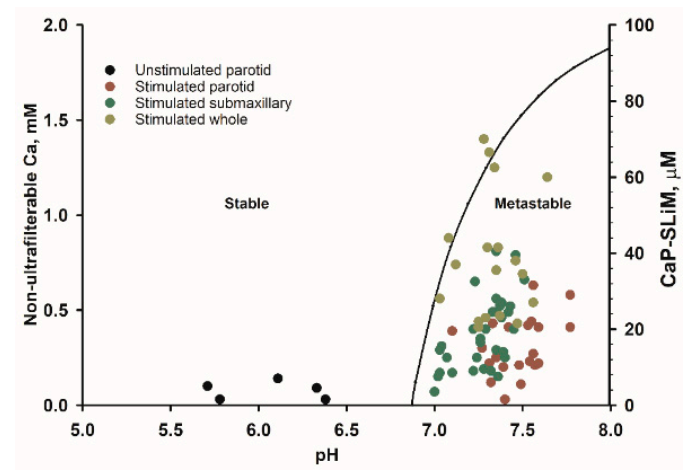

Figure 12. Superposition of salt partition data for stimulated and unstimulated saliva [122,227] on the stability diagram of saliva calculated by [13]. The composition of unstimulated saliva falls is in the stable part of the diagram but the rise in $\mathrm{pH}$ on stimulation increases the $\mathrm{pH}$ to where the saliva may be either stable or metastable, depending on the concentration of CaP-SLiMs.

\subsection{Tooth Remineralization}

In a solution of $\mathrm{CaP}$ nanoclusters sequestered by an excess of a competent phosphoprotein, the process of Ostwald ripening of the $\mathrm{CaP}$ into a more stable, crystalline, phase cannot occur because of the large activation energy required to escape the local free energy minimum in which the solution sits. When the solution is brought into contact with a crystalline phase, however, an alternative maturation mechanism comes into play whereby a solution-mediated transfer of calcium and $P_{i}$ ions takes place from the amorphous nanocluster to the more stable crystalline phase (Section 3.2). The advantage of a thermodynamically stable solution over a metastable one is that an arbitrarily large concentration of calcium and $P_{i}$ can be brought to the tooth surface without there being a spinodal boundary. However, controlled remineralization of the crystalline phase can also occur from a metastable solution in the 
lag stage before the onset of precipitation. Fundamental research, much of it from the Forsyth Dental Centre in Boston (now Forsyth Institute) established the role of saliva in tooth remineralization and the importance of statherin and the PRPs [64,175]. From observations of the anticariogenic effects of dairy products, E. C. Reynolds and co-workers developed a biomimetic system using a mixture of tryptic casein phosphopeptides and sequestered $\mathrm{CaP}$ in a range of tooth remineralization products $[151,231]$. Structural studies $[152,172]$ showed that the biomimetic complexes were comparable to the micellar $\mathrm{CaP}$ of native casein micelles and the artificial nanocluster complexes prepared with pure casein or OPN phosphopeptides, first described in 1994 [18,24,62,110-112].

\subsection{Stability of Urine}

For typical urine from non-stone-formers, the physiological $\mathrm{pH}$ is well below the critical $\mathrm{pH}$ (Equation (16)) so that normally the fluid is undersaturated with respect to CaP though it may be supersaturated with respect to some other phases such as calcium oxalate [118-120]. Steric stabilization of crystals by mucins, other hydrophilic proteins and polysaccharides such as chondroitin sulphate appears to be important in urine [187]. The concentration of uropontin, a urinary polymorph of OPN [232], is very low at about $1.9 \mathrm{mg} \mathrm{L}^{-1}$ and inversely proportional to urine volume [233]. Nevertheless, even at this low concentration it is effective at suppressing the precipitation of calcium salts [234]. However, when infected by micro-organisms that secrete urease, the $\mathrm{pH}$ of urine may rise to above 10 and urolithiasis involving $\mathrm{CaP}$ and other stones can result [160]. Because of the high concentrations of calcium and $P_{i}$ in urine compared to serum or even saliva, the concentrations of sequestering phosphopeptides needed to form thermodynamically stable complexes with the $\mathrm{CaP}$ at alkaline $\mathrm{pH}$ would be comparable to those in human milk (Figure 11b). This emphasizes the importance of $\mathrm{pH}$ in maintaining urine as a stable solution and of steric stabilization otherwise.

\subsection{Mineralization in the Extracellular Matrix of Collagenous Hard Tissues}

Various mechanisms have been proposed for the mineralization of collagen by vesicles, including pre-formed crystals of $\mathrm{HA}$, precursor phase complexes and heterogeneous nucleation of calcium or $\mathrm{P}_{\mathrm{i}}$ ions through the interaction with extracellular non-collagenous proteins or collagen itself [43,235-240]. According to the PILP (polymer-induced liquid phase) hypothesis of L. B. Gower and collaborators [43], an electrostatic and sterically stabilized but thermodynamically unstable liquid-like precursor phase of $\mathrm{CaP}$ penetrates collagen fibers by capillary action and matures into oriented crystals of HA. Evidence from simplified in vitro models of mineralization indicated that intrafibrillar oriented growth of HA crystals occurred which did not require any of the non-collagenous phosphoproteins to act epitaxially in nucleating oriented crystals of HA [241]. The polymer used in the PILP process, referred to as the process directing agent, was usually polyaspartate but similar anionic polyelectrolytes were also used [242,243]. Model systems were devised for biomimetic mineralization of collagen sponges [241,244,245] and models of bone [42,241,242,246], tendon [247], dentin [248] and soft tissues [249-252].

Biomimetic studies of collagen mineralization were also been made with OPN [41,159,250-254] and interpreted as due to the PILP mechanism. A comparative study showed that collagen mineralization using solutions containing OPN was more homogeneous, rapid and reproducible than with polyaspartate [159]. The OPN sample used in the biomimetic modelling work was not the whole protein but a mixture of phosphopeptides from milk [41] and the same as that used to make the CaP nanocluster complexes with OPNmix, described in Section 4.2. It comprises approximately $10 \mathrm{wt} . \%$ intact OPN (33.9 kDa), $57 \mathrm{wt} . \%$ OPN1-149 with a molar mass of $19.8 \mathrm{kDa}$ and $33 \mathrm{wt} . \%$ smaller phosphopeptides. The solution used to mineralize collagen in the work of Rodriguez et al. [41] was designed [112] so that the OPNmix was largely in the form of the equilibrium CaP nanocluster complexes described in Section 4.2. The same OPNmix sample, in a closely similar solution with some minor changes in buffering, was used in subsequent work [159,251-254]. Almost certainly these studies were also made with the equilibrium $\mathrm{CaP}$ nanocluster complexes. Thus, the mechanism of collagen mineralization using "OPN as the process directing agent" is different from the PILP mechanism using polyaspartate-type stabilizers, at least in 
the stability of the starting solution. It also differs because the OPNmix contains phosphopeptides that could penetrate the collagen fibrils to potentially act epitaxially to nucleate and orient $\mathrm{CaP}[75,76]$, a mechanism excluded by the PILP hypothesis [43].

It is desirable to integrate as far as possible the theory of biofluid stability with mineralization in the extracellular matrix of hard tissues, while recognizing that many of the important details of composition and interactions in the matrix are unknown and mineralization may begin in the smallest intrafibrillar spaces [239]. Destabilization of a supersaturated biofluid containing complexed forms of ACP can occur if is brought into contact with a more stable crystalline phase of CaP or if the concentration of the stabilizing protein or polymer is reduced. This principle is illustrated in Figure 13.

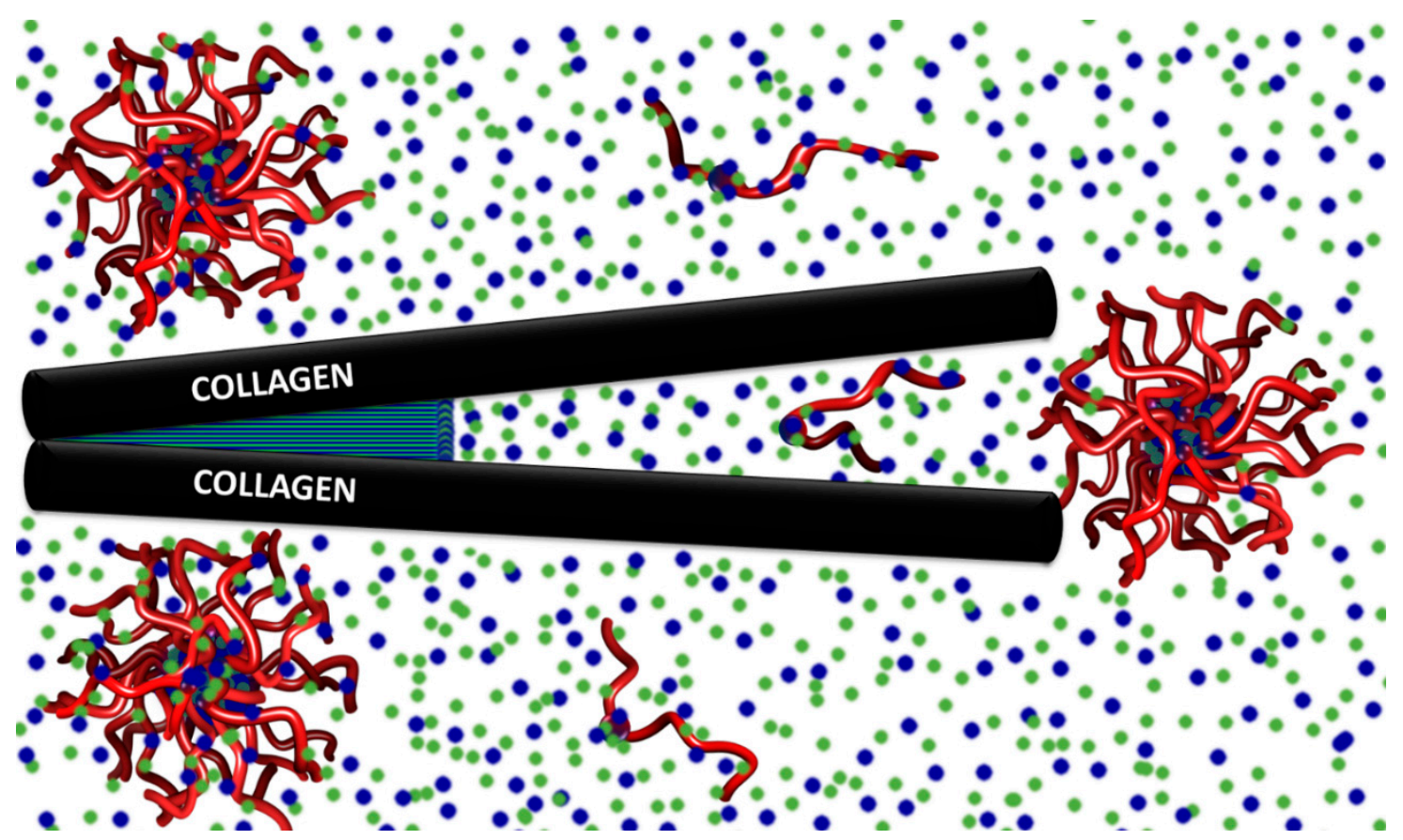

Figure 13. Schematic illustration of intrafibrillar mineralization due to steric exclusion of stabilizing polymers or phosphoproteins. According to this proposal, nucleation of CaP begins in the smallest intrafibrillar spaces because polymers that can inhibit nucleation and growth, or phosphoproteins that can inhibit or even reverse, nucleation and growth, are sterically excluded from those spaces. Nucleation and growth of ACP is inhibited in the larger pores and extrafibrillar spaces accessible to the polymer or phosphopeptide. Once intrafibrillar HA crystals are formed, their growth can continue by the solution-mediated transfer of ions from the metastable or stable complexes of CaP with polymers or phosphoproteins, respectively.

To understand better how stable and metastable complexes can both lead to the intrafibrillar mineralization of collagen, consider the following. In both the thermodynamically stable and the metastable solutions the continuous phase is supersaturated with respect to HA, but nucleation is suppressed by the process directing agent in the PILP proposal or by the free (i.e., uncomplexed) phosphopeptides in the equilibrium nanocluster complexes. In Section 3.5 expressions are given showing how the size of the equilibrium CaP nanocluster complexes depends on the affinity and concentration of the sequestering phosphopeptides. In Figure $8 \mathrm{~b}$ of Section 4 a calculation is given to show that as the concentration of free sequestering phosphopeptide decreases towards zero, the size of the complexes increases towards infinity. In other words, precipitation of CaP occurs. Once begun, HA growth can continue by the solution-mediated transfer of ions from the complexes to the HA without necessarily requiring the complexes to penetrate the fibrils or have liquid-like properties.

These ideas may help to explain how, in biomimetic mineralization experiments using stable or metastable $\mathrm{CaP}$ complexes, intrafibrillar mineralization of collagen fibers can occur while extrafibrillar 
mineralization is suppressed. If small ions can penetrate some of the smallest collagen intrafibrillar spaces but the stabilizing polymers are excluded in whole or part, the continuous phase in those spaces becomes less stable and phase separation and maturation of CaP may occur. In the extrafibrillar medium, however, phase separation is suppressed by the stabilizing polymer or protein.

\section{Summary and Conclusions}

\subsection{Equilibrium Complexes of $\mathrm{CaP}$ and Phosphoproteins}

Most studies of the effect of phosphoproteins on CaP precipitation have been carried out at high ratios of $\mathrm{CaP}$ to phosphopeptide where metastable conditions prevail. At lower ratios, an equilibrium complex can be formed which, at its simplest, comprises a core of amorphous $\mathrm{CaP}$ and a sequestering shell of the phosphoprotein. Application of equilibrium thermodynamics shows that for an ideal solution the condition for forming stable complexes is $K_{\text {seq }} a_{0,1} \geq 1$ whereas a metastable solution results if $K_{\text {seq }} a_{0,1}<1$, where $K_{\text {seq }}$ is the affinity constant for the binding of the peptide to the core CaP and $a_{0,1}$ is the concentration of free phosphoprotein (i.e., the concentration remaining in the continuous phase after forming the nanocluster complexes).

A key property of a solution of the equilibrium complexes is that it is undersaturated with respect to the amorphous $\mathrm{CaP}$ of the core and as a result $\mathrm{ACP}$ will not precipitate even if the solution contains arbitrarily high concentrations of total calcium and phosphate. A second key property is that while it can exist indefinitely in a local free energy minimum, if the solution is brought into contact with a more stable crystalline phase of $\mathrm{CaP}$, the crystalline phase will grow at the expense of the $\mathrm{CaP}$ in the nanocluster complexes. Both key properties have been exploited in biology.

For any given solution composition, the minimum concentration of sequestering phosphoprotein needed for a stable solution can be calculated. A protein stability diagram is a plot of the minimum concentration of sequestering protein versus $\mathrm{pH}$; above a critical $\mathrm{pH}, \mathrm{pH}_{\mathrm{c}}$, the minimum concentration is greater than zero and a proportion of the total calcium, phosphate, and phosphoprotein are present as the nanocluster complexes.

\subsection{Protein Structural Requirements for CaP Sequestration}

The structural requirements for $\mathrm{CaP}$ sequestration are incompletely defined. The known examples are all intrinsically disordered proteins containing several phosphorylated residues within a short sequence, known as a CaP-SLiM or phosphate center. The affinity of the phosphoprotein for the CaP determines the minimum effective concentration for forming the complexes. Experiments suggest that a protein with three phosphorylated residues in a sequence of length 4 has a higher affinity for $\mathrm{CaP}$ than one with the same total number of phosphorylated residues, of which none are consecutive.

\subsection{Core Radius of the Nanocluster Complexes}

The core radius of the nanocluster complexes depends on the ratio of the free energy of forming the shell of sequestering phosphoproteins to the free energy of forming the core $\mathrm{CaP}$ multiplied by the core surface area. The calculation can also be made for individual protein molecules in the shell or for each individual CaP-SLiM and the area they occupy on the core surface. Steric, electrostatic, or other lateral interactions in the shell may affect core size.

\subsection{Biofluid Stability}

The evidence that milk contains nanocluster complexes within the casein micelle is abundant and compelling. There is not yet any direct experimental evidence of similar complexes in other biofluids. A phosphopeptide from OPN, roughly residues 1-149 of the mature protein has been shown to form the nanocluster complexes. Since OPN is present in very many tissues and biofluids and belongs to the same paralogous group as caseins and many of the other phosphoproteins involved in the control of biocalcification, we argue that the sequestration of CaP by SCPPs and cognate phosphoproteins 
is a more general mechanism through which physiological fluids can be maintained in a stable state. In fact, the ion activity product in fresh saliva and blood serum displays a striking similarity to that seen in a solution with $\mathrm{CaP}$ nanoclusters sequestered by OPN peptides, even though the sequestering phosphopeptides may be different in each fluid (Figure 4). The ion activity products of the CaP, measured by the invariant $\mathrm{p} K_{S}$ values for fresh saliva, blood serum, and a pure nanocluster solution prepared from OPN peptides are also similar at $9.26 \pm 0.35,9.27 \pm 0.13$ and $9.12 \pm 0.05$, respectively. These ion activity products are statistically indistinguishable. It is hard to escape the conclusion that blood, and saliva contain similar forms of sequestered ACP. When sequestered within nanocluster, the CaP remains bio-available and can be deposited on mineral surfaces. Thus, allowing physiological fluids to maintain the integrity of mineral phases with which they are in contact, without causing the unwanted mineralization of soft tissue. The specific roles of the SCPPs casein and OPN have been highlighted; however, other CaP-SLiM-containing SCPPs present in physiological fluids may exert the same sequestration effect. Thus, sequestration of $\mathrm{CaP}$ nanoclusters may provide a general mechanism of in vivo stabilization of biofluids and provide the means to create artificial physiological fluids that more closely mimic their natural counterparts.

\subsection{Artificial and Biomimetic Materials}

There are many possible applications of the science described in this review. These include, but are not limited to, biomimetic materials for the repair of bone fractures and demineralized teeth. Artificial biofluids with superior shelf-life that can be used in the irrigation of wounds during and after surgery, the irrigation of joints to help remove erosive crystals from synovial spaces, artificial serum for rapid rehydration of dehydrated patients, a superior kidney dialysis fluid that reproduces more closely the composition of blood serum and a growth medium for tissue engineering applications that can support the in vitro growth of mineralized tissues. Here the relation between the ACP protein complex and interfacial behavior is crucial not only for the understanding of biomineralization, but also for the preparation of nano-structured surfaces by means of controlled deposition.

\subsection{Basic Research Needs}

Fluids that are stable and have arbitrarily high concentrations of calcium and phosphate have many potential applications. Here we limit ourselves to a few that are still closely related to the topic of the control of biocalcification.

Is it possible to design phosphopeptides that will suppress or reverse ectopic or other forms of pathological calcification when they are present at low concentration? The effective concentration at which phosphopeptides can stabilize biofluids is determined by their affinity of binding to CaP. Systematic studies are therefore required of the relationship between peptide sequence and phosphorylation and the thermodynamics of $\mathrm{CaP}$ nanocluster sequestration.

Is it possible to design nanocluster complexes that form rapidly and have a specified size and structure? There is still a lack of knowledge of the structure of individual nanoclusters, the conformation and dynamics of the peptide chains and the type of disorder in the core. Some peptides form an equilibrium complex in hours while others take several days. Is it possible to reduce the equilibration time to seconds or less? We do not yet know the detailed structure of the peptide/protein shell and how the peptides/proteins are attached and oriented at the interface! The CaP nanoclusters are stabilized by a rather specific interaction between phosphorylation sites on the peptide with the CaP which gives directionality to the interaction. Here, further applications of advanced scattering and spectroscopic techniques and studies of the effects of the sample environment will be rewarded by rapid progress in our fundamental understanding.

Is it possible to make plant derived foods and beverages that have the same remarkable stability as casein-based products? It is still a challenge to make plant-based beverages with the same high content of calcium as milk but with high stability. 
Is it possible to design a biomimetic remineralization system that can be directed to the sites where mineral loss is occurring? We have only briefly touched on the mechanisms of biomineralization and how the presence of the nanocluster complexes could provide $\mathrm{CaP}$ to ensure that tooth and bone mineralization are maintained. A biomimetic delivery system directed to sites of mineralization, possibly in the form of vesicles [255] containing suitable nanocluster complexes would be a long-term goal. Here, inverse lipid-water phases such as bi-continuous cubic phase dispersions (cubosomes), could be useful because of their higher loading capacity and structure with intertwined water channels that can accommodate CaP [256].

How is CaP transferred from the biofluid to the bone tissue? In principle, at least, the total calcium and phosphate concentrations could be made very high and sequestering peptide sequences could be engineered and optimized for intrafibrillar mineralization of the extracellular matrix of bone, for example [41]. Here there is knowledge gap in terms of the mechanism of transport and attachment of complexes to the site of biomineralization. We do not yet understand well enough how and under what conditions biomineralization could occur. In fact, the detailed understanding on how and in which form $\mathrm{CaP}$ is transferred from circulating biofluids to the extracellular matrix of mineralizing tissues is still incomplete $[1,43,255,257-260]$. Increased effort is needed on model systems of greater complexity to simulate processes in the extracellular matrix and material science studies on glass ionomer cements, teeth and bones [261].

Author Contributions: All authors contributed to editing and revising the manuscript. First drafts of Section 1, Section 2, Section 3, Section 5, and Section 6 were prepared by S.T., S.L., C.H., S.T. and T.N., respectively. Section 4 was initially drafted by S.L., Q.W. and C.H. All authors have read and agreed to the published version of the manuscript.

Funding: Q.W. is supported by China Scholarship Council Grant No. 201906120367. T.N. received financial support from the Swedish Research Council (Grant Nos. 2016-05390, 2017-06716 and 2018-05013), NanoLund and Lund Institute of Advanced Neutron and X-ray Science (LINXS). S.T. acknowledges the NIST Centre for Neutron Research for general support; this manuscript was prepared under cooperative agreements \#370NANB17H302 and \#70NANB15H260 from NIST, U.S. Department of Commerce. The statements, findings, conclusions and recommendations are those of the authors and do not necessarily reflect the view of NIST or the U.S. Department of Commerce.

Conflicts of Interest: The authors declare no conflict of interest.

\section{References}

1. George, A.; Veis, A. Phosphorylated Proteins and Control over Apatite Nucleation, Crystal Growth, and Inhibition. Chem. Rev. 2008, 108, 4670-4693. [CrossRef]

2. Wang, L.; Nancollas, G.H. Pathways to Biomineralization and Biodemineralization of Calcium Phosphates: The Thermodynamic and Kinetic Controls. Dalton Trans. 2009, 15, 2665-2672. [CrossRef]

3. Dorozhkin, S.V. Calcium Orthophosphates: Occurrence, Properties, Biomineralization, Pathological Calcification and Biomimetic Applications. Biomatter 2011, 1, 121-164. [CrossRef]

4. Alvares, K. The Role of Acidic Phosphoproteins in Biomineralization. Connect. Tissue Res. 2014, 55, 34-40. [CrossRef]

5. Dhami, N.K.; Sudhakara Reddy, M.; Mukherjee, A. Bionnineralization of Calcium Carbonates and Their Engineered Applications: A Review. Front. Microbiol. 2013, 4, 314. [CrossRef]

6. Weiner, S.; Addadi, L. Crystallization Pathways in Biomineralization. Annu. Rev. Mater. Res. 2011, 41, 21-40. [CrossRef]

7. Gelli, R.; Ridi, F.; Baglioni, P. The Importance of Being Amorphous: Calcium and Magnesium Phosphates in the Human Body. Adv. Colloid Interface Sci. 2019, 269, 219-235. [CrossRef]

8. Jahnen-Dechent, W.; Heiss, A.; Schäfer, C.; Ketteler, M. Fetuin-A Regulation of Calcified Matrix Metabolism. Circ. Res. 2011, 108, 1494-1509. [CrossRef]

9. Boskey, A.L.; Villarreal-Ramírez, E. Intrinsically Disordered Proteins and Biomineralization. Matrix Boil. 2016, 52, 43-59. [CrossRef] 
10. Tsuji, T.; Iijima, M.; Onuma, K. Biomineralization; Apatite Protein Interaction. In Bioinspiration: From Nano to Micro Scales, Biology, Medical Physics and Biomedical Engineering; Liu, X.Y., Ed.; Springer Science + Business Media: New York, NY, USA, 2012; pp. 135-159.

11. Hunter, G.K.; O'Young, J.; Grohe, B.; Karttunen, M.; Goldberg, H.A. The Flexible Polyelectrolyte Hypothesis of Protein-Biomineral Interaction. Langmuir 2010, 26, 18639-18646. [CrossRef]

12. Holt, C. Inorganic Constituents of Milk 3. The Colloidal Calcium Phosphate of Cows' Milk. J. Dairy Res. 1982, 49, 29-38. [CrossRef] [PubMed]

13. Holt, C.; Lenton, S.; Nylander, T.; Sørensen, E.S.; Teixeira, S.C.M. Mineralisation of Soft and Hard Tissues and the Stability of Biofluids. J. Struct. Biol. 2014, 185, 383-396. [CrossRef]

14. Kawasaki, K.; Suzuki, T.; Weiss, K.M. Genetic Basis for the Evolution of Vertebrate Mineralized Tissue. Proc. Natl. Acad. Sci. USA 2004, 101, 11356-11361. [CrossRef]

15. Kawasaki, K.; Weiss, K.M. Mineralized Tissue and Vertebrate Evolution: The Secretory Calcium-Binding Phosphoprotein Gene Cluster. Proc. Natl. Acad. Sci. USA 2003, 100, 4060-4065. [CrossRef] [PubMed]

16. Bertrand, S.; Fuentealba, J.; Aze, A.; Hudson, C.; Yasuo, H.; Torrejon, M.; Escriva, H.; Marcellini, S. A Dynamic History of Gene Duplications and Losses Characterizes the Evolution of the SPARC Family in Eumetazoans. Proc. R. Soc. B Boil. Sci. 2013, 280, 20122963. [CrossRef]

17. Mazzali, M.; Kipari, T.; Ophascharoensuk, V.; Wesson, J.; Johnson, R.; Hughes, J. Osteopontin-A Molecule for All Seasons. QJM Int. J. Med. 2002, 95, 3-13. [CrossRef]

18. Wahlgren, N.M.; Holt, C.; Drakenberg, T. A Multi-Nuclear Magnetic Resonance Study of Calcium Phosphate Clusters Stabilised by ß-Casein 1-25. In Proceedings of the 2nd International Conference on Applications of Magnetic Resonance in Food Science, Aveiro, Portugal, 19-21 September 1994.

19. Rao, A.; Drechsler, M.; Schiller, S.M.; Scheffner, M.; Gebauer, D.; Cölfen, H. Stabilization of Mineral Precursors by Intrinsically Disordered Proteins. Adv. Funct. Mater. 2018, 28. [CrossRef]

20. Elsharkawy, S.; Al-Jawad, M.; Pantano, M.F.; Tejeda-Montes, E.; Mehta, K.; Jamal, H.; Agarwal, S.; Shuturminska, K.; Rice, A.; Tarakina, N.V.; et al. Protein disorder-Order Interplay to Guide the Growth of Hierarchical Mineralized Structures. Nat. Commun. 2018, 9, 2145. [CrossRef]

21. Elsharkawy, S.; Mata, A. Hierarchical Biomineralization: From Nature's Designs to Synthetic Materials for Regenerative Medicine and Dentistry. Adv. Heal. Mater. 2018, 7. [CrossRef]

22. KalmarKalmár, L.; Homola, D.; Varga, G.; Tompa, P. Structural Disorder in Proteins Brings Order to Crystal Growth in Biomineralization. Bone 2012, 51, 528-534. [CrossRef]

23. Ren, S.; Uversky, V.N.; Chen, Z.; Dunker, A.K.; Obradovic, Z. Short Linear Motifs Recognized by SH2, SH3 and Ser/Thr Kinase Domains Are Conserved in Disordered Protein Regions. BMC Genom. 2008, 9, S26. [CrossRef] [PubMed]

24. Holt, C.; Sørensen, E.S.; Clegg, R.A. Role of calcium Phosphate Nanoclusters in the Control of Calcification. FEBS J. 2009, 276, 2308-2323. [CrossRef] [PubMed]

25. Piovesan, D.; Tabaro, F.; Micetic, I.; Necci, M.; Quaglia, F.; Oldfield, C.J.; Aspromonte, M.C.; Davey, N.E.; Davidovic, R.; Dosztanyi, Z.; et al. Disprot 7.0: A Major Update of the Database of Disordered Proteins. Nucleic Acids Res. 2017, 45, D219-D227. [CrossRef]

26. Kawasaki, K. The Scpp Gene Family and the Complexity of Hard Tissues in Vertebrates. Cells Tissues Organs 2011, 194, 108-112. [CrossRef]

27. Fisher, L.W.; Torchia, D.; Fohr, B.; Young, M.; Fedarko, N.S. Flexible Structures of SIBLING Proteins, Bone Sialoprotein, and Osteopontin. Biochem. Biophys. Res. Commun. 2001, 280, 460-465. [CrossRef]

28. Holt, C.; Raynes, J.K.; Carver, J.A. Sequence Characteristics Responsible for Protein-Protein Interactions in the Intrinsically Disordered Regions of Caseins, Amelogenins, and Small Heat-Shock Proteins. Biopolymers 2019, 110, e23319. [CrossRef]

29. Arachchige, R.J.; Burton, S.D.; Lu, J.-X.; Ginovska, B.; Harding, L.K.; Taylor, M.E.; Tao, J.; Dohnalkova, A.; Tarasevich, B.J.; Buchko, G.W.; et al. Solid-State NMR Identification of Intermolecular Interactions in Amelogenin Bound to Hydroxyapatite. Biophys. J. 2018, 115, 1666-1672. [CrossRef]

30. Ndao, M.; Dutta, K.; Bromley, K.M.; Lakshminarayanan, R.; Sun, Z.; Rewari, G.; Moradian-Oldak, J.; Evans, J.S. Probing the Self-Association, Intermolecular Contacts, and Folding Propensity of Amelogenin. Protein Sci. 2011, 20, 724-734. [CrossRef] 
31. Wald, T.; Osickova, A.; Sulc, M.; Benada, O.; Semeradtova, A.; Rezabkova, L.; Veverka, V.; Bednarova, L.; Maly, J.; Macek, P.; et al. Intrinsically Disordered Enamel Matrix Protein Ameloblastin Forms Ribbon-like Supramolecular Structures via an N-terminal Segment Encoded by Exon 5*. J. Boil. Chem. 2013, 288, 22333-22345. [CrossRef]

32. Carver, J.A.; Holt, C. Chapter Five-Functional and Dysfunctional Folding, Association and Aggregation of Caseins. In Advances in Protein Chemistry and Structural Biology; Donev, R., Ed.; Academic Press: Cambridge, MA, USA, 2019; pp. 163-216.

33. Carneiro, K.M.M.H.; Zhai, H.; Zhu, L.; Horst, J.A.; Sitlin, M.; Nguyen, M.; Wagner, M.; Simpliciano, C.; Milder, M.; Chen, C.-L.; et al. Amyloid-like Ribbons of Amelogenins in Enamel Mineralization. Sci. Rep. 2016, 6, 23105. [CrossRef]

34. Wald, T.; Špoutil, F.; Osickova, A.; Prochazkova, M.; Benada, O.; Kasparek, P.; Bumba, L.; Klein, O.D.; Sedlacek, R.; Sebo, P.; et al. Intrinsically Disordered Proteins Drive Enamel Formation via an Evolutionarily Conserved Self-Assembly Motif. Proc. Natl. Acad. Sci. USA 2017, 114, E1641-E1650. [CrossRef] [PubMed]

35. Dalgleish, D.G.; Parker, T.G. Binding of Calcium Ions to Bovine Alpha-S1-Casein and Precipitability of the Protein-Calcium Ion Complexes. J. Dairy Res. 1980, 47, 113-122. [CrossRef]

36. Parker, T.G.; Dalgleish, D.G. Dalgleish. Binding of Calcium Ions to Bovine Beta-Casein. J. Dairy Res. 1981, 48, 71-76. [CrossRef] [PubMed]

37. Sleigh, R.W.; Mackinlay, A.G.; Pope, J. Nmr-Studies of the Phosphoserine Regions of Bovine Alpha-S1-Casein and Beta-Casein-Assignment of P-31 Resonances to Specific Phosphoserines and Cation Binding Studied by Measurement of Enhancement of H-1 Relaxation Rate. Biochim. Biophys. Acta 1983, 742, 175-183. [CrossRef]

38. Sleigh, R.W.; Sculley, T.B.; Mackinlay, A.G. Mackinlay. Binding of Beta Casein to Hydroxyapatite-Effect of Phosphate Content and Location. J. Dairy Res. 1979, 46, 337-342. [CrossRef]

39. Bijl, E.; Huppertz, T.; Van Valenberg, H.; Holt, C. A Quantitative Model of the Bovine Casein Micelle: Ion Equilibria and Calcium Phosphate Sequestration by Individual Caseins in Bovine Milk. Eur. Biophys. J. 2019, 48, 45-59. [CrossRef]

40. Clegg, R.A.; Holt, C.; An, E. Coli over-Expression System for Multiply-Phosphorylated Proteins and Its Use in a Study of Calcium Phosphate Sequestration by Novel Recombinant Phosphopeptides. Protein Expr. Purif. 2009, 67, 23-34. [CrossRef]

41. Rodriguez, D.E.; Thula-Mata, T.; Toro, E.J.; Yeh, Y.-W.; Holt, C.; Holliday, L.S.; Gower, L. Multifunctional Role of Osteopontin in Directing Intrafibrillar Mineralization of Collagen and Activation of Osteoclasts. Acta Biomater. 2014, 10, 494-507. [CrossRef]

42. Wingender, B.; Bradley, P.; Saxena, N.; Ruberti, J.W.; Gower, L. Biomimetic Organization of Collagen Matrices to Template Bone-Like Microstructures. Matrix Biol. 2016, 52-54, 384-396. [CrossRef]

43. Gower, L.B. Biomimetic Model Systems for Investigating the Amorphous Precursor Pathway and Its Role in Biomineralization. Chem. Rev. 2008, 108, 4551-4627. [CrossRef]

44. Addison, W.N.; Nakano, Y.; Loisel, T.; Crine, P.; McKee, M.D. Mepe-Asarm Peptides Control Extracellular Matrix Mineralization by Binding to Hydroxyapatite: An Inhibition Regulated by Phex Cleavage of Asarm. J. Bone Miner. Res. 2008, 23, 1638-1649. [CrossRef]

45. Christensen, B.; Schytte, G.N.; Scavenius, C.; Enghild, J.J.; McKee, M.D.; Sørensen, E.S. Fam20c-Mediated Phosphorylation of Mepe and Its Acidic Serine- and Aspartate-Rich Motif. JBMR Plus 2020, 4, e10378. [CrossRef]

46. Salmon, B.; Bardet, C.; Khaddam, M.; Naji, J.; Coyac, B.R.; Baroukh, B.; Letourneur, F.; Lesieur, J.; Decup, F.; Le Denmat, D.; et al. Mepe-Derived Asarm Peptide Inhibits Odontogenic Differentiation of Dental Pulp Stem Cells and Impairs Mineralization in Tooth Models of X-Linked Hypophosphatemia. PLoS ONE 2013, 8 , e56749. [CrossRef]

47. Boskey, A.L.; Chiang, P.; Fermanis, A.; Brown, J.; Taleb, H.; David, V.; Rowe, P.S.N. Mepe's Diverse Effects on Mineralization. Calcif. Tissue Int. 2010, 86, 42-46. [CrossRef]

48. Minamizaki, T.; Yoshiko, Y. The Bioactive Acidic Serine- and Aspartate-Rich Motif Peptide. Curr. Protein Pept. Sci. 2015, 16, 196-202. [CrossRef]

49. Schwartz, S.S.; Hay, D.I.; Schluckebier, S.K. Inhibition of Calcium Phosphate Precipitation by Human Salivary Statherin: Structure-Activity Relationships. Calcif. Tissue Int. 1992, 50, 511-517. [CrossRef]

50. Gorski, J.P.; Kremer, E.A.; Chen, Y.; Ryan, S.; Fullenkamp, C.; DelViscio, J.; Jensen, K.; McKee, M.D. Bone Acidic Glycoprotein-75 Self-Associates to Form Macromolecular Complexes in Vitro and in Vivo with the Potential to Sequester Phosphate Ions. J. Cell. Biochem. 1997, 64, 547-564. [CrossRef] 
51. Walker, J.; Saraste, M.; Runswick, M.; Gay, N. Distantly Related Sequences in the Alpha-Subunits and Beta-Subunits of Atp Synthase, Myosin, Kinases and Other Atp-Requiring Enzymes and a Common Nucleotide Binding Fold. EMBO J. 1982, 1, 945-951. [CrossRef]

52. Hirsch, A.K.H.; Fischer, F.R.; Diederich, F. Phosphate Recognition in Structural Biology. Angew. Chem. Int. Ed. 2007, 46, 338-352. [CrossRef]

53. Bianchi, A.; Giorgi, C.; Ruzza, P.; Toniolo, C.; Milner-White, E.J. A Synthetic Hexapeptide Designed to Resemble a Proteinaceous P-Loop Nest Is Shown to Bind Inorganic Phosphate. Proteins Struct. Funct. Bioinform. 2012, 80, 1418-1424. [CrossRef]

54. BBuckle, E.L.; Prakash, A.; Bonomi, M.; Sampath, J.; Pfaendtner, J.; Drobny, G.P. Solid-State Nmr and Md Study of the Structure of the Statherin Mutant Sna15 on Mineral Surfaces. J. Am. Chem. Soc. 2019, 141, 1998-2011. [CrossRef] [PubMed]

55. Goobes, R.; Goobes, G.; Shaw, W.J.; Drobny, G.P.; Campbell, C.T.; Stayton, P.S. Thermodynamic Roles of Basic Amino Acids in Statherin Recognition of Hydroxyapatite. Biochemistry 2007, 46, 4725-4733. [CrossRef] [PubMed]

56. Ndao, M.; Ash, J.T.; Stayton, P.S.; Drobny, G.P. The Role of Basic Amino Acids in the Molecular Recognition of Hydroxyapatite by Statherin Using Solid State Nmr. Surf. Sci. 2010, 604, L39-L42. [CrossRef] [PubMed]

57. Holt, C.; Sawyer, L. Caseins as Rheomorphic Proteins-Interpretation of Primary and Secondary Structures of the Alpha-S1-Caseins, Beta-Caseins and Kappa-Caseins. J. Chem. Soc. Faraday Trans. 1993, 89, 2683-2692. [CrossRef]

58. Holt, C.; Sawyer, L. Primary and Predicted Secondary Structures of the Caseins in Relation to Their Biological Functions. Protein Eng. Des. Sel. 1988, 2, 251-259. [CrossRef]

59. Dyson, H.J. Making Sense of Intrinsicaly Disordered Proteins. Biophys. J. 2016, 110, 1013-1016. [CrossRef]

60. Fujisawa, R.; Kuboki, Y. Conformation of Dentin Phosphophoryn Adsorbed on Hydroxyapatite Crystals. Eur. J. Oral Sci. 1998, 106, 249-253. [CrossRef]

61. Samoshina, Y.; Nylander, T.; Shubin, V.; Bauer, R.; Eskilsson, K. Equilibrium Aspects of Polycation Adsorption on Silica Surface: How the Adsorbed Layer Responds to Changes in Bulk Solution. Langmuir 2005, 21, 5872-5881. [CrossRef]

62. Lenton, S.; Seydel, T.; Nylander, T.; Holt, C.; Härtlein, M.; Teixeira, S.; Zaccai, G. Dynamic Footprint of Sequestration in the Molecular Fluctuations of Osteopontin. J. R. Soc. Interface 2015, 12, 20150506. [CrossRef]

63. Moreno, E.C.; Varughese, K.; Hay, D.I. Effect of Human Salivary Proteins on the Precipitation Kinetics of Calcium Phosphate. Calcif. Tissue Int. 1979, 28, 7-16. [CrossRef]

64. Hay, D.I.; Carlson, E.R.; Schluckebier, S.K.; Moreno, E.C.; Schlesinger, D.H. Inhibition of Calcium Phosphate Precipitation by Human Salivary Acidic Proline-Rich Proteins-Structure-Activity Relationships. Calcif. Tissue Int. 1987, 40, 126-132. [CrossRef] [PubMed]

65. Uversky, V.N.; Gillespie, J.R.; Fink, A.L. Why Are Natively Unfolded Proteins Unstructured under Physiologic Conditions? Proteins Struct. Funct. Gene. 2000, 41, 415-427. [CrossRef]

66. Tagliabracci, V.S.; Wiley, S.E.; Guo, X.; Kinch, L.N.; Durrant, E.; Wen, J.; Xiao, J.; Cui, J.; Nguyen, K.B.; Engel, J.L.; et al. A Single Kinase Generates the Majority of the Secreted Phosphoproteome. Cell 2015, 161, 1619-1632. [CrossRef] [PubMed]

67. Bah, A.; Forman-Kay, J.D. Modulation of Intrinsically Disordered Protein Function by Post-Translational Modifications. J. Biol. Chem. 2016, 291, 6696-6705. [CrossRef]

68. Gao, J.J.; Xu, D. Correlation between Posttranslational Modification and Intrinsic Disorder in Protein. In Pacific Symposium on Biocomputing 2012; Altman, R.B., Dunker, A.K., Hunter, L., Murray, T., Klein, T.E., Eds.; World Scientific Publ. Co. Pte Ltd.: Singapore, 2012; pp. 94-103.

69. He, G.; Gajjeraman, S.; Schultz, D.; Cookson, D.; Qin, C.; Butler, W.T.; Hao, J.; George, A. Spatially and Temporally Controlled Biomineralization is Facilitated by Interaction between Self-Assembled Dentin Matrix Protein 1 and Calcium Phosphate Nuclei in Solution. Biochemistry 2005, 44, 16140-16148. [CrossRef]

70. Tartaix, P.H.; Doulaverakis, M.; George, A.; Fisher, L.W.; Butler, W.T.; Qin, C.L.; Salih, E.; Tan, M.L.; Fujimoto, Y.; Spevak, L.; et al. In Vitro Effects of Dentin Matrix Protein-1 on Hydroxyapatite Formation Provide Insights into in Vivo Functions. J. Biol. Chem. 2004, 279, 18115-18120. [CrossRef]

71. Raj, P.A.; Johnsson, M.; Levine, M.J.; Nancollas, G.H. Salivary Statherin-Dependence on Sequence, Charge, Hydrogen-Bonding Potency and Helical Conformation for Adsorption to Hydroxyapatite and Inhibition of Mineralization. J. Biol. Chem. 1992, 267, 5968-5976. 
72. Zhang, J.; Wang, L.; Zhang, W.; Putnis, C.V. Phosphorylated/Nonphosphorylated Motifs in Amelotin Turn off/on the Acidic Amorphous Calcium Phosphate-to-Apatite Phase Transformation. Langmuir 2020, 36, 2102-2109. [CrossRef]

73. He, G.; Ramachandran, A.; Dahl, T.; George, S.; Schultz, D.; Cookson, D.; Veis, A.; George, A. Phosphorylation of Phosphophoryn Is Crucial for Its Function as a Mediator of Biomineralization. J. Biol. Chem. 2005, 280, 33109-33114. [CrossRef]

74. Baht, G.S.; O’Young, J.; Borovina, A.; Chen, H.; Tye, C.E.; Karttunen, M.; Lajoie, G.A.; Hunter, G.K.; Goldberg, H.A. Phosphorylation of Ser(136) Is Critical for Potent Bone Sialoprotein-Mediated Nucleation of Hydroxyapatite Crystals. Biochem. J. 2010, 428, 385-395. [CrossRef]

75. Boskey, A.L.; Christensen, B.; Taleb, H.; Sørensen, E.S. Post-Translational Modification of Osteopontin: Effects on in Vitro Hydroxyapatite Formation and Growth. Biochem. Biophys. Res. Commun. 2012, 419, 333-338. [CrossRef] [PubMed]

76. Gericke, A.; Qin, C.; Spevak, L.; Fujimoto, Y.; Butler, W.T.; Sørensen, E.S.; Boskey, A.L. Importance of Phosphorylation for Osteopontin Regulation of Biomineralization. Calcif. Tissue Int. 2005, 77, 45-54. [CrossRef] [PubMed]

77. Shoemaker, B.A.; Portman, J.J.; Wolynes, P.G. Speeding Molecular Recognition by Using the Folding Funnel: The Fly-Casting Mechanism. Proc. Natl. Acad. Sci. USA 2000, 97, 8868-8873. [CrossRef] [PubMed]

78. Nývlt, J. The Ostwald Rule of Stages. Cryst. Res. Technol. 1995, 30, 443-449. [CrossRef]

79. Levin, A.; Mason, T.O.; Adler-Abramovich, L.; Buell, A.K.; Meisl, G.; Galvagnion, C.; Bram, Y.; Stratford, S.A.; Dobson, C.M.; Knowles, T.P.J.; et al. Ostwald's Rule of Stages Governs Structural Transitions and Morphology of Dipeptide Supramolecular Polymers. Nat. Commun. 2014, 5, 5219. [CrossRef]

80. Ostwald, W. Studien über die Bildung und Umwandlung Fester Körper. Z. Phys. Chem. 1897, 22, 289. [CrossRef]

81. Threlfall, T. Structural and Thermodynamic Explanations of Ostwald's Rule. Org. Process Res. Dev. 2003, 7, 1017-1027. [CrossRef]

82. Combes, C.; Rey, C. Amorphous Calcium Phosphates: Synthesis, Properties and Uses in Biomaterials. Acta Biomater. 2010, 6, 3362-3378. [CrossRef]

83. Christoffersen, M.R.; Christoffersen, J.; Kibalczyc, W. Apparent Solubilities of 2 Amorphous Calcium Phosphates and of Octacalcium Phosphate in the Temperature-Range 30-42-Degrees-C. J. Cryst. Growth 1990, 106, 349-354. [CrossRef]

84. Meyer, J.L.; Eanes, E.D. Thermodynamic Analysis of Secondary Transition in Spontaneous Precipitation of Calcium-Phosphate. Calcif. Tissue Res. 1978, 25, 209-216. [CrossRef]

85. Termine, J.D.; Eanes, E.D. Comparative Chemistry of Amorphous and Apatitic Calcium Phosphate Preparations. Calcif. Tissue Res. 1972, 10, 171-197. [CrossRef] [PubMed]

86. Wuthier, R.E.; Rice, G.S.; Wallace, J.E.B.; Weaver, R.L.; LeGeros, R.Z.; Eanes, E.D. In Vitro Precipitation of Calcium-Phosphate under Intracellular Conditions-Formation of Brushite from an Amorphous Precursor in the Absence of Atp. Calcif. Tissue Int. 1985, 37, 401-410. [CrossRef] [PubMed]

87. Holt, C.; Van Kemenade, M.; Nelson, L.; Hukins, D.; Bailey, R.; Harries, J.; Hasnain, S.; De Bruyn, P. Amorphous Calcium Phosphates Prepared at PH 6.5 and 6.0. Mater. Res. Bull. 1989, 24, 55-62. [CrossRef]

88. Posner, A.S.; Betts, F. Synthetic Amorphous Calcium-Phosphate and Its Relation to Bone-Mineral Structure. Accounts Chem. Res. 1975, 8, 273-281. [CrossRef]

89. Lu, B.-Q.; Garcia, N.A.; Chevrier, D.M.; Zhang, P.; Raiteri, P.; Gale, J.D.; Gebauer, D. Short-Range Structure of Amorphous Calcium Hydrogen Phosphate. Cryst. Growth Des. 2019, 19, 3030-3038. [CrossRef]

90. Betts, F.; Posner, A.S. X-Ray Radial Distribution Study of Amorphous Calcium Phosphate. Mater. Res. Bull. 1974, 9, 353-360. [CrossRef]

91. Holt, C.; Hukins, D.W.L. Structural Analysis of the Environment of Calcium Ions in Crystalline and Amorphous Calcium Phosphates by X-ray Absorption Spectroscopy and a Hypothesis Concerning the Biological Function of the Casein Micelle. Int. Dairy J. 1991, 1, 151-165. [CrossRef]

92. Williams, R.J.P. Biochemistry of Sodium, Potassium, Magnesium and Calcium. Q. Rev. 1970, 24, 331. [CrossRef]

93. Lu, B.-Q.; Willhammar, T.; Sun, B.-B.; Hedin, N.; Gale, J.D.; Gebauer, D. Introducing the Crystalline Phase of Dicalcium Phosphate Monohydrate. Nat. Commun. 2020, 11, 1546. [CrossRef]

94. Greco, K.; Bogner, R.H. Solution-Mediated Phase Transformation: Significance During Dissolution and Implications for Bioavailability. J. Pharm. Sci. 2012, 101, 2996-3018. [CrossRef] [PubMed] 
95. Gal, A.; Weiner, S.; Addadi, L. A Perspective on Underlying Crystal Growth Mechanisms in Biomineralization: Solution Mediated Growth versus Nanosphere Particle Accretion. Crystengcomm 2015, 17, 2606-2615. [CrossRef]

96. Elliot, J.C. Structure and Chemistry of the Apatites and Other Calcium Orthophosphates; Studies in Inorganic Chemistry; Elsevier: Amsterdam, The Netherlands, 1994.

97. Von Euw, S.; Wang, Y.; Laurent, G.; Drouet, C.; Babonneau, F.; Nassif, N.; Azais, T. Bone Mineral: New Insights into Its Chemical Composition. Sci. Rep. 2019, 9, 8456. [CrossRef] [PubMed]

98. Yang, X.; Wang, L.; Qin, Y.; Sun, Z.; Henneman, Z.J.; Moradian-Oldak, J.; Nancollas, G.H. How Amelogenin Orchestrates the Organization of Hierarchical Elongated Microstructures of Apatite. J. Phys. Chem. B 2010, 114, 2293-2300. [CrossRef] [PubMed]

99. Fincham, A.; Moradian-Oldak, J.; Simmer, J.P. The Structural Biology of the Developing Dental Enamel Matrix. J. Struct. Boil. 1999, 126, 270-299. [CrossRef]

100. Enriquez, D.J.P.; Dell'arciprete, M.L.; Dittler, M.L.; Miñan, A.; Prieto, E.; Gonzalez, M.C. Amorphous Calcium Organophosphate Nanoshells as Potential Carriers for Drug Delivery to $\mathrm{Ca}^{2+}$-Enriched Surfaces. New J. Chem. 2020, 44, 7541-7551. [CrossRef]

101. Liu, X.; Jing, X.; Liu, P.; Pan, M.; Liu, Z.; Dai, X.; Lin, J.; Li, Q.; Wang, F.; Yang, S.; et al. DNA Framework-Encoded Mineralization of Calcium Phosphate. Chem 2020, 6, 472-485. [CrossRef]

102. Napper, D.H. Steric Stabilization. J. Colloid Interface Sci. 1977, 58, 390-407. [CrossRef]

103. Van Der Lee, R.; Buljan, M.; Lang, B.; Weatheritt, R.J.; Daughdrill, G.W.; Dunker, A.K.; Fuxreiter, M.; Gough, J.; Gsponer, J.; Jones, D.T.; et al. Classification of Intrinsically Disordered Regions and Proteins. Chem. Rev. 2014, 114, 6589-6631. [CrossRef]

104. Burke, E.; Guo, Y.; Colon, L.A.; Rahima, M.; Veis, A.; Nancollas, G.H. Influence of Polyaspartic Acid and Phosphophoryn on Octacalcium Phosphate Growth Kinetics. Colloids Surf. B Biointerfaces 2000, 17, 49-57. [CrossRef]

105. De Bruyn, J.R.; Goiko, M.; Mozaffari, M.; Bator, D.; Dauphinee, R.L.; Liao, Y.; Flemming, R.L.; Bramble, M.S.; Hunter, G.K.; Goldberg, H.A. Dynamic Light Scattering Study of Inhibition of Nucleation and Growth of Hydroxyapatite Crystals by Osteopontin. PLOS ONE 2013, 8, e56764. [CrossRef]

106. Goldberg, H.A.; Warner, K.J.; Li, M.C.; Hunter, G.K. Binding of Bone Sialoprotein, Osteopontin and Synthetic Polypeptides to Hydroxyapatite. Connect. Tissue Res. 2001, 42, 25-37. [CrossRef]

107. Hunter, G.K.; Hauschka, P.V.; Poole, R.A.; Rosenberg, L.C.; Goldberg, H.A. Nucleation and Inhibition of Hydroxyapatite Formation by Mineralized Tissue Proteins. Biochem. J. 1996, 317, 59-64. [CrossRef]

108. Pampena, D.A.; Robertson, K.A.; Litvinova, O.; Lajoie, G.; Goldberg, H.A.; Hunter, G.K. Inhibition of Hydroxyapatite Formation by Osteopontin Phosphopeptides. Biochem. J. 2004, 378, 1083-1087. [CrossRef]

109. Tarasevich, B.J.; Howard, C.J.; Larson, J.L.; Snead, M.L.; Simmer, J.P.; Paine, M.; Shaw, W.J. The Nucleation and Growth of Calcium Phosphate by Amelogenin. J. Cryst. Growth 2007, 304, 407-415. [CrossRef]

110. Holt, C.; Wahlgren, N.M.; Drakenberg, T. Ability of a Beta-Casein Phosphopeptide to Modulate the Precipitation of Calcium Phosphate by Forming Amorphous Dicalcium Phosphate Nanoclusters. Biochem. J. 1996, 314, 1035-1039. [CrossRef]

111. Holt, C.; Timmins, P.A.; Errington, N.; Leaver, J. A Core-Shell Model of Calcium Phosphate Nanoclusters Stabilized by Beta-Casein Phosphopeptides, Derived from Sedimentation Equilibrium and Small-Angle X-Ray and Neutron-Scattering Measurements. Eur. J. Biochem. 1998, 252, 73-78. [CrossRef]

112. Little, E.M.; Holt, C. An Equilibrium Thermodynamic Model of the Sequestration of Calcium Phosphate by Casein Phosphopeptides. Eur.Biophys. J. 2004, 33, 435-447. [CrossRef]

113. Tercinier, L.; Ye, A.; Anema, S.G.; Singh, A.; Singh, H. Interactions of Casein Micelles with Calcium Phosphate Particles. J. Agric. Food Chem. 2014, 62, 5983-5992. [CrossRef]

114. Fan, H.-X.; Gou, B.-D.; Gao, Y.-X.; Wu, G.; Zhang, T.-L. Pseudo-Equilibrium Equation of Calcium Phosphate Precipitation from Aqueous Solution. Phys. Chem. Chem. Phys. 2019, 21, 22057-22066. [CrossRef]

115. Gebauer, D.; Cölfen, H. Prenucleation Clusters and Non-Classical Nucleation. Nano Today 2011, 6, 564-584. [CrossRef]

116. Weber, E.M.M.; Kress, T.; Abergel, D.; Sewsurn, S.; Azais, T.; Kurzbach, D. Assessing the Onset of Calcium Phosphate Nucleation by Hyperpolarized Real-Time Nmr. Anal. Chem. 2020, 92, 7666-7673. [CrossRef] [PubMed] 
117. Garcia, N.A.; Malini, R.I.; Freeman, C.L.; Demichelis, R.; Raiteri, P.; Sommerdijk, N.A.J.M.; Harding, J.H.; Gale, J.D.; Freeeman, C.L. Simulation of Calcium Phosphate Prenucleation Clusters in Aqueous Solution: Association beyond Ion Pairing. Cryst. Growth Des. 2019, 19, 6422-6430. [CrossRef] [PubMed]

118. Ashby, R.A.; Byrne, J.P.; Györy, Á.Z. Urine Is a Saturated Equilibrium and Not a Metastable Supersaturated Solution: Evidence from Crystalluria and the General Composition of Calcium Salt and Uric Acid Calculi. Urol. Res. 1999, 27, 297-305. [CrossRef] [PubMed]

119. Györy, A.Z.; Ashby, R. Equilibrium Versus Supersaturated Urine Hypothesis in Calcium Salt Urolithiasis: A New Theoretical and Practical Approach to a Clinical Problem. Scanning Microsc. 1999, 13, 261-265.

120. Kavanagh, J.P. A Critical Appraisal of the Hypothesis That Urine Is a Saturated Equilibrium with Respect to Stone-Forming Calcium Salts. BJU Int. 2001, 87, 589-598. [CrossRef]

121. Eidelman, N.; Chow, L.C.; Brown, W.E. Calcium Phosphate Saturation Levels in Ultrafiltered Serum. Calcif. Tissue Int. 1987, 40, 71-78. [CrossRef]

122. Grøn, P. Saturation of Human Saliva with Calcium Phosphates. Arch. Oral Biol. 1973, 18, 1385-1392. [CrossRef]

123. May, P.M.; Rowland, D. Jess, a Joint Expert Speciation System-Vi: Thermodynamically-Consistent Standard Gibbs Energies of Reaction for Aqueous Solutions. New J. Chem. 2018, 42, 7617-7629. [CrossRef]

124. Larsen, M.J.; Pearce, E.I.F. Pearce. Saturation of Human Saliva with Respect to Calcium Salts. Arch. Oral Biol. 2003, 48, 317-322. [CrossRef]

125. Walser, M. Separate Effects of Hyperparathyroidism, Hypercalcaemia of Malignancy, Renal Failure, and Acidosis on State of Calcium, Phosphate and Other Ions in Plasma. J. Clin. Investig. 1962, 41, 1454-1471. [CrossRef]

126. Walser, M. Ion Association 6. Interactions between Calcium, Magnesium, Inorganic Phosphate, Citrate and Protein in Normal Human Plasma. J. Clin. Investig. 1961, 40, 723-730. [CrossRef] [PubMed]

127. White, J.C.D.; Davies, D.T. The Relation between the Chemical Composition of Milk and the Stability of the Caseinate Complex. 1. General Introduction, Description of Samples, Methods and Chemical Composition of Samples. J. Dairy Res. 1958, 25, 236-255. [CrossRef]

128. Holt, C. An Equilibrium Thermodynamic Model of the Sequestration of Calcium Phosphate by Casein Micelles and Its Application to the Calculation of the Partition of Salts in Milk. Eur. Biophys. J. Biophys. Lett. 2004, 33, 421-434. [CrossRef] [PubMed]

129. Thomsen, J.K.; Jakobsen, H.J.; Nielsen, N.; Petersen, T.E.; Rasmussen, L.K. Solid-State Magic-Angle Spinning 31p-Nmr Studies of Native Casein Micelles. Eur. J. Biochem. 1995, 230, 454-459. [CrossRef] [PubMed]

130. de Kruif, C.G. The Structure of Casein Micelles: A Review of Small-Angle Scattering Data. J. Appl. Crystallogr. 2014, 47, 1479-1489. [CrossRef]

131. Holt, C. The Milk Salts and Their Interaction with Casein. In Advanced Dairy Chemistry; Fox, P.F., Ed.; Chapman and Hall: London, UK, 1997; pp. 233-254.

132. Ingham, B.; Erlangga, G.D.; Smialowska, A.; Kirby, N.M.; Wang, C.; Matia-Merino, L.; Haverkamp, R.G.; Carr, A.J. Solving the Mystery of the Internal Structure of Casein Micelles. Soft Matter 2015, 11, 2723-2725. [CrossRef]

133. Kamigaki, T.; Ito, Y.; Nishino, Y.; Miyazawa, A. Microstructural Observation of Casein Micelles in Milk by Cryo-Electron Microscopy of Vitreous Sections (Cemovis). Microscopy 2018, 67, 164-170. [CrossRef]

134. Hettiarachchi, C.A.; Swulius, M.T.; Harte, F. Assessing Constituent Volumes and Morphology of Bovine Casein Micelles Using Cryo-Electron Tomography. J. Dairy Sci. 2020, 103, 3971-3979. [CrossRef]

135. McMahon, D.; Oommen, B.S. Casein Micelle Structure, Functions and Interactions. In Advanced Dairy Chemistry; Fox, P.F., McSweeney, P.L.H., Eds.; Springer: New York, NY, USA, 2012; pp. 185-210.

136. Volmer, M.; Weber, A. Germ-Formation in Oversaturated Figures. Z. Phys. Chem. Stochiom. Verwandtschaftslehre 1926, 119, 277-301.

137. Prigogine, I.; Defay, R.; Everett, D.H. Chemical Thermodynamics; Everett, D.H., Ed.; John Wiley \& Sons: New York, NY, USA, 1962.

138. Holt, C. A Quantitative Calcium Phosphate Nanocluster Model of the Casein Micelle: The Average Size, Size Distribution and Surface Charge Density. 2020; Unpublished work.

139. Holt, C. Unfolded Phosphopolypeptides Enable Soft and Hard Tissues to Coexist in the Same Organism with Relative Ease. Curr. Opin. Struct. Boil. 2013, 23, 420-425. [CrossRef]

140. Neville, M.C.; Keller, R.P.; Casey, C.; Allen, J.C. Calcium Partitioning in Human and Bovine Milk. J. Dairy Sci. 1994, 77, 1964-1975. [CrossRef] 
141. Jahnen-Dechent, W.; Schäfer, C.; Ketteler, M.; McKee, M.D. Mineral Chaperones: A Role for Fetuin-a and Osteopontin in the Inhibition and Regression of Pathologic Calcification. J. Mol. Med. 2008, 86, 379-389. [CrossRef] [PubMed]

142. Hill, A.V. Proceedings of the Physiological Society: 22 January 1910. J. Physiol. 1910, 40, i-vii.

143. Pyne, G.T.; McGann, T.C.A. The Colloidal Phosphate of Milk: II. Influence of Citrate. J. Dairy Res. 1960, 27, 9-17. [CrossRef]

144. McGann, T.C.A.; Pyne, G.T. The Colloidal Phosphate of Milk: III. Nature of its Association with Casein. J. Dairy Res. 1960, 27, 403-417. [CrossRef]

145. Holt, C.; van Kemenade, M.J.J.M.; Nelson, L.S.; Sawyer, L.; Harries, J.E.; Bailey, R.T.; Hukins, D.W.L. Composition and Structure of Micellar Calcium-Phosphate. J. Dairy Res. 1989, 56, 411-416. [CrossRef]

146. Lyster, R.L.J.; Mann, S.; Parker, S.B.; Williams, R.J.P. Nature of Micellar Calcium Phosphate in Cows' Milk as Studied by High Resolution Electron Microscopy. Biochim. Biophys. Acta 1984, 801, 315-317. [CrossRef]

147. McGann, T.C.A.; Kearney, R.D.; Buchheim, W.; Posner, A.S.; Betts, F.; Blumenthal, N.C. Amorphous Calcium-Phosphate in Casein Micelles of Bovine-Milk. Calcif. Tissue Int. 1983, 35, 821-823. [CrossRef]

148. Ono, T.; Ohotawa, T.; Takagi, Y. Complexes of Casein Phosphopetides and Calcium Phosphate Prepared from Casein Micelles by Tryptic Digestion. Biosci. Biotechnol. Biochem. 1994, 58, 1376-1380. [CrossRef]

149. Holt, C.; de Kruif, C.G.; Tuinier, R.; Timmins, P.A. Substructure of Bovine Casein Micelles by Small-Angle X-Ray and Neutron Scattering. Colloids Surf. Physicochem. Eng. Asp. 2003, 213, 275-284. [CrossRef]

150. Ellegård, K.H.; Gammelgård-Larsen, C.; Sørensen, E.S.; Fedosov, S. Process Scale Chromatographic Isolation, Characterization and Identification of Tryptic Bioactive Casein Phosphopeptides. Int. Dairy J. 1999, 9, 639-652. [CrossRef]

151. Cochrane, N.J.; Cai, F.; Huq, N.L.; Burrow, M.F.; Reynolds, E.C. New Approaches to Enhanced Remineralization of Tooth Enamel. J. Dent. Res. 2010, 89, 1187-1197. [CrossRef] [PubMed]

152. Cross, K.J.; Huq, N.L.; Reynolds, E.C. Casein Phosphopeptide-Amorphous Calcium Phosphate Nanocomplexes: A Structural Model. Biochemistry 2016, 55, 4316-4325. [CrossRef] [PubMed]

153. On-Nom, N.; Grandison, A.S.; Lewis, M.J. Measurement of Ionic Calcium, PH, and Soluble Divalent Cations in Milk at High Temperature. J. Dairy Sci. 2010, 93, 515-523. [CrossRef] [PubMed]

154. Gaucheron, F. (Ed.) Minéraux et Produits Laitiers; Tec \& Doc Paris: Paris, France, 2004.

155. Pouliot, Y.; Boulet, M.; Paquin, P. Observations on the Heat-Induced Salt Balance Changes in Milk 1. Effect of Heating Time between 4 Degrees C and 90 Degrees C. J. Dairy Res. 1989, 56, 185-192. [CrossRef]

156. Depalle, B.; McGilvery, C.M.; Nobakhti, S.; Aldegaither, N.; Shefelbine, S.J.; Porter, A.E. Osteopontin Regulates Type I Collagen Fibril Formation in Bone Tissue. Acta Biomater. 2020, in press. [CrossRef]

157. Foster, B.L.; Ao, M.; Salmon, C.R.; Chavez, M.B.; Kolli, T.N.; Tran, A.B.; Chu, E.Y.; Kantovitz, K.R.; Yadav, M.; Narisawa, S.; et al. Osteopontin Regulates Dentin and Alveolar Bone Development and Mineralization. Bone 2018, 107, 196-207. [CrossRef]

158. Jinyan, S.; Wang, C.; Zhang, D.; Wang, B.; Hou, W.; Zhou, Y. Osteopontin in Bone Metabolism and Bone Diseases. Med. Sci. Monit. 2020, 26, e919159-1.

159. Franca, C.M.; Thrivikraman, G.; Athirasala, A.; Tahayeri, A.; Gower, L.B.; Bertassoni, L.E. The Influence of Osteopontin-Guided Collagen Intrafibrillar Mineralization on Pericyte Differentiation and Vascularization of Engineered Bone Scaffolds. J. Biomed. Mater. Res. Part B Appl. Biomater. 2019, 107, 1522-1532. [CrossRef]

160. Thurgood, L.A.; Ryall, R.L. Proteomic Analysis of Proteins Selectively Associated with Hydroxyapatite, Brushite, and Uric Acid Crystals Precipitated from Human Urine. J. Proteome Res. 2010, 9, 5402-5412. [CrossRef]

161. Hoyer, J.R.; Asplin, J.R.; Otvos, L. Phosphorylated Osteopontin Peptides Suppress Crystallization by Inhibiting the Growth of Calcium Oxalate Crystals. Kidney Int. 2001, 60, 77-82. [CrossRef] [PubMed]

162. Li, S.Y.; Wang, L.J. Phosphorylated Osteopontin Peptides Inhibit Crystallization by Resisting the Aggregation of Calcium Phosphate Nanoparticles. Crystengcomm 2012, 14, 8037-8043. [CrossRef]

163. Lenton, S.; Grimaldo, M.; Roosen-Runge, F.; Schreiber, F.; Nylander, T.; Clegg, R.A.; Holt, C.; Hartlein, M.; Sakai, V.G.; Seydel, T.; et al. Effect of Phosphorylation on a Human-Like Osteopontin Peptide. Biophys. J. 2017, 112, 1586-1596. [CrossRef] [PubMed]

164. Platzer, G.; Żerko, S.; Saxena, S.; Koźmiński, W.; Konrat, R. 1h, 15n, 13c Resonance Assignment of Human Osteopontin. Biomol. NMR Assign. 2015, 9, 289-292. [CrossRef] 
165. Schack, L.; Lange, A.; Kelsen, J.; Agnholt, J.; Christensen, B.; Petersen, T.E.; Sorensen, E.S. Considerable Variation in the Concentration of Osteopontin in Human Milk, Bovine Milk, and Infant Formulas. J. Dairy Sci. 2009, 92, 5378-5385. [CrossRef]

166. Christensen, B.; Sorensen, E.S. Osteopontin Is Highly Susceptible to Cleavage in Bovine Milk and the Proteolytic Fragments Bind the Alpha(V)Beta(3)-Integrin Receptor. J. Dairy Sci. 2014, 97, 136-146. [CrossRef]

167. Sørensen, E.S.; Hojrup, P.; Petersen, T.E. Posttranslational Modifications of Bovine Osteopontin-Identification of 28 Phosphorylation and 3 O-Glycosylation Sites. Protein Sci. 1995, 4, 2040-2049. [CrossRef]

168. Ibsen, C.J.S.; Gebauer, D.; Birkedal, H. Osteopontin Stabilizes Metastable States Prior to Nucleation during Apatite Formation. Chem. Mater. 2016, 28, 8550-8555. [CrossRef]

169. Lenton, S.; Nylander, T.; Teixeira, S.C.M.; Holt, C. A Review of the Biology of Calcium Phosphate Sequestration with Special Reference to Milk. Dairy Sci. Technol. 2015, 95, 3-14. [CrossRef]

170. Lenton, S.; Nylander, T.; Holt, C.; Sawyer, L.; Härtlein, M.; Müller, H.; Teixeira, S.C.M. Structural Studies of Hydrated Samples of Amorphous Calcium Phosphate and Phosphoprotein Nanoclusters. Eur. Biophys. J. Biophys. Lett. 2016, 45, 405-412. [CrossRef]

171. Cross, K.J.; Huq, N.L.; Stanton, D.P.; Sum, M.; Reynolds, E.C. Nmr Studies of a Novel Calcium, Phosphate and Fluoride Delivery Vehicle-Alpha(S1)-Casein(59-79) by Stabilized Amorphous Calcium Fluoride Phosphate Nanocomplexes. Biomaterials 2004, 25, 5061-5069. [CrossRef]

172. Cross, K.J.; Huq, N.L.; Palamara, J.E.; Perich, J.W.; Reynolds, E.C. Physicochemical Characterization of Casein Phosphopeptide-Amorphous Calcium Phosphate Nanocomplexes. J. Biol. Chem. 2005, 280, 15362-15369. [CrossRef] [PubMed]

173. Cesaro, L.; Pinna, L.A. Prevalence and Significance of the Commonest Phosphorylated Motifs in the Human Proteome: A Global Analysis. Cell. Mol. Life Sci. 2020, 1-18. [CrossRef] [PubMed]

174. Hay, D.I.; Smith, D.J.; Schluckebier, S.K.; Moreno, E.C. Basic Biological Sciences Relationship between Concentration of Human Salivary Statherin and Inhibition of Calcium Phosphate Precipitation in Stimulated Human Parotid Saliva. J. Dent. Res. 1984, 63, 857-863. [CrossRef] [PubMed]

175. Hay, D.I.; Moreno, E.C.; Schlesinger, D.H. Phosphoprotein Inhibitors of Calcium Phosphate Precipitation from Salivary Secretions. Inorg. Perspect. Biol. Med. 1979, 2, 271-285.

176. Davenport, H.W. The ABC of Acid-Base Chemistry. The Elements of Physiological Blood-Gas Chemistry for Medical Students and Physicians, 6th ed.; University of Chicago Press: Chicago, IL, USA, 1974.

177. Miura, Y.; Iwazu, Y.; Shiizaki, K.; Akimoto, T.; Kotani, K.; Kurabayashi, M.; Kurosu, H.; Kuro-o, M. Identification and Quantification of Plasma Calciprotein Particles with Distinct Physical Properties in Patients with Chronic Kidney Disease. Sci. Rep. 2018, 8, 1256. [CrossRef] [PubMed]

178. Price, P.A.; Nguyen, T.M.T.; Williamson, M.K. Biochemical Characterization of the Serum Fetuin-Mineral Complex. J. Biol. Chem. 2003, 278, 22153-22160. [CrossRef]

179. Brylka, L.; Jahnen-Dechent, W. The Role of Fetuin-A in Physiological and Pathological Mineralization. Calcif. Tissue Int. 2013, 93, 355-364. [CrossRef]

180. Jahnen-Dechent, W.; Smith, E.R. Nature's Remedy to Phosphate Woes: Calciprotein Particles Regulate Systemic Mineral Metabolism. Kidney Int. 2020, 97, 648-651. [CrossRef]

181. Heiss, A.; Eckert, T.; Aretz, A.; Richtering, W.; van Dorp, W.; Schafer, C.; Jahnen-Dechent, W. Hierarchical Role of Fetuin-A and Acidic Serum Proteins in the Formation and Stabilization of Calcium Phosphate Particles. J. Biol. Chem. 2008, 283, 14815-14825. [CrossRef]

182. Jahnen-Dechent, W.; Büscher, A.; Köppert, S.; Heiss, A.; Kuro-o, M.; Smith, E.R. Mud in the Blood the Role of Protein-Mineral Complexes and Extracellular Vesicles in Biomineralisation and Calcification. J. Struct. Biol. 2020, 212, 107577. [CrossRef]

183. Koppert, S.; Buscher, A.; Babler, A.; Ghallab, A.; Buhl, E.M.; Latz, E.; Hengstler, J.G.; Smith, E.R.; Jahnen-Dechent, W. Cellular Clearance and Biological Activity of Calciprotein Particles Depend on Their Maturation State and Crystallinity. Front. Immunol. 2018, 9, 17. [CrossRef] [PubMed]

184. Holt, C. Interrelationships of the Concentrations of Some Ionic Constituents of Human-Milk and Comparison with Cow and Goat Milk. Comp. Biochem. Physiol. 1993, 104, 35-41. [CrossRef]

185. Halperin, M.L.; Dhadli, S.C.; Kamel, K.S. Physiology of Acid-Base Balance: Links with Kidney Stone Prevention. Semin. Nephrol. 2006, 26, 441-446. [CrossRef] [PubMed]

186. Hill Michael, G.; Königsberger, E.; May Peter, M. Mineral Precipitation and Dissolution in the Kidney. Am. Mineral. 2017, 102, 701-710. [CrossRef] 
187. Khan, S.R.; Kok, D.J. Modulators of Urinary Stone Formation. Front. Biosci. Landmark 2004, 9, 1450-1482. [CrossRef]

188. Kuruppath, S.; Bisana, S.; Sharp, J.A.; Lefevre, C.; Kumar, S.; Nicholas, K.R. Monotremes and Marsupials: Comparative Models to Better Understand the Function of Milk. J. Biosci. 2012, 37, 581-588. [CrossRef]

189. McClellan, H.L.; Miller, S.J.; Hartmann, P.E. Evolution of Lactation: Nutrition V. Protection with Special Reference to Five Mammalian Species. Nutr. Res. Rev. 2008, 21, 97-116. [CrossRef]

190. Oftedal, O.T. The Evolution of Milk Secretion and Its Ancient Origins. Animal 2012, 6, 355-368. [CrossRef]

191. Holt, C.; Carver, J.A. Darwinian Transformation of a 'Scarcely Nutritious Fluid' into Milk. J. Evol. Biol. 2012, 25, 1253-1263. [CrossRef]

192. Jenness, R.; Sloan, R.E. The Composition of Milk of Various Species: A Review. Dairy Sci. Abstr. 1970, 32, 599-612.

193. Eisert, R.; Oftedal, O.T. Capital expenditure and income (foraging) during pinniped lactation: The example of the weddell seal (Leptonychotes weddellii). In Smithsonian at the Poles: Contributions to International Polar Year Science; Lang, M.A., Miller, S.E., Krupnik, I., Eds.; Smithsonian Institute: Washington, DC, USA, 2009; pp. 335-346.

194. Jenness, R.; Holt, C. Casein and Lactose Concentrations in Milk of 31 Species Are Negatively Correlated. Experientia 1987, 43, 1015-1018. [CrossRef] [PubMed]

195. Aoki, T.; Sakamoto, H.; Kako, Y. Cross-Linking of Caseins by Colloidal Calcium Phosphate in the Presence of Urea. Int. Dairy J. 1991, 1, 67-75. [CrossRef]

196. Umeda, T.; Aoki, T. Relation between Micelle Size and Micellar Calcium Phosphate. Milchwiss. Milk Sci. Int. 2002, 57, 131-133.

197. Wang, Q.; Holt, C.; Nylander, T.; Ma, Y. Salt Partition, Ion Equilibria and the Structure, Composition and Solubility of Micellar Calcium Phosphate in Bovine Milk with Added Calcium Salts. J. Dairy Sci. 2020, in press.

198. Follows, D.; Holt, C.; Nylander, T.; Thomas, R.K.; Tiberg, F. Beta-Casein Adsorption at the Silicon Oxide-Aqueous Solution Interface: Calcium Ion Effects. Biomacromolecules 2004, 5, 319-325. [CrossRef]

199. Follows, D.; Holt, C.; Thomas, R.K.; Tiberg, F.; Fragneto, G.; Nylander, T. Co-Adsorption of Beta-Casein and Calcium Phosphate Nanoclusters (Cpn) at Hydrophilic and Hydrophobic Solid-Solution Interfaces Studied by Neutron Reflectometry. Food Hydrocoll. 2011, 25, 724-733. [CrossRef]

200. Blackburn, D.G.; Hayssen, V.; Murphy, C.J. The Origin of Lactation and the Evolution of Milk: A Review with New Hypotheses. Mammal. Rev. 1989, 19, 1-26. [CrossRef]

201. Capuco, A.V.; Michael Akers, R. The Origin and Evolution of Lactation. J. Biol. 2009, 8, 37. [CrossRef]

202. Haldane, J.B.S. The Possible Evolution of Lactation. Zool. Jb. Syst. 1965, 92, 41-48.

203. Kawasaki, K.; Lafont, A.-G.; Sire, J.-Y. The Evolution of Casein Genes from Tooth Genes before the Origin of Mammals. Mol. Biol. Evol. 2011, 28, 2053-2061. [CrossRef] [PubMed]

204. Lefèvre, C.M.; Sharp, J.A.; Nicholas, K.R. Evolution of Lactation: Ancient Origin and Extreme Adaptations of the Lactation System. Ann. Rev. Genom. Hum. Gene 2010, 11, 219-238. [CrossRef] [PubMed]

205. Vorbach, C.; Capecchi, M.R.; Penninger, J.M. Evolution of the Mammary Gland from the Innate Immune System? Bioessays 2006, 28, 606-616. [CrossRef] [PubMed]

206. Beems, R.B.; Gruys, E.; Spit, B.J. Amyloid in Corpora Amylacea of Rat Mammary Gland. Vet. Pathol. 1978, 15, 347-352. [CrossRef]

207. Brooker, B.E. Origin Structure and Occurrence of Corpora Amylacea in Bovine Mammary Gland and in Milk. Cell Tissue Res. 1978, 191, 525-538. [CrossRef]

208. Niewold, T.A.; Murphy, C.L.; Hulskamp-Koch, C.A.M.; Tooten, P.C.J.; Gruys, E. Casein Related Amyloid, Characterization of a New and Unique Amyloid Protein Isolated from Bovine Corpora Amylacea. Amyloid Int. J. Exp. Clin. Investig. 1999, 6, 244-249. [CrossRef]

209. Reid, I.M. Corpora Amylacea of Bovine Mammary Gland-Histochemical and Electron Microscopic Evidence for Their Amyloid Nature. J. Comp. Pathol. 1972, 82, 409-413. [CrossRef]

210. Hagsten, C.; Altskar, A.; Gustafsson, S.; Loren, N.; Hamberg, L.; Innings, F.; Paulsson, M.; Nylander, T. Composition and Structure of High Temperature Dairy Fouling. Food Struct. 2016, 7, 13-20. [CrossRef]

211. Qi, P.X.; Wickham, E.D.; Farrell, H.M. Thermal and Alkaline Denaturation of Bovine Beta-Casein. Protein J. 2004, 23, 389-402. [CrossRef] 
212. Carver, J.A.; Holt, C. Functional and Dysfunctional Folding, Association and Aggregation of Caseins. Adv. Protein Chem. Struct. Biol. 2020, 118, 163-216.

213. Carver, J.A.; Ecroyd, H.; Truscott, R.J.W.; Thorn, D.C.; Holt, C. Proteostasis and the Regulation of Intra- and Extracellular Protein Aggregation by Atp-Independent Molecular Chaperones: Lens A-Crystallins and Milk Caseins. Acc. Chem. Res. 2018, 51, 745-752. [CrossRef] [PubMed]

214. McMeekin, T.L. Milk Proteins in Retrospect. In Milk Proteins Chemistry and Molecular Biology; McKenzie, H.A., Ed.; Academic Press: New York, NY, USA; London, UK, 1970; pp. 3-15.

215. Foley, R.N.; Parfrey, P.S.; Harnett, J.D.; Kent, G.M.; Martin, C.J.; Murray, D.C.; Barre, P.E. Clinical and Echocardiographic Disease in Patients Starting End-Stage Renal Disease Therapy. Kidney Int. 1995, 47, 186-192. [CrossRef] [PubMed]

216. Pasch, A.; Jahnen-Dechent, W.; Smith, E.R. Phosphate, Calcification in Blood, and Mineral Stress: The Physiologic Blood Mineral Buffering System and Its Association with Cardiovascular Risk. Int. J. Nephrol. 2018, 2018, 9182078. [CrossRef] [PubMed]

217. Tintut, Y.; Demer, L.L. Recent Advances in Multifactorial Regulation of Vascular Calcification. Curr. Opin. Lipidol. 2001, 12, 555-560. [CrossRef] [PubMed]

218. Sage, A.P.; Tintut, Y.; Demer, L.L. Regulatory Mechanisms in Vascular Calcification. Nat. Rev. Cardiol. 2010, 7, 528-536. [CrossRef] [PubMed]

219. Heiss, A.; Pipich, V.; Jahnen-Dechent, W.; Schwahn, D. Fetuin-a Is a Mineral Carrier Protein: Small Angle Neutron Scattering Provides New Insight on Fetuin-A Controlled Calcification Inhibition. Biophys. J. 2010, 99, 3986-3995. [CrossRef]

220. Wald, J.; Wiese, S.; Eckert, T.; Jahnen-Dechent, W.; Heiss, A.; Richtering, W. Fetuin-A Mediated Formation and Ripening of Colloidal Calciprotein Particles. Eur. Biophys. J. Biophys. Lett. 2011, 40, 64-65.

221. Wald, J.; Wiese, S.; Eckert, T.; Jahnen-Dechent, W.; Richtering, W.; Heiss, A. Formation and Stability Kinetics of Calcium Phosphate-Fetuin-a Colloidal Particles Probed by Time-Resolved Dynamic Light Scattering. Soft Matter 2011, 7, 2869-2874. [CrossRef]

222. Proctor, G.B. The Physiology of Salivary Secretion. Periodontology 2000 2016, 70, 11-25. [CrossRef]

223. Castagnola, M.; Cabras, T.; Iavarone, F.; Vincenzoni, F.; Vitali, A.; Pisano, E.; Nemolato, S.; Scarano, E.; Fiorita, A.; Vento, G.; et al. Top-Down Platform for Deciphering the Human Salivary Proteome. J. Matern. Fetal Neonatal Med. 2012, 25, 27-43. [CrossRef]

224. Brandao, E.; Soares, S.; Mateus, N.; de Freitas, V. Human Saliva Protein Profile: Influence of Food Ingestion. Food Res. Int. 2014, 64, 508-513. [CrossRef] [PubMed]

225. Xie, H.W.; Rhodus, N.L.; Griffin, R.J.; Carlis, J.V.; Griffin, T.J. A Catalogue of Human Saliva Proteins Identified by Free Flow Electrophoresis-Based Peptide Separation and Tandem Mass Spectrometry. Mol. Cell. Proteom. 2005, 4, 1826-1830. [CrossRef] [PubMed]

226. Amado, F.; Lobo, M.J.C.; Domingues, P.; Alberto Duarte, J.; Vitorino, R. Salivary Peptidomics. Expert Rev. Proteom. 2010, 7, 709-721. [CrossRef] [PubMed]

227. Grøn, P. State of Calcium and Inorganic Orthophosphate in Human Saliva. Arch. Oral Biol. 1973, 18, 1365-1378. [CrossRef]

228. Poff, A.M.; Pearce, E.I.F.; Larsen, M.J.; Cutress, T.W. Human Supragingival in Vivo Calculus Formation in Relation to Saturation of Saliva with Respect to Calcium Phosphates. Arch. Oral Biol. 1997, 42, 93-99. [CrossRef]

229. Jin, Y.; Yip, H.K. Supragingival Calculus: Formation and Control. Crit. Rev. Oral Biol. Med. 2002, 13, $426-441$. [CrossRef]

230. Hay, D.I.; Schlesinger, D.H. Human Salivary Statherin: A Peptide Inhibitor of Calcium Phosphate Precipitation. In Calcium-Binding Proteins and Calcium Functions, Proceedings of the International Symposium on Calcium Binding Proteins and Calcium Functions in Health and Disease, San Diego, CA, USA, 5-9 June 1977; Wassermann, R.H., MacLennan, D.H., Siegel, F., Eds.; Elsevier North Holland: New York, NY, USA, 1977; pp. 401-408.

231. Reynolds, E.C. Remineralization of Enamel Subsurface Lesions by Casein Phosphopeptide-Stabilized Calcium Phosphate Solutions. J. Dent. Res. 1997, 76, 1587-1595. [CrossRef]

232. Bautista, D.S.; Denstedt, J.; Chambers, A.F.; Harris, J.F. Low-Molecular-Weight Variants of Osteopontin Generated by Serine Proteinases in Urine of Patients with Kidney Stones. J. Cell. Biochem. 1996, 61, 402-409. [CrossRef] 
233. Wei, M.; Shiraga, H.; Chalko, C.; Goldfarb, S.; Gopal Krishna, G.; Hoyer, J.R. Quantitative Studies of Human Urinary Excretion of Uropontin. Kidney Int. 1998, 53, 189-193.

234. Schlieper, G.; Westenfeld, R.; Brandenburg, V.; Ketteler, M. Inhibitors of Calcification in Blood and Urine. Semin. Dial. 2007, 20, 113-121. [CrossRef]

235. Anderson, H. Clarke. Matrix Vesicles and Calcification. Curr. Rheumatol. Rep. 2003, 5, 222-226. [CrossRef] [PubMed]

236. Landis, W.J.; Jacquet, R. Association of Calcium and Phosphate Ions with Collagen in the Mineralization of Vertebrate Tissues. Calcif. Tissue Int. 2013, 93, 329-337. [CrossRef] [PubMed]

237. Niu, L.; Jee, S.E.; Jiao, K.; Tonggu, L.; Li, M.; Wang, L.; Yang, Y.; Bian, J.; Breschi, L.; Jang, S.S.; et al. Collagen Intrafibrillar Mineralization as a Result of the Balance between Osmotic Equilibrium and Electroneutrality. Nat. Mater. 2017, 16, 370-378. [CrossRef] [PubMed]

238. Silver, F.H.; Landis, W.J. Deposition of Apatite in Mineralizing Vertebrate Extracellular Matrices: A Model of Possible Nucleation Sites on Type I Collagen. Connect. Tissue Res. 2011, 52, 242-254. [CrossRef]

239. Zou, Z.Y.; Tang, T.T.; Macias-Sanchez, E.; Sviben, S.; Landis, W.J.; Bertinetti, L.; Fratzl, P. Three-Dimensional Structural Interrelations between Cells, Extracellular Matrix, and Mineral in Normally Mineralizing Avian Leg Tendon. Proc. Natl. Acad. Sci. USA 2020, 117, 14102-14109. [CrossRef]

240. Mertz, E.L.; Leikin, S. Interactions of Inorganic Phosphate and Sulfate Anions with Collagen. Biochemistry 2004, 43, 14901-14912. [CrossRef]

241. Olszta, M.J.; Cheng, X.G.; Jee, S.S.; Kumar, R.; Kim, Y.Y.; Kaufman, M.J.; Douglas, E.P.; Gower, L.B. Bone Structure and Formation: A New Perspective. Mater. Sci. Eng. R Rep. 2007, 58, 77-116. [CrossRef]

242. Thula, T.T.; Rodriguez, D.E.; Lee, M.H.; Pendi, L.; Podschun, J.; Gower, L.B. In Vitro Mineralization of Dense Collagen Substrates: A Biomimetic Approach toward the Development of Bone-Graft Materials. Acta Biomater. 2011, 7, 3158-3169. [CrossRef]

243. Jiang, Y.; Gower, L.; Volkmer, D.; Coelfen, H. The Existence Region and Composition of a Polymer-Induced Liquid Precursor Phase for Dl-Glutamic Acid Crystals. Phys. Chem. Chem. Phys. 2012, 14, 914-919. [CrossRef]

244. Olszta, M.J.; Douglas, E.P.; Gower, L.B. Scanning Electron Microscopic Analysis of the Mineralization of Type I Collagen via a Polymer-Induced Liquid-Precursor (Pilp) Process. Calcif. Tissue Int. 2003, 72, 583-591. [CrossRef]

245. Thula, T.T.; Svedlund, F.; Rodriguez, D.E.; Podschun, J.; Pendi, L.; Gower, L.B. Mimicking the Nanostructure of Bone: Comparison of Polymeric Process-Directing Agents. Polymers 2011, 3, 10-35. [CrossRef] [PubMed]

246. Jee, S.-S.; Thula, T.T.; Gower, L.B. Development of Bone-Like Composites Via the Polymer-Induced Liquid-Precursor (Pilp) Process. Part 1: Influence of Polymer Molecular Weight. Acta Biomater. 2010, 6, 3676-3686. [CrossRef] [PubMed]

247. Jee, S.S.; Kasinath, R.K.; DiMasi, E.; Kim, Y.-Y.; Gower, L. Oriented Hydroxyapatite in Turkey Tendon Mineralized via the Polymer-Induced Liquid-Precursor (Pilp) Process. Crystengcomm 2011, 13, 2077-2083. [CrossRef]

248. Burwell, A.K.; Thula-Mata, T.; Gower, L.B.; Habeliz, S.; Kurylo, M.; Ho, S.P.; Chien, Y.-C.; Cheng, J.; Cheng, N.F.; Gansky, S.A.; et al. Functional Remineralization of Dentin Lesions Using Polymer-Induced Liquid-Precursor Process. PLoS ONE 2012, 7, e38852. [CrossRef] [PubMed]

249. Khan, S.R.; Rodriguez, D.E.; Gower, L.B.; Monga, M. Association of Randall Plaque with Collagen Fibers and Membrane Vesicles. J. Urol. 2012, 187, 1094-1100. [CrossRef]

250. Chidambaram, A.; Rodriguez, D.; Khan, S.; Gower, L. Biomimetic Randall's Plaque as an in Vitro Model System for Studying the Role of Acidic Biopolymers in Idiopathic Stone Formation. Urolithiasis 2015, 43, S77-S92. [CrossRef]

251. O'Kell, A.L.; Lovett, A.C.; Canales, B.K.; Gower, L.B.; Khan, S.R. Development of a Two-Stage Model System to Investigate the Mineralization Mechanisms Involved in Idiopathic Stone Formation: Stage 2 in Vivo Studies of Stone Growth on Biomimetic Randall's Plaque. Urolithiasis 2019, 47, 335-346. [CrossRef]

252. Kuliasha, C.A.; Rodriguez, D.; Lovett, A.; Gower, L.B. In Situ Flow Cell Platform for Examining Calcium Oxalate and Calcium Phosphate Crystallization on Films of Basement Membrane Extract in the Presence of Urinary 'Inhibitors'. Crystengcomm 2020, 22, 1448-1458. [CrossRef]

253. Thrivikraman, G.; Athirasala, A.; Gordon, R.; Zhang, L.M.; Bergan, R.; Keene, D.R.; Jones, J.M.; Xie, H.; Chen, Z.Q.; Tao, J.; et al. Rapid Fabrication of Vascularized and Innervated Cell-Laden Bone Models with Biomimetic Intrafibrillar Collagen Mineralization. Nat. Commun. 2019, 10, 3520. [CrossRef] 
254. Lovett, A.C.; Khan, S.R.; Gower, L.B. Development of a Two-Stage in Vitro Model System to Investigate the Mineralization Mechanisms Involved in Idiopathic Stone Formation: Stage 1-Biomimetic Randall's Plaque Using Decellularized Porcine Kidneys. Urolithiasis 2019, 47, 321-334. [CrossRef]

255. Akiva, A.; Malkinson, G.; Masic, A.; Kerschnitzki, M.; Bennet, M.; Fratzl, P.; Addadi, L.; Weiner, S.; Yaniv, K. On the Pathway of Mineral Deposition in Larval Zebrafish Caudal Fin Bone. Bone 2015, 75, 192-200. [CrossRef] [PubMed]

256. Larsson, K. Lyotropic Liquid Crystals and Their Dispersions Relevant in Foods. Curr. Opin. Colloid Interface Sci. 2009, 14, 16-20. [CrossRef]

257. Kerschnitzki, M.; Akiva, A.; Shoham, A.B.; Koifman, N.; Shimoni, E.; Rechav, K.; Arraf, A.A.; Schultheiss, T.M.; Talmon, Y.; Zelzer, E.; et al. Transport of Membrane-Bound Mineral Particles in Blood Vessels During Chicken Embryonic Bone Development. Bone 2016, 83, 65-72. [CrossRef]

258. Mahamid, J.; Aichmayer, B.; Shimoni, E.; Ziblat, R.; Li, C.; Siegel, S.; Paris, O.; Fratzl, P.; Weiner, S.; Addadi, L. Mapping Amorphous Calcium Phosphate Transformation into Crystalline Mineral from the Cell to the Bone in Zebrafish Fin Rays. Proc. Natl. Acad. Sci. USA 2010, 107, 6316-6321. [CrossRef] [PubMed]

259. Mahamid, J.; Sharir, A.; Gur, D.; Zelzer, E.; Addadi, L.; Weiner, S. Bone Mineralization Proceeds through Intracellular Calcium Phosphate Loaded Vesicles: A Cryo-Electron Microscopy Study. J. Struct. Biol. 2011, 174, 527-535. [CrossRef]

260. Nudelman, F.; Pieterse, K.; George, A.; Bomans, P.H.H.; Friedrich, H.; Brylka, L.J.; Hilbers, P.A.J.; de With, G.; Sommerdijk, N. The Role of Collagen in Bone Apatite Formation in the Presence of Hydroxyapatite Nucleation Inhibitors. Nat. Mater. 2010, 9, 1004-1009. [CrossRef]

261. Nudelman, F.; Sommerdijk, N. Biomineralization as an Inspiration for Materials Chemistry. Angew. Chem. Int. Ed. 2012, 51, 6582-6596. [CrossRef]

(C) 2020 by the authors. Licensee MDPI, Basel, Switzerland. This article is an open access article distributed under the terms and conditions of the Creative Commons Attribution (CC BY) license (http://creativecommons.org/licenses/by/4.0/). 